\title{
Modeling the Relationship Between Identity and Self-Efficacy in Intercollegiate StudentAthletes: An Exploratory Study
}

\author{
Aaron Goodson
}

Follow this and additional works at: https://researchrepository.wvu.edu/etd

\footnotetext{
Recommended Citation

Goodson, Aaron, "Modeling the Relationship Between Identity and Self-Efficacy in Intercollegiate StudentAthletes: An Exploratory Study" (2018). Graduate Theses, Dissertations, and Problem Reports. 7288.

https://researchrepository.wvu.edu/etd/7288

This Dissertation is protected by copyright and/or related rights. It has been brought to you by the The Research Repository @ WVU with permission from the rights-holder(s). You are free to use this Dissertation in any way that is permitted by the copyright and related rights legislation that applies to your use. For other uses you must obtain permission from the rights-holder(s) directly, unless additional rights are indicated by a Creative Commons license in the record and/ or on the work itself. This Dissertation has been accepted for inclusion in WVU Graduate Theses, Dissertations, and Problem Reports collection by an authorized administrator of The Research Repository @ WVU. For more information, please contact researchrepository@mail.wvu.edu.
} 
Modeling the Relationship Between Identity and Self-Efficacy in Intercollegiate StudentAthletes: An Exploratory Study

\title{
Aaron Goodson
}

Dissertation submitted to the College of Physical Activity and Sport Sciences at West Virginia University in partial fulfillment of the requirements for the degree of

\section{Doctor of Philosophy}

in

Sport, Exercise, and Performance Psychology

\author{
Dana Brooks, Ed.D., Chair \\ Jack C. Watson, II, Ph.D. \\ Aaron Metzger, Ph.D. \\ Joseph N. Cooper, Ph.D. \\ Department of Sport Sciences
}

Morgantown, West Virginia

2018

Keywords: student-athlete development, identity, locus of control, role conflict, self-efficacy 


\begin{abstract}
Modeling the Relationship Between Identity and Self-Efficacy in Intercollegiate StudentAthletes: An Exploratory Study
\end{abstract}

\begin{abstract}
Aaron Goodson
Research has shown that collegiate student-athletes experience stressors that influence their development different from the general college population. Student-athlete development research concludes that constructs such as identity (Yukhymento-Lesocroart, 2013), role conflict (Adler \& Adler, 1987; Settles et al., 2002), locus of control (Watson, 2016) impact the academic outcomes and life skills development. However, to date, there is no published research that examines the potential relationships among the different constructs and how they influence overall life skill development for student-athletes. Based on the review of the literature, the purpose of this study was to explore how and to what extent different aspects of student-athlete identity are related to self-efficacy. Additionally, the study aimed to situate the relationship between student-athlete identity and self-efficacy into the context of student-athlete development. More explicitly, the goal of this study is to construct a model that includes the concepts of identity, role conflict, locus of control, and self-efficacy using fit indices of structural equation modeling (SEM). The results revealed that the models have good fit and there are positive and negative associations among variables in models that included identity, role conflict, locus of control, and self-efficacy. The results also have implications for student-athlete behavior, programming efforts from administrators in athletic departments, and anyone who works with collegiate student-athletes.
\end{abstract}




\section{Acknowledgements}

First, I would like to thank God and my family, immediate and extended, for their consistent support of my educational journey. God has watched over and protected me in so many ways on this journey as well as opened doors and provided experiences that I couldn't have imagined having at the beginning of this journey. To my family, the support that you have consistently shown me has influenced the way that I approach all of my personal and professional responsibilities.

Second, I would like to thank my WVU SEP colleagues, past and present, for making this journey as enjoyable as it can be. I'll always cherish the warmth I have been embraced with from my time as a prospective student visiting Morgantown and attending AASP for the first time to the mini-reunions we have when we see each other at conferences or in town. To the students currently in the program, thank you for your encouragement through the rough times and the celebrations through the good ones. I would particularly like to thank Jay Stewart and Zenzi Huysmans, undoubtedly two people that were introduced to me as colleagues but have become lifelong friends. Their willingness to advise and provide support in ways that I didn't even know that I needed has been the most crucial part of this journey.

Third, I would like to thank the WVU SEP faculty for guiding my path in the five years that I have spent to complete this process. Dean Brooks, your trust in me to follow my thought patterns and intuition has been a tremendous part of my growth and development as a student and a scholar. Dr. Watson, your willingness to ensure that I did not slip through the cracks in my own thinking patterns and progress through the program has not gone unnoticed and tremendously appreciated. Dr. Etzel, your constant wisdom and supervision of my applied sport psychology work has been invaluable and has also driven my research agenda in ways that you may not recognize. Dr. Clement, thank you for taking a chance on me and allowing me to co-teach my first undergraduate class when I arrived. I truly appreciate your guidance and feedback during that critical time in my growth and development as an instructor and have appreciated your willingness to be available for support any time I've needed since then. Dr. Zizzi, thank you for introducing me to and encouraging me throughout the beginning of my research journey. Your constant reminders of 'the path is the goal' and creation of the metaphor of research mountain will always stay with me as I transition from here into the professional side of academia. Dr. Voelker, your willingness to jump in and provide honest, critical feedback and follow up with me about it in my teaching and research is greatly appreciated. I hope to mirror your engagement and impact on students as I set off to blaze my own trail in my academic career. Additionally, I would like to thank Dr. Aaron Metzger for expanding my knowledge of statistics and always being available to talk through different methods of analysis through this project.

Also, thank you to Dr. Joseph Cooper at the University of Connecticut School of Education, for providing the strongest support and instilling a sense of confidence in myself and my abilities as an emerging scholar.

Fourth, I would like to thank the WVU and greater Morgantown community for embracing me to develop social relationships and have a life outside of my program. This particularly includes the faculty of the Clinical Mental Health Counseling Master's program who have played a vital role 
in my educational journey. I fully recognize that I have been blessed to fall into a such a warm community of people outside of my program and truly appreciate all of the experiences that have allowed me to grow personally and not professionally. Additionally, the professional community of friends and colleagues I have developed outside of my academic programs have been a tremendous source of support during my time in Morgantown.

Fifth, I would like to thank all of the student-athletes and athletic administrators that contributed to the successful completion of this project. I know that there are so many people out there doing quality work to help the growth and development of collegiate student-athletes, and I am

honored to have met some of them through this study. However, without the voice of the studentathlete, the work can never be complete.

Finally, I would like to thank my partner, Tyler Davis, who came into my life at a time at an unexpected time and has truly been the best thing I never knew I needed throughout this journey. I look forward to continuing to grow closer to you and see where our respective professional journeys take us. 


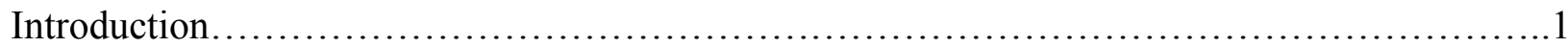

Theoretical Framework ......................................................... 11

Problem Statement...........................................................

Significance/Potential Implications............................................... 16

Purpose Statement............................................................ 17

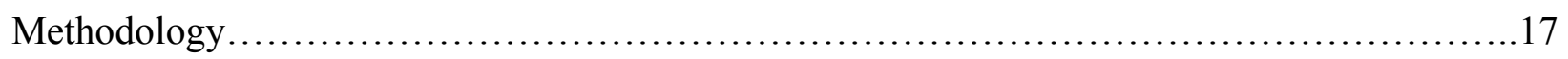

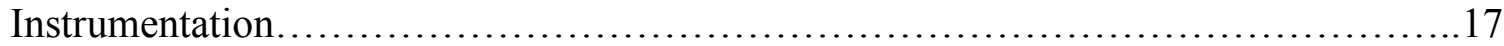

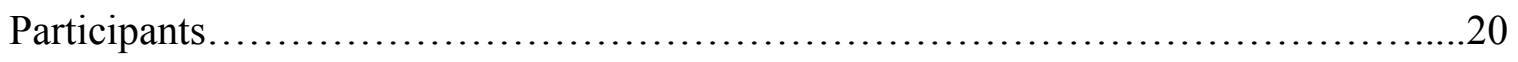

Recruitment and Administration...............................................21

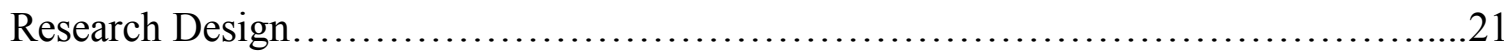

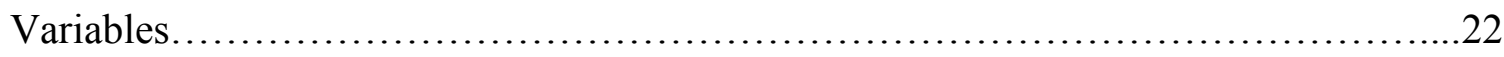

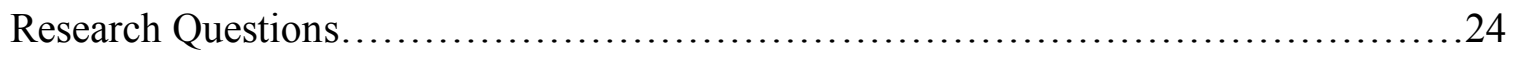

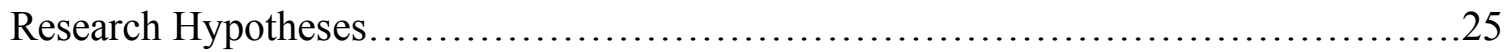

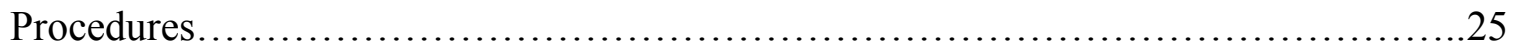

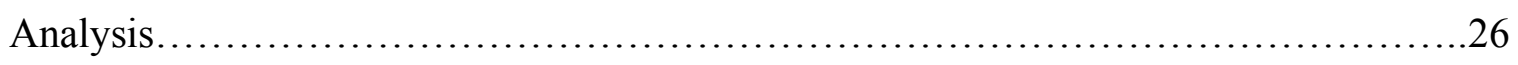

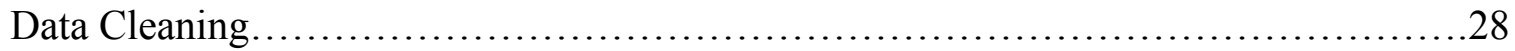

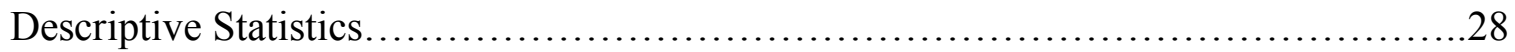

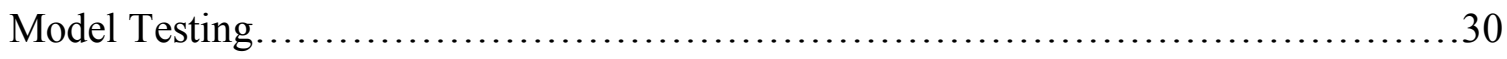

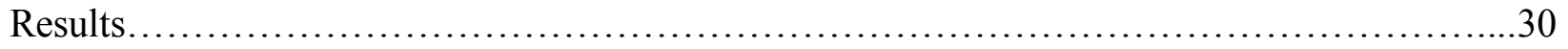

Model 1 - Academic, Athletic, and Ethnic Identity as Predictors of Self-Efficacy........32

Model 2 - Role Interference and Role Separation as Predictors of Self-Efficacy..........32

Model 3 - Internal and External Locus of Control as Predictors of Self-Efficacy.........33

Model 4 - Role Conflict and Locus of Control as Predictors of Self-Efficacy.............34

Model 5 - Academic Identity, Role Conflict, and Locus of Control as Predictors of Self-

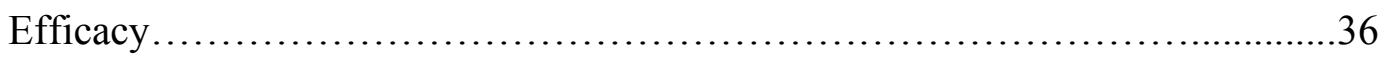

Model 6 - Athletic Identity, Role Conflict, and Locus of Control as Predictors of Self-

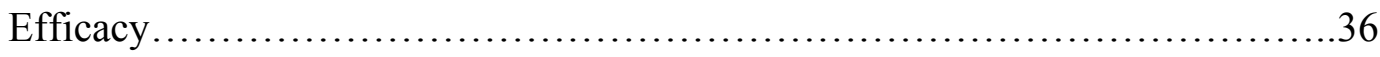

Model 7 - Ethnic Identity, Role Conflict, and Locus of Control as Predictors of Self-

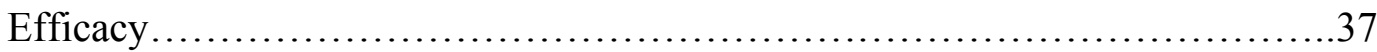

Ad Hoc Analysis............................................................ 38 
Results Summary...........................................................

Discussion............................................................................

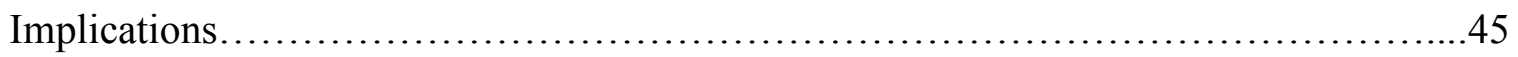

Student-Athletes...............................................47

Athletic Administrators...............................................47

Athletic Departments............................................48

Conference and National Policy......................................48

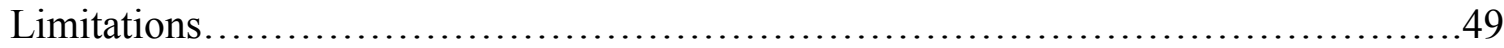

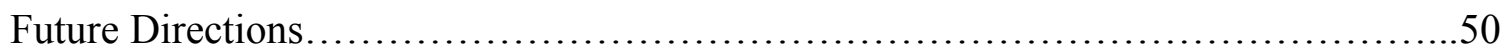

References................................................................ 52

Appendices

Appendix A - Extended Literature Review................................. 61

Introduction...................................................... 61

Theoretical Framework..............................................61

College Student Development.......................................62

Identity Foreclosure.............................................63

College Student-Athletes..........................................67

Role Conflict.........................................................69

College Student-Athlete Academic and Personal Development

Experiences............................................... 71

Athletic and Racial Identity.......................................... 74

Athletic Identity.............................................74

Ethnic/Racial Identity......................................... 76

The Intersection of Athletic and Racial Identity......................77

Locus of Control.................................................. 81

Levenson's Locus of Control.....................................81

Locus of Control and Other Variables..............................84

Self-Efficacy.................................................. 86

Self-Efficacy vs. Locus of Control................................86

Academic Self-Efficacy......................................... 88

Athletic Self-Efficacy....................................... 90 
Career Self-Efficacy......................................... 90

Summary......................................................94

Conclusion............................................. 95

References............................................................... 97

Appendix B - Hypothesized Structural Model.....................................114

Appendix C - Survey Instrument....................................... 115

Appendix D - Transcript of YouTube Recruitment Video....................... 123

Appendix E - Recruitment Message to Athletic Administration.................... 125

Appendix F - Demographics of Sample..................................... 126 


\section{Introduction}

The growth and development of collegiate student-athletes has been publicly debated and researched in the academic disciplines of higher education, sociology, and psychology for over thirty years (Adler \& Adler, 1985, 1987; Ferrera, Watson, \& Zizzi, 2017; Purdy, Eitzen, \& Hufnagel, 1982; Singer, 2008). As early as 1982, Chu argued that United States higher education system and sport exist in the same setting because leaders of colleges and universities were not clear about the charter of American higher education when it was established in the early 1800s. A lack of clear objectives and purposes of higher education and the role of college sport in the United States allowed for debate and discussion about new programs to include that differ from European higher education curriculum and models. It became clear that including sport in the formal social structure of higher education would aid in attracting students and would provide new funds to support activities, programs, and the overall mission of colleges and universities (Chu, 1982). It appears that notions of attracting students and providing funds have been proven

true throughout history, as intercollegiate sport has been responsible for the integration of several different sectors of the American population into higher education from women and minorities to those low in socioeconomic status. At the beginning of the $20^{\text {th }}$ century, intercollegiate sport was firmly implanted into the structure of higher education and the hiring of full-time coaches, offering of scholarships, and formal schedules of competition amongst schools became the norm (Chu, 1982). Scholars who studied the structure and function of intercollegiate sport began to raise questions about the possible exploitation of some student-athletes based on race, ethnicity and educational experience (Edwards, 1985; Leonard, 1986; Nyquist, 1979; Sailes, 1986; Beamon, 2008). 
Other scholars (Cornelius, 1995; Pascarella, Bohr, Nora, \& Terenzini, 1995) have not focused on possible student-athlete exploitation and instead focus on the ways that participation in sport facilitates effective management of issues that appear during the college student experience. These issues can range from developing autonomy and establishing identity to managing relationship and planning for the future (Cornelius, 1995). The justification of sports as a means of personal development and the acquisition of life skills for college students has happened long before formal programming was developed and initiated (Chu, 1982). However, formal programs driven by research have allowed practitioners to support student-athletes in their growth and development. Challenging Athletes’ Minds for Personal Success (CHAMPS)/Life Skills model was the foundation for nationwide student-athlete programming in the National Collegiate Athletic Association (NCAA). In 1994, the NCAA launched inaugural CHAMPS/Life Skills program to support student-athletes and counter the notion that many student-athletes appeared to be exploited through their intercollegiate sport participation. The CHAMPS/Life Skills program addresses five areas of life to support the student-athlete: 1) academics, 2) athletics, 3) career development, 4) personal development, and 5) service to the community (Ahlren-Bedics \& Monda, 2009). Only 46 institutions utilized the program in its inaugural year, but the number jumped to over 630 NCAA institutions in 2008 (Ahlren-Bedics \& Monda, 2009). There are many factors that contribute to the success of these programs at each institution: staffing, needs assessment, topics and programming (Ahlren-Bedics \& Monda, 2009).

To supplement the CHAMPS/Life Skills programming efforts at individual institutions, the NCAA regularly conducts and publishes research on the benefits that collegiate studentathletes receive from their sport participation through their NCAA Growth, Opportunities, Aspirations, and Learning of Students in college (GOALS) study (NCAA, 2015). The most 
recent study was conducted in 2015 and included responses from over 21,000 student-athletes at nearly 600 schools across NCAA Divisions I, II, and III. The survey covered topics such as college athletic, academic, and social experience, health and well-being, time commitments, and on-campus support. The results of this study indicated that an overwhelming percentage $(65 \%-$ 93\%) of college student-athletes across NCAA Divisions reported that their college athletics participation has had a positive effect on areas of their personal growth and development such as personal responsibility, work ethic, personal values and ethics, understanding of other races, and self-confidence (NCAA, 2015). During the same time period as the 2015 study, the NCAA witnessed an increase in the membership (NCAA Research, 2017), and overall saw a more diverse student-athlete population across membership divisions. The additional diversity includes an increase in the number of black student-athletes, female student-athletes, and first-generation college student-athletes (NCAA Research, 2018).

Much of the existing peer-reviewed research on the experiences of student-athletes has left the concept of 'student-athlete development' open to interpretation ranging from academic achievement and athletic identity to personal and life skills development (Cornelius, 1995; Howard-Hamilton \& Sina, 2001; Pascarella et al., 1995). Some scholars have chosen to focus on academic development and achievement (Comeaux \& Harrison, 2011; Harrison et al., 2009) and outcomes or career development (Brown, Glastetter-Fender, \& Shelton, 2000; Ferrera, Watson, \& Zizzi, 2017). Expanding the literature, other scholars have focused on the impact that athletic identity has had on student-athlete growth, development, and engagement in aspects of their college experience beyond athletics (Adler \& Adler, 1987; Bimper, 2014; Yopyk \& Prentice, 2005). Findings from each of the studies listed above focused on the impact of athletic identity on collegiate student-athlete experience warned against identity foreclosure, the dynamic where 
an individual has an identity but has not explored other options or ideas outside of and around that identity (Adler \& Adler, 1987; Brown et al., 2000). Adler and Adler's (1987) research found that athletic identity foreclosure can lead to academic disengagement. Expanding on Adler and Adler's (1987) research, Brown et al. (2000) concluded that athletic identity foreclosure led to a lack of career maturity and development and a higher likelihood of having issues with transition out of sport in collegiate student-athletes. Much of the research (Brewer, Van Raalte, \& Linder, 1993; Cornelius, 1995) on the collegiate student-athlete experience has focused on the existence of athletic identity in participants and how this contributes to the foreclosure of other aspects of their identity and negative outcomes. Athletic identity foreclosure and a subsequent lack of exploration of other aspects of identity signifies missing a crucial element of identity development in the lifespan and can lead to issues in adjustment and transition into other parts of life (Brewer \& Petitpas, 2017). Once student-athletes complete their collegiate athletic careers, they often transition into a life that includes less involvement (if any) in their sport, which has often occurred for a large portion of their lives. Identity foreclosure prevents student-athletes from exploring what their life looks like without the structure, routine, peer support, etc. of their sport participation and therefore struggle to make healthy adjustments at the conclusion of their athletic careers.

This struggle to make healthy adjustments due to a foreclosed athletic identity could be alleviated by intentional engagement in identity exploration. Brewer and Petitpas (2017) described how one of the primary tasks of late adolescence is to develop a sense of identity, which optimally occurs when one has the opportunity to explore a variety of activities. The exploration process is crucial for helping make informed decisions and developing effective coping strategies (Brewer \& Petitpas, 2017). However, those who do not have the opportunity to 
engage in this exploratory process are said to be in a state of identity foreclosure (Petitpas \& Champagne, 1988; Marcia, 1966), a term first used by Erikson (1959) in his stages of human development. Marcia (1966) later re-introduced the term in his ego-identity development process of adolescents and described it as the dynamic that occurs when individuals prematurely commit to an occupation, ideology, or roles associated with those in order to avoid a crisis in their identity. Despite the fact that a commitment to an identity provides a sense of psychological safety and security, identity foreclosure sacrifices personal freedoms and opportunities for further psychosocial growth (Brewer \& Petitpas, 2017). Marcia's $(1966,1976,2002)$ research determined that it is critical for individuals to engage in identity exploratory behavior before expressing commitment to an identity, or they will experience identity foreclosure marked by elevated levels of adherence to authority at the expense of personal freedom, lower autonomy and self-directedness, and an external locus of control (Marcia, Waterman, Matteson, Archer, \& Orlofsky, 1993). Each of these outcomes does not support what research has outlined as healthy adolescent growth and development through college (Chickering, 1969; Cornelius, 1995; Medalie, 1981).

Although the degree of identity foreclosure that one experiences can be mitigated by psychological and situational factors such as life stress and background (Marcia, 2002), foreclosure occurs when one commits to a career or option due to its approval from parents and/or society to avoid a crisis at a later time. In sport participation, this can happen for athletes at any age when they get enmeshed in the sport system, spend an extended amount of time, and begin to experience some of the benefits of sport participation such as approval from peers, intrinsic and extrinsic rewards that come from competition (Brewer \& Petitpas, 2017). Athletic identity has often been measured using the Athletic Identity Measurement Scale (AIMS), but 
there has been no way to consistently measure identity foreclosure. Because of an inability to consistently measure the degree of identity foreclosure in participants, research has been marked by inferences and correlations among scores on the AIMS and other outcomes such as grade point average and career planning and development (Lally \& Kerr, 2005). Previous research (Miller \& Kerr, 2003) has indicated that athletic identity and identity foreclosure did not differ in college athletes in their first two years as compared to their last two years (Brewer \& Petitpas, 2017). There have been mixed results about the correlations between athletic and academic identity and academic performance in collegiate student-athletes (Yukhymenko-Lescroart, 2014; Harrison et al., 2009). Therefore, although athletic identity has sometimes been found to lead to negative outcomes for participants, the impact that athletic identity in conjunction with academic or student identity, other aspects of identity, and subsequent college student development and academic performance is unclear.

Ethnic identity is an element of identity that can be developed in a college setting (Howard-Hamilton \& Sina, 2001). Pizzolato, Chaudhari, Murrell, Podobnik, and Schaeffer (2008) outlined how ethnic identity development has been found to be an important element of the student experience for college students and also serves as a key construct in the explanation for why some non-White students experience success and thrive in some college settings while other non-White students do not. Before non-White students attend college, they often encounter messages about what it means to be a member of their racial or ethnic group and experience messages that can impact their identity development, academic achievement, and overall college experience. Racial and ethnic identity literature reveals that commitment alone is not sufficient for a secure sense of identity and that exploration is a key component of racial and ethnic identity development and movement towards overall sense of group belonging and positive well-being 
(Phinney \& Ong, 2007; Torres, Jones, \& Renn, 2009; Torres, 2011). Research about the coexistence of athletic and racial identity has yielded noteworthy results related to the impact of identity on performance and student-athlete experience. Bimper and Harrison (2011) concluded that athletic identity may actually mask the development and persistence of a racial or ethnic identity, particularly reinforced by themes in sport such as coming together as a team regardless of color or other cultural identifiers not being of importance in the midst of competition. Racial and ethnic identity development is a critical part of the college student experience that may be impeded for student-athletes due to their sport participation (Bimper \& Harrison, 2011). The degree to which racial and ethnic identity exploration and commitment occurs for all studentathletes is not fully understood. The impact of racial and ethnic identity exploration and commitment on the growth and development of all student-athletes is also not fully known. Research focused on ethnic identity development reveals that establishing an achieved ethnic identity can promote overall psychosocial wellbeing and a stronger sense of self for non-White college students in a way that leads to increased cognitive development and higher academic achievement (Pizzolato et al., 2008).

Although identity development is a critical part of the college student experience (Chickering, 1969; Howard-Hamilton \& Sina, 2001), a recent increased emphasis on the mental health and wellbeing of student-athletes has emerged as a primary topic of research on the student-athlete development. For example, on the current NCAA webpage about student-athlete wellbeing, information about the NCAA Sport Science Institute and collaboration with organizations designed to enhance physical safety (particularly around concussions) is available as well as information about discouraging alcohol and other drug abuse as well as managing mental health (NCAA, 2018b). This emphasis has led to a shift in seeking to understand and 
support student-athletes beyond their academic experiences and career readiness. After reviewing the NCAA.com webpage and mental health resources in March 2018, the researcher found that existing research has been limited in the concepts used to measure the mental health and wellbeing of student-athletes by focusing on resiliency and destigmatizing seeking help. Much of the research conducted by the NCAA is limited to questions that simply inquire about student-athlete satisfaction about their experiences through college (NCAA, 2016; NCAA, 2018d). There has also been a failure by the NCAA to use evidence beyond personal anecdotes from current and former student-athletes and traditional measures of academic success to measure the effectiveness of student-athlete development programs designed to enhance growth and development. A potential way to measure the effectiveness of these programs would be to assess student-athletes' self-efficacy, their beliefs in their ability to carry out certain tasks and skills. The aim of student-athlete development programs is to share information and develop skills that are important to achieve success throughout and after college (NCAA, 2018c).

However, to date, there has not been a systematic way to measure the impact and significance of student-athlete development as they matriculate through college and engage in programs at their respective institutions. Currently, the NCAA has conducted the Study of College Outcomes and Recent Experiences (SCORE), a longitudinal study designed to gather in-depth information from former collegiate student-athletes in the areas of college sport experiences, college educational experiences, current career and work experiences, and health and wellbeing (NCAA, 2018d). However, the last cohort to complete this survey graduated college in 1996. This data has not been gathered recently and only relies on memory and recollection instead of utilizing real-time data gathered during the student-athlete experience. Furthermore, the SCORE study asks about former college sport and educational experiences but does not assess for information related to 
the process of development. Instead, SCORE only focuses on the outcomes of sport participation such as current career and work experiences and daily life experiences after their college educational and sport experiences.

Assessing student-athlete self-efficacy across different domains throughout their time in college can be an effective way to gain a better understanding of student-athlete development. Self-efficacy is a concept formulated by Bandura $(1977,1986,1997,2012)$ that assesses a person's belief in their ability to take action to complete a given task. Self-efficacy not only influences whether one will engage in an action but influences how much effort they will expend and how they will persist to complete that activity in the face of adversity (Bandura, 1977). It is developed and maintained through performance accomplishments or mastery experiences, vicarious experiences, verbal or social persuasion, and affective states (Bandura, 1977). Another concept often examined in conjunction with self-efficacy is locus of control. Locus of control (Levenson, 1981) is the degree to which people believe they have control over the events that happen to them in their lives. People can have either an internal or external locus of control. According to Rotter (1966) and Levenson (1981), participants with an internal locus of control have been found to achieve more academic success, persist more in the face of adversity, and other positive outcomes. As these outcomes are aligned with the desired outcomes of those in student-athlete development, examining the degree to which an internal locus of control exists in student-athletes would provide valuable information. However, Levenson (1981) warned against devaluing an external locus of control as its existence may not signify an inability to experience similar benefits as those with an internal locus of control. More research is necessary to understand how those an external locus of control affects the experiences of those in specific 
populations whose culture and history clarify how an external locus of control can be beneficial for moderating stress and daily functioning (Levenson, 1981).

Assessing self-efficacy and locus of control together is important. The two constructs are often assessed together in research because of their similarities. Both constructs have implications for the individual and their environment. Although the items for each scale ask about the individual's experience, the environment heavily influences one's self-efficacy and locus of control. However, Bandura (1977) differentiated self-efficacy from locus of control by explaining that locus of control is more concerned with causal beliefs about action-outcome contingencies than personal efficacy. For example, one who believes that their actions can have a significant impact on the outcome of an event can still have low efficacy about their ability to perform the actions necessary to be successful. Bandura's (1977) theory stated that one's locus of control (internal or external) can mediate the effects of the impact of successful mastery experiences as it contributes to their self-efficacy. Bandura (1977) also noted that exploring the notion of learned helplessness can also elucidate the difference between self-efficacy and locus of control. For example, one can give up trying because they do not have the efficacy to successfully complete the task at hand, or they can give up trying because they don't expect their behavior to have any effect on the outcome of an event despite having high efficacy (Bandura, 1977). The notion that the impetus for behavior or lack thereof can be impacted by either the belief in one's capacity or the thought of the influence on the outcome of an event emphasizes the importance of perceptions of the environment and reinforcement of behavior.

Consequently, it becomes imperative to gather information about levels of different identities, role conflict, locus of control, and self-efficacy. Data about these constructs in studentathlete lives may contribute to the understanding and existing knowledge of student-athlete 
development in a valuable way. Each of these constructs have been revealed in the literature to have an influence on college student development and experience, but research has not explored the existence and strength of possible relationships among these constructs. This information can be utilized to modify existing and create new programs to better serve student-athletes from diverse populations.

\section{Theoretical Framework}

There are several applicable theories to analyze the intersections between identities, locus of control, and self-efficacy: social cognitive theory (SCT) and social identity theory (SIT). Social cognitive theory (SCT) has its genesis in Bandura's social learning theory in the 1960s and posits that learning happens in an environment where there are interrelationships among behavior, personal factors, and environmental factors (LaMorte, 2016). SCT is a unique way of examining how learning occurs because it considers the environment and social influence as well as the emphasis on social influence and how it can lead to external and internal social reinforcement (LaMorte, 2016). The theory considers the environment where one will perform a behavior as well as the different ways that one acquires and maintains behavior in and out of that environment (LaMorte, 2016). SCT is a theory designed to understand human agency and human behavior (Bandura, 1989). However, SCT is limited in its assumption that changing the environment will certainly lead to a change in individual behavior and unclear about the nature of the relationships among person, behavior, and environment. Additionally, SCT is limited in its lack of focus on emotion or motivation outside of connection to past experiences (LaMorte, 2016). A central tenet of collegiate student-athlete development is that participation in college sport teaches student-athletes skills that will prepare them for life after college. Paraphrased, it can be stated that a goal of student-athlete development in each athletic department is to help 
improve self-efficacy for student-athletes to function as adults outside of the college setting after they graduate. Based on the literature, it is important to ensure that programming and other developmental approaches are able to reach the diverse population of student-athletes whether that diversity is by sport or other social identities based on demographic factors.

Social identities such as race, ethnicity, gender, socioeconomic status, and firstgeneration status have been found to impact the college choice and college experience for students (Cho, Hudley, Lee, Barry, \& Kelly, 2008). It is important not to generalize results that come from different social identifiers despite the fact that Social Identity Theory (SIT) explains that members of different in-groups and out-groups are subject to different experiences (Tajfel \& Turner, 1979). Research that fails to explore the differences in student-athlete experiences based on these social identifiers is limited in its findings and application. This limitation does a disservice to those who work to support student-athletes during this crucial growth and development period in their lives.

Social identity theory has three stages - social categorization, social identification, and social comparison (Jackson, Sullivan, Harnish, \& Hodge, 1996). Individuals start with social categorization to understand and identify themselves. Then, individuals identify with one or many of the groups they have categorized based on their environment and messages they receive about each group. Some social identities such as race/ethnicity, gender, and socioeconomic status are ascribed, while other social identities such as athlete are achieved (Deaux, Reid, Mizrahi, \& Ethier, 1995) Additionally, individuals seek to make sense of the groups in a hierarchical manner, usually by examining their own group and comparing them to others. In group comparisons, there is always an in-group and an out-group, and individuals' self-esteem is better when they compare favorably to the in-group. Tajfel and Turner (1979) concluded that a social 
identity is satisfied if there is favorable comparison to the in-group. Student-athletes hold many social identities, most notably those of a college student and an intercollegiate athlete (Melendez, 2010). Each identity is performed with roles, responsibilities that influence values and behaviors. Student-athletes hold many other social identities such as the aforementioned demographic factors. Over 460,000 student-athletes compete at NCAA member institutions across the United States (NCAA, 2018a). Even NCAA member institutions have different demographic characteristics that make them distinct such as the racial, ethnic, and gender breakdown of the student body, the number of undergraduate and graduate students, the number and types of sports that they offer, and whether they offer athletic financial aid. The student-athletes that compete at these different institutions are subjected to different experiences based on the institutional characteristics, which is further complicated by the fact that student-athletes hold a number of social identities such as race, gender, socioeconomic status, and/or first-generation college student status (Cho et al., 2008).

In this study, the theoretical framework is at the intersection of the three aforementioned theories: college student development theories, social cognitive theory, social identity theory.

\section{Problem Statement}

Over the past three decades, scholars and practitioners have analyzed the experiences of studentathletes using data relative to academic achievement such as grade point average, retention and eligibility, choice in academic majors, and graduation rates (Scott, Paskus, Miranda, Petr, \& McArdle, 2008). Unfortunately, a dearth of literature exists about the psychological processes that can influence a college student's approach to his or her academic studies. Much of the existing literature about social psychological processes that influence student-athlete academics has focused on motivation (Simons, Van Rheenen, \& Covington, 1999; Gaston-Gayles, 2004; 
Harrison, Martin, \& Fuller, 2015) with a growing emphasis on self-efficacy, one's belief in their capacity to complete a task in a specific domain (Bandura, 1997; MacNab, 2015). Academic self-efficacy has been found to predict college student performance and adjustment to college as well as predict academic persistence (Bandura, 1986; Chemers, Hu, and Garcia, 2001). One unpublished Master's thesis examined the relationship between athletic and academic identity, academic and sport self-efficacy, and academic performance (MacNab, 2015). MacNab (2015) found that there was a positive significant relationship between the dual identities of student and athlete and the degree of self-efficacy that these individuals felt in their academic and athletic responsibilities. This is significant because acknowledging the multidimensional nature of college student-athlete identity can have implications for the way that those who support these individuals engage and interact with them (MacNab, 2015).

To date, no literature has examined how locus of control (Rotter, 1966; Levenson, 1981), the degree to which one feels they have control over the events that happen to them in their life, is related to academic and athletic identity and self-efficacy. Locus of control is a significant construct to add to our understanding of student-athlete experience because of the desire for student-athletes to develop a sense of autonomy (Kimball, 2007) and independence despite being in an environment whose structure resists that development (Adler \& Adler, 1987; Logan, Harrison, \& Logan, 2015). Through specific experiences, teaching, and the feedback and reinforcement one receives in their environment, locus of control and self-efficacy can be changed in a positive manner to help manage effort, increase persistence in the face of adversity, and generally help an individual better complete a task or meet his or her goals consistently over time. (Gist \& Mitchell, 1992). 
Rotter (1966) created the construct of locus of control to determine whether individuals believe that their behaviors and actions influence outcomes in their lives or if those outcomes are determined externally, such as by fate or chance. Based on Rotter's seminal research and all subsequent research, those with an internal locus of control are referred to as 'internals' are more likely to have many positive outcomes than those with an external locus of control, referred to as 'externals.' Through Rotter's scale, one can interpret that it is more desirable to have an internal locus of control and the way that the scale is designed, participants must choose one or the other. Levenson (1981) believed that the dichotomous nature of Rotter's scale was limiting and modified the scale to divide the external locus of control into two domains_-powerful others and chance. The creation of these domains is significant because those who believe that the world is controlled by powerful others may also hold the belief that they have the capability to become a person of power (Levenson, 1981). This is distinctly different from one who believes that the events in their lives are unordered and unpredictable. Levenson's distinction between powerful others and chance also implies that having an external locus of control is not always undesirable or bad (Levenson, (1981). Also, Levenson's (1981) locus of control scale differs from Rotter's scale in two significant ways: 1) The use of a Likert-type scale helps the dimensions be more statistically independent of one another; 2) The statements in the I, P, C scales are phrased so that they only apply to the person answering, not a general belief about what happens to people.

The constructs of locus of control and self-efficacy allow for one to develop different paradigms in examining the experience of student-athletes who do not achieve academically. If a student-athlete believes he or she can achieve academically but that academic achievement has no bearing on the outcome of their growth and development, then one must take a specific approach to engage that student-athlete. If a student-athlete does not believe he or she can 
achieve academically but that academic achievement does have bearing on their growth and development, then one must take a different approach to engage that student-athlete. While both of the previously mentioned examples feature a student-athlete not achieving academically, a distinction between whether an approach addresses self-efficacy or locus of control is critical to effectively engage the student-athlete.

\section{Significance/Potential Implications}

Numerous studies (Adler \& Adler, 1987; Beamon, 2008; Kimball, 2007; Melendez, 2010;

Woodruff \& Schallart, 2008) explored the psychosocial experience of collegiate student-athletes. Scholars (Petrie \& Russell, 1995; Settles, Sellers, \& Damas, 2002) also explored the psychological experience of student-athletes tend to focus on mental health outcomes and their effect on the entire college experience instead of specific aspects of the experience (athletic, academic, social, etc.). This paper is significant because of the focus on the psychosocial development of student-athletes exclusive of outcomes such as grade point average or graduation rates. Instead, the study contributes to the exploration of the holistic understanding of the collegiate student-athlete experience. Also, just as the Academic Progress Rate (APR) was designed to gain a real-time understanding of student-athlete academic progress, the scores on the AAIS, Levinson's Locus of Control Scale, and the researcher-generated self-efficacy scale will provide a real-time understanding of student-athlete academic experience and overall growth and development as they matriculate.

The model developed for this study attempted to depict the relationships among the various constructs. The results of this study inform the efforts of athletic administration committed to effective student-athlete development programming at the institutional, conference, 
and possibly national level. The practical applications can be directed by the newly understood relationship between identity and self-efficacy mediated by role conflict and locus of control.

\section{Purpose Statement}

Based on the review of the literature, the purposes of this study are as follows: 1) to explore how different aspects of student-athlete identity are related to self-efficacy, 2) to what extent different aspects of student-athlete identity are related to self-efficacy, 3) to construct an exploratory model that includes the concepts of identity, role conflict, locus of control, and self-efficacy. Research has shown that these constructs are integral parts of the student-athlete experience but has not uncovered implications of these constructs coexisting simultaneously.

\section{Methodology}

\section{Instrumentation}

The survey was made available using Qualtrics ${ }^{\circledR}$. The survey was comprised of questions from five instruments. The Academic Athletic Identity Scale (AAIS) (Yukhymenko-Lescroart, 2014), the Multigroup Ethnic Identity Measure - Revised (MEIM-R) (Phinney \& Ong, 2007), the Levenson Locus of Control Scale (Levenson, 1981), the Role Conflict Measure Scale (Settles et al., 2002), a researcher created self-efficacy scale, and a researcher-designed demographic survey. The survey was administered in the following order: AAIS, MEIM-R, Role Conflict Measures, Locus of Control Measures, Self-Efficacy Scale, and Demographic Survey.

The order that questions appear on a survey dictate the survey's logic and flow as well as influence participant first impressions and willingness to complete the survey (Fanning, 2005). Lavrakas (2008) described the influence of ordering effect on the distribution of survey responses and revealed that responses are most likely to be evenly distributed if the instruments appear in random order. Lavrakas (2008) discussed a concept called 'part-whole contrast effect' 
that can occur when a series of items on a survey includes a general item and more specific question. Lavrakas (2008) stated that participants may alter their responses to the specific question if asked about the general item first although the same dynamic does not always exist when asked the specific question first. However, Fanning (2005) described the importance of ensuring that the first question (or question set) is one that is general but pertains to the purpose of the survey. The number of items and content of the items in the AAIS scale are general and have shorter prompts and easier directions than other instruments in the survey. Therefore, the researcher feels it is best to keep the order of the survey as previously stated, and specifically important to keep the demographic questionnaire as the last part of the survey. Every participant as existing literature warns that questions that are personal in nature may impact response rate and engagement with the survey (Dillman, 2000; Fanning, 2005).

The AAIS was constructed by Yukhymenko-Lescroart (2014) to assess identity of those engaged in sports under structures where they must be a student and an athlete. YukhymenkoLescroart (2014) constructed the scale and initially tested it with college students participating in club sport and varsity sport. The 11-item scale was found to have a two-factor structure with reliability and factorial validity across sport participation level (club and varsity) and gender. The AAIS is an 11-item questionnaire that were scored from 1 (Not central to who I really am) to 7 (The central core to who I really am). The Multigroup Ethnic Identity Measure - Revised (MEIM-R) (Phinney \& Ong, 2007) explores the amount of exploration that participants have had of their ethnic identity and the amount of commitment that participants have to their ethnic identity. The MEIM-R is a six-item questionnaire scored from 1 (Strongly Disagree) to 5 (Strongly Agree). 
Another section of the questionnaire assessed the participants' locus of control. This section consisted of Levenson's (1981) Locus of Control Scale, which allows participants to determine how much control they have over events that happen in their lives using a 7-point Likert-type scale ranging from -3 = "Strongly Disagree" to $+3=$ "Strongly Agree." Rotter's Locus of Control scale is the most popular measure of locus of control used in research, but Levenson's scale is more fitting for this study for three reasons: 1) Levenson's scale is presented as a Likert-type scale instead of a forced choice scale, 2) Statements are presented in a way that makes a distinction between a participant's beliefs about him or herself and how they believe it works for people in general, and 3) All statements are worded such that a participant would not be able to modify the issues in question. Data assessing social desirability using the MarloweCrowne Social Desirability Scale were analyzed with the initial validation of the IPC scale. Levenson (1981) and Wallston, Wallston, and DeVellis (1978) found correlations with the I (.04-.09), P (.04-.11), and C (-.10-.08) scales that were considered negligible.

Another section of the questionnaire assessed the participants' self-efficacy across five domains: general, academic, athletic, social, and career. Creation of the questions for the selfefficacy scales were guided by the book chapter, "Guide for Constructing Self-Efficacy Scales" (Bandura, 2006). Bandura (2006) indicated that questions regarding self-efficacy should be written using language that indicates what the participant believes he or she "can" do and should be scaled 0 to 100 . Using smaller scales such as 0 to 10 or 1 to 5 make it difficult for participants to accurately gauge efficacy and make the analysis less significant (Bandura, 2006). Also, Bandura (2006) indicated that self-efficacy assessments should not be labeled as such as that label can influence the responses from participants. 
Another section of the questionnaire assessed the potential conflict between participants' role as a student and role as a varsity athlete. The role conflict measure consisted of two scales: Student-Athlete Role Interference Scale and Student-Athlete Role Separation Scale. The role interference scale consists of 12 items, and the role separation scale consists of four items that began with, "Some student-athletes...". Each item was scored on a Likert-type scale that ranged from 1 (not really true of me) to 7 (really true of me). The researcher reverse-coded and reversescored appropriate items. There is no reliability and validity data for this measure because it was an in-house created survey that has not been utilized since its creation.

The final section of the survey was the demographic questionnaire constructed by the researcher to collect descriptive information from student-athletes. The questionnaire asked for gender, race, socioeconomic status, sport, sport status (first team, second team, third team, or practicing), athletic scholarship (none, partial, full), in-season or out of season, academic major, overall grade point average, most recent previous academic institution, current academic classification, first generation college student, and number of years as a varsity athlete. Each of these pieces of information have been shown to influence identity development, adjustment to college, and overall college experiences.

\section{Participants}

Participants in this study were NCAA Division I varsity student athletes from member institutions in the southeastern and mid-Atlantic region of the United States. Male and female varsity student-athletes from all sports were asked to participate in this study. All participants were over the age of 18 and enrolled full-time as a student at their respective institution. The survey reached 4410 student-athletes and 293 completed it for a $6.6 \%$ response rate. 


\section{Recruitment and Administration}

Participants were recruited for this study (Spring and Summer 2018) via contact with each conference's Director of Academic Support, Director of Student-Athlete Programs or Director of Compliance. When those officials could not be reached at the conference level, the researcher contacted individuals with those titles and the athletic director at each institution. Each contact person received at least one email and telephone call. Upon agreement to help with recruitment, each contact was sent an email with a link to a YouTube video the researcher created for participants and a link to complete the survey. The researcher also discussed the most effective way for athletic administration at each institution to follow-up and remind student-athletes about the survey. Athletic administration was encouraged to endorse the study — communicate that they hope that students would take the survey as the participation would be of value to the athletic department and the university. Athletic administration and participants were made aware of the way that the results of this study can inform student-athlete development programming and policy at an institutional, conference, and national level.

A unique link to the survey created by Qualtrics was provided for student-athletes based on the conference they compete in or their individual institution. The unique link was made available in the description box of the institution's YouTube video.

\section{Research Design}

The study was a quantitative, cross-sectional survey-design study. The purpose of the surveydesign approach is to survey a large number of collegiate student-athletes across a number of demographic variables - gender, race, sport, socioeconomic status, first-generation college student status - to capture the diversity of backgrounds represented in collegiate student-athlete participation across the nation. To examine the student-athlete experience across the nation, it is 
important to have a large number of participants to make conclusions more generalizable.

Therefore, survey research is the preferred method of research to examine a cross-section of collegiate student-athletes across the nation. Although quantitative survey-design studies are also not generalizable, they sometimes aim to move closer to that categorization by aiming to capture a larger sample size.

\section{Variables}

The variables tested and analyzed in the proposed structural model were as follows: athletic identity, academic identity, ethnic identity, locus of control, role conflict, and self-efficacy. Athletic, academic, and ethnic identity were predictor variables in the model. The self-efficacy (dependent) variable is comprised of general self-efficacy, academic self-efficacy, athletic selfefficacy, career self-efficacy, and social self-efficacy. In the proposed model, the subscales of locus of control and the subscales of role conflict were moderator variables between identity and self-efficacy. Ethnic identity, locus of control, role conflict, and self-efficacy were latent variables, not directly measured by the responses on the respective survey items. Athletic identity and academic identity were observed variables, measured directly by the responses given on those survey items.

Identity is understood to be a combination of the self in different domains, but certain identities become more salient throughout different elements of our lives (Lyons, Dorsch, Bell, \& Mason, 2018). For collegiate student-athletes, two of the most salient identities during their time in college are those as a college student and as an athlete (NCAA, 2013). Previous scholars (Brewer et al., 1993) have examined how athletic identity in collegiate athletes has led to identity foreclosure (Murphy, Petitpas, \& Brewer, 1996; Marcia, 1980) and negative consequences related to development during college (Ferrera, Watson, \& Zizzi, 2017) and transitioning out of 
sport after college (Wylleman \& Lavallee, 2004). The identity that is most often foreclosed is that as a student, which can lead to academic problems (NCAA, 2013). It is well documented that the academic experience of collegiate student-athletes is different than that of their nonathlete peers because of the structure and demands that accompany competing at the collegiate level (Melendez, 2010). Research indicated that some student-athletes struggle to balance the demands of being a college student and being a college athlete (Adler \& Adler, 1987; Melendez, 2010), and that has been explored through the concept of role conflict.

Role conflict has been measured and studied using various research methodologies. Qualitative measures have consisted of semi-structured interviews that allow participants to describe their experiences balancing the roles of a student and an athlete. Adler and Adler (1987) uncovered details surrounding the role conflict that college basketball student-athletes may experience through a series of interviews that indicated participants' academic roles and responsibilities were engulfed by their athletic participation, which led to giving up on their academics and emphasizing athletics despite entering college with high academic aspirations. Settles et al. (2002) developed and utilized a quantitative measure to assess role conflict in collegiate student-athletes. Settles et al. (2002) divided the questionnaire into two parts that assessed each participant's integration of the student and athlete roles and each participant's separation of the two roles. The degree that the roles were separated for a student-athlete were positively correlated with well-being and the degree that the roles interfered were negatively related to well-being. The results of the study suggest that student-athletes who are able to see their roles as student and athlete as separate may better be able to focus on the demands of each role separately and therefore perform better in both. 
Locus of control research has consistently documented the benefits and advantages of those who have an internal locus of control when compared to those who have an external locus of control across a number of different populations and a variety of domains (Levenson, 1981). However, the dichotomous nature of internal and external loci of control has been criticized as limiting in its discussion and practical implications. Levenson (1981) created and tested a locus of control measure that divides external locus of control into two domains, powerful others and chance. This distinction is significant because it allows for a more in-depth understanding of what influences one to have an external locus of control. The powerful others subscale is important because it is distinctly different than the belief that one's life is subject to the events of chance. A higher score on the powerful others subscale may indicate the belief that one may have the capacity to occupy a position as a powerful other, which is a moderate position between internal and external loci of control.

Self-efficacy can dictate the amount of perceived effort one will put into beginning a task and persistence in achieving it in the face of adversity. The collegiate sport model is purportedly designed to facilitate student-athlete growth and development across a number of domainsathletic, academic, social, and career (NCAA, 2018). However, this process is likely inhibited based on the amount of role conflict experiences and the locus of control that a student-athlete holds.

\section{Research Question}

The primary research question for this study was: What relationships exist among identity, role conflict, locus of control, and self-efficacy in collegiate student-athletes? This question was analyzed through examining the fit of a specified, measured model that depicts the constructs of locus of control and role conflict as moderating variables in the relationship that exists between 
academic and athletic identity (predictor variable) and self-efficacy (outcome variable). The fit of the model was assessed using numerous measures of model fit such as chi-squared difference tests, comparative fit indices, absolute fit index, and residual-based fit indices. During the analysis, the model revealed standardized regression weights, signifying the relationships between and among each variable. (see Figure 1 and Appendix B)

\section{Research Hypotheses}

The researcher had six hypotheses. First, the researcher hypothesized that there would be a positive relationship between identity and self-efficacy across domains as latent variables. Second, the researcher hypothesized that there is a negative relationship between identity and role conflict. Third, the researcher hypothesized that there is a negative relationship between identity and locus of control. Fourth, the researcher hypothesized that there is a negative relationship between role conflict and self-efficacy. Fifth, the researcher hypothesized that there is a positive relationship between locus of control and self-efficacy. Finally, the researcher hypothesized that role conflict and locus of control mediate the relationship between identity and perceived self-efficacy in different domains.

\section{Procedures}

A protocol was submitted to the West Virginia University Institutional Review Board outlining the data collection procedures and any known risks associated with completing the study. Upon receiving IRB approval, administrators in each university's athletic department were contacted to ask for their support in distributing the YouTube link to the student-athletes at their institution along with an endorsement of the study in hopes that would increase participation. Reminder messages via email were sent to student-athlete participants. Data were checked for missingness before beginning analysis. 


\section{Analysis}

Data was exported to IBM SPSS for Statistics Version 24 and coded for use with IBM SPSS AMOS. Statistical analyses for this study was conducted using structural equation modeling (SEM) techniques. SEM was chosen to conduct the analysis to examine relationships among the latent variables of identity, locus of control, role conflict, and self-efficacy and compare them with observed demographic variables. A model that has a "good" fit would support that there is a relationship among athletic and academic identity and self-efficacy mediated by locus of control and role conflict (Byrne, 2001). A large sample size, at least 250, is recommended for SEM to be effective and reduce the risk of Type II error. Although there is no firm way to calculate an appropriately-sized sample, a commonly utilized approach is to have a sample with a number of participants that is 10 times the number of variables. Therefore, this study requires at least 250 participants to test the model and receive accurate results. The hypothesized structural model is depicted below (Figure 1). 


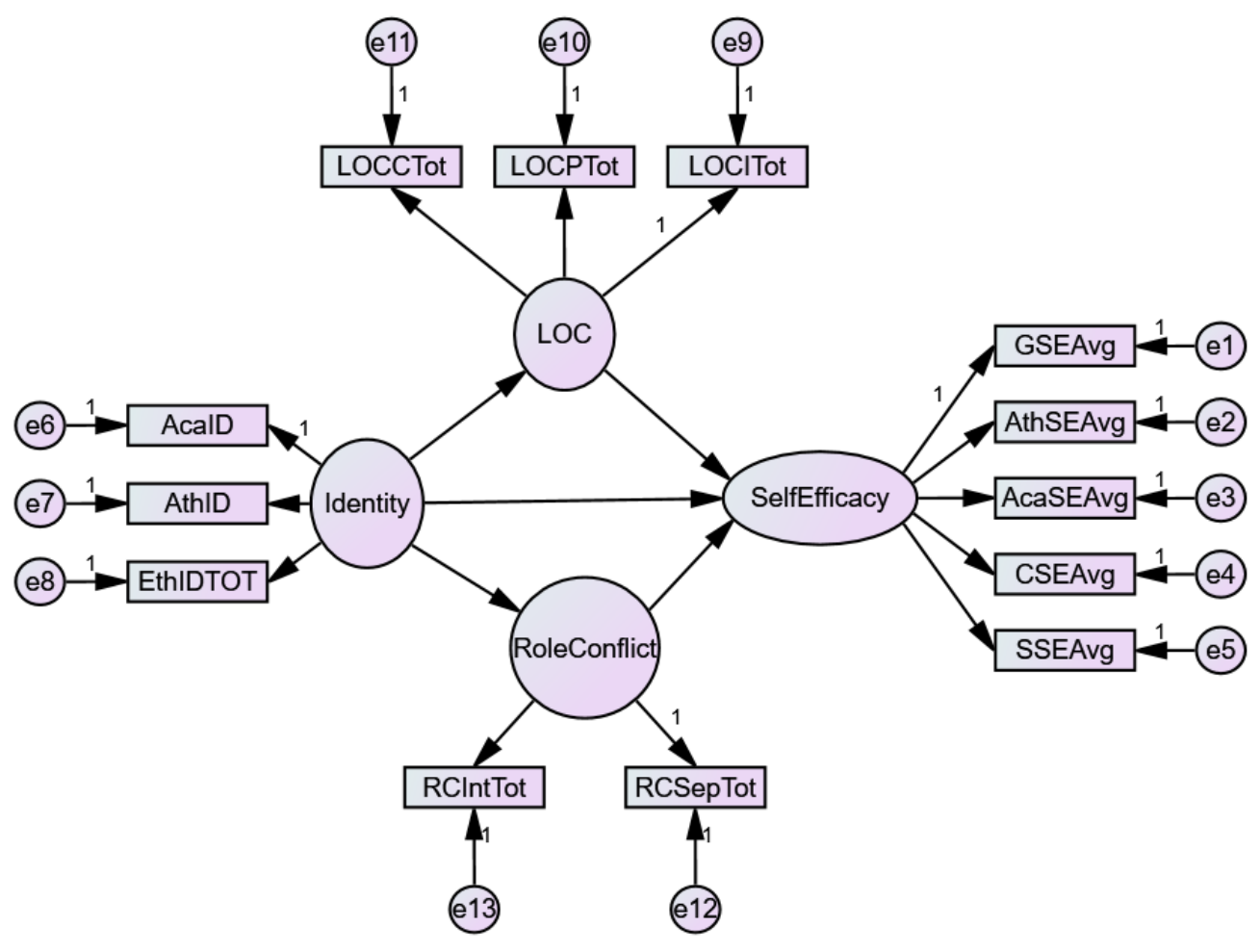

Figure 1. Hypothesized Structural Model.

The model depicts identity as a latent exogenous (independent) variable. As an exogenous variable, identity predicts locus of control, role conflict, and self-efficacy. The direct path between identity and self-efficacy allows for locus of control and role conflict to be tested as mediators of the relationship between identity and self-efficacy. If the model fit indices are satisfactory, then the standardized regression weights for each predictive path will indicate the strength of association among the variables.

The sample was comprised of 265 respondents. The sample was comprised of 196 females and 69 males ranging in age from 18 to 23 years $(M=20.06, S D=1.328)$. The sample was comprised of 167 student-athletes who identified as White (63\%). The student-athletes competed across 21 different NCAA sports, with 30 participants from revenue-generating sports (football, men's and women's basketball) and 11 participants that participated in more than one sport at their institution. The majority of the participants competed on the 'first team' or starting lineup in 
their sport (63\%) and received at least a partial athletics scholarship (77\%). Participants were nearly evenly distributed across academic classification with freshman (57), sophomore (55), junior (72), and senior (68). A small percentage (5\%) of participants were graduate students. Only $15 \%$ of participants were first-generation college students.

\section{Data Cleaning}

There were 290 respondents to the survey. However, three respondents were removed because they selected 'No, I do not want to take the survey' option in their informed consent. Then, there were ten respondents who only completed the Identity portion of the survey. Those ten responses were removed from the data set. Finally, there were two cases where participants reported their age as 17 . Because all participants must be 18 years of age, those responses were deleted from the data set. Before analysis, all data were checked for missing responses and missing responses were imputed using expectation maximization (EM). The missing responses were tested to determine whether data were missing completely at random (MCAR) or not missing at random (NMCAR). Little's MCAR Test revealed that the data was $\operatorname{MCAR}\left(\mathrm{X}^{2}=.000, \mathrm{df}=1727, p=\right.$ 1.00). After data were imputed, the data was checked for univariate and multivariate outliers. The researcher used Mahalanobis' distance to determine multivariate outliers. There were ten outliers based on the value of 36.123 at .001 significance and the decision was made to remove the outliers.

\section{Descriptive Statistics}

The variables included in the model were comprised of the item totals across the different questionnaires in the survey. Academic identity (AcaID) and athletic identity (AthID) each have a maximum score of 35 . The ethnic identity exploration subscale (EIExpTot) and commitment subscale (EIComTot) each have a maximum score of 15. Each of the self-efficacy variables were 
computed by the mean of the items in each domain. For example, the three questions that assessed general self-efficacy were averaged together to comprise the score for the variable GSEAvg. The same was done for athletic (AthSEAvg), academic (AcaSEAvg), career (CSEAvg), and social self-efficacy (SSEAvg). The role conflict questionnaire has two subscales, interference (RCIntTot) and separation (RCSepTot). The Levenson Locus of Control scale has three subscales, internal (LOCITot), powerful others (LOCPTot), and chance (LOCCTot), with each subscale having 8 items scored on a scale of 1 to 6 . The minimum and maximum values for the sample as well as the mean and standard deviation of each variable included in the models are listed in Table 1.

Table 1

Descriptive Statistics of Sample Minimum Maximum Mean

Std.

$\begin{array}{lrrrr} & & & & \text { Deviation } \\ \text { AcaID } & 6.00 & 35.00 & 26.600 & 5.5546 \\ \text { AthID } & 9.00 & 35.00 & 26.727 & 5.4896 \\ \text { EIExpTot } & 3.00 & 15.00 & 8.324 & 2.9336 \\ \text { EIComTot } & 3.00 & 15.00 & 10.143 & 2.5941 \\ \text { GSEAvg } & 33.33 & 100.00 & 79.817 & 14.1652 \\ \text { AthSEAvg } & 22.50 & 100.00 & 82.637 & 14.7313 \\ \text { AcaSEAvg } & 27.50 & 100.00 & 76.434 & 15.9873 \\ \text { CSEAvg } & 15.83 & 100.00 & 76.658 & 16.1528 \\ \text { SSEAvg } & 22.00 & 100.00 & 79.647 & 14.8010 \\ \text { RCIntTot } & 12.00 & 81.08 & 45.539 & 14.7983 \\ \text { RCSepTot } & 7.00 & 27.00 & 16.022 & 3.5867 \\ \text { LOCITot } & 21.00 & 48.00 & 35.930 & 4.1727 \\ \text { LOCPTot } & 11.00 & 40.00 & 24.976 & 5.7462 \\ \text { LOCCTot } & 10.00 & 40.00 & 23.181 & 6.0697\end{array}$

Table 1 - Descriptive Statistics of Sample 


\section{Model Testing}

The goodness of fit for all models was determined by the values of the ratio of chi-squared to degrees of freedom (CMIN/DF), comparative fit index (CFI), the root mean square error of approximation (RMSEA), and the standardized root mean square residual (SRMR). In order to be a good fit, a model must meet the standard in all four fit indices. For a good-fitting model, the fit indices must be as follows: CMIN/DF less than or equal to 3, CFI greater than or equal to .95, SRMR less than or equal to .08, and RMSEA less than or equal to .06.

\section{Results}

The hypothesized measurement model that depicted relationships among identity, locus of control, role conflict, and self-efficacy as latent variables did not have a good fit $(\mathrm{CMIN} / \mathrm{DF}=4.261, \mathrm{CFI}=.796, \mathrm{RMSEA}=.111, \mathrm{SRMR}=.0748)$. After examining the modification indices, the decision was made to covary the error terms attached to variables AthSEAvg and AcaSEAvg, covary the error terms attached to variables AthSEAvg and CSEAvg, and covary the error terms attached to the variables GSEAvg and SSEAvg. These modifications improved the fit of the model $(\mathrm{CMIN} / \mathrm{DF}=3.729, \mathrm{CFI}=.838, \mathrm{RMSEA}=.102, \mathrm{SRMR}=.0735)$, but did not result in the model becoming one of good fit. Additionally, the factor loadings of observed variables onto the latent variables indicated that testing a model that tests identity, locus of control, role conflict, and self-efficacy as latent variables will not produce accurate results. Self-efficacy was the only latent variable where each of the factor loadings was of appropriate strength to utilize in accurate analysis. The Powerful Others subscale and Chance subscale of Levenson's locus of control scale also have appropriately strong factor loadings for external locus of control to be analyzed as a latent variable in future analysis (Figure 2). 


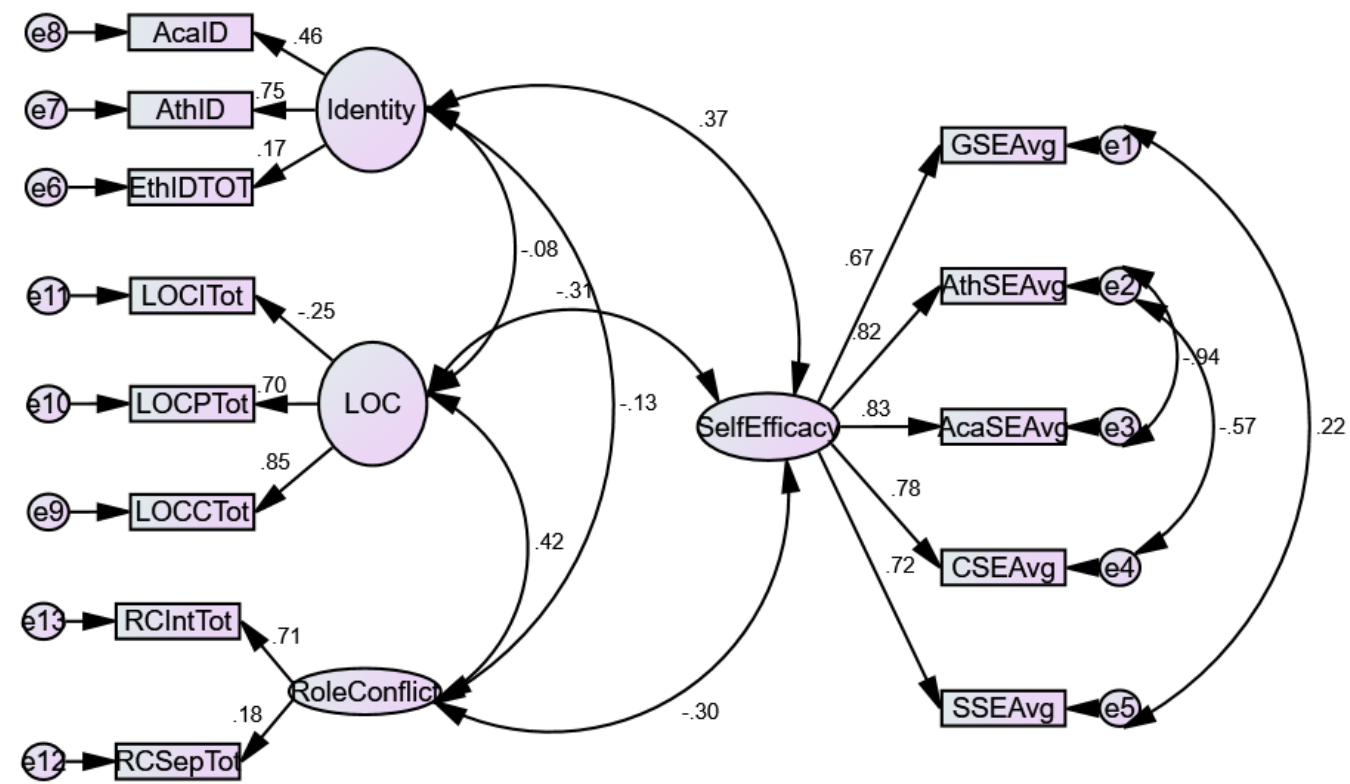

Figure 2. Measurement Model of Hypothesized Structural Model.

However, positive relationships between the latent variables identity and self-efficacy and latent variables locus of control and role conflict led the researcher to test the fit of the hypothesized structural model. The hypothesized structural model depicts the latent variable identity as an exogenous (independent) variable and the latent variable self-efficacy as an endogenous (dependent) variable. The hypothesized structural model also depicts the latent variables of locus of control and role conflict as two mediator variables in the relationship between the latent variables identity and self-efficacy. The hypothesized structural model did not have a good fit $(\mathrm{CMIN} / \mathrm{DF}=4.044, \mathrm{CFI}=.803, \mathrm{RMSEA}=.107, \mathrm{SRMR}=.0910)$. After examining the modification indices, the decision was made to covary the latent variables of locus of control and role conflict. This modification improved the fit of the model (CMIN/DF=3.729, CFI $=.830$, RMSEA=.102, SRMR=.0814), but did not result in the model becoming one of good fit.

Because of the lack of good fit among the latent variables in the hypothesized measurement and structural models, the researcher tested additional models comprised of the observed variables that determined the latent variables. In the following seven models, the 
researcher kept one latent variables, self-efficacy, and tested the relationship between observed variables of academic, athletic, and ethnic identity, interference and separation in role conflict, and internal, powerful others, and chance loci of control.

\section{Model 1 - Academic, Athletic, and Ethnic Identity as a Predictor of Self-Efficacy}

Model 1 depicts the observed variables of academic identity, athletic identity, ethnic identity exploration, and ethnic identity commitment as predictors of the latent variable self-efficacy (Figure 3).

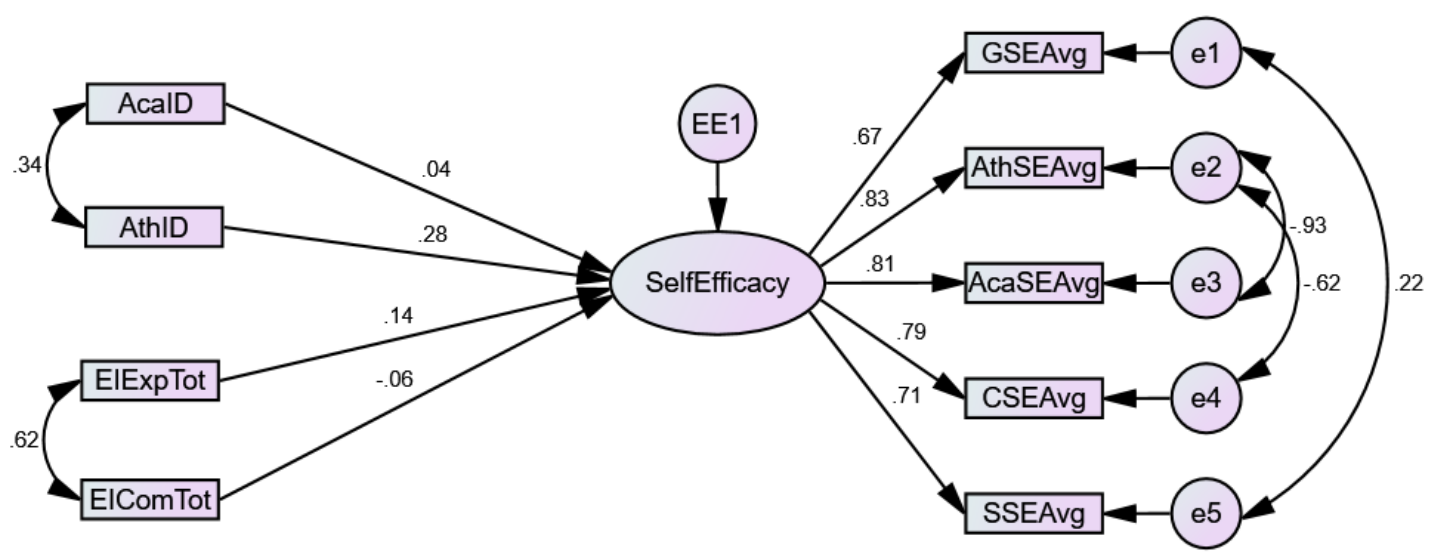

Figure 3. Academic, Athletic, and Ethnic Identity as Predictors of Self-Efficacy.

Model 1 did not have a good fit (CMIN/DF=7.287, CFI=.831, RMSEA=.154, SRMR=.0947).

After examining the modification indices, it was determined that a covariance between academic identity and athletic identity could improve the fit of the model. The resulting model still did not have a good fit $(\mathrm{CMIN} / \mathrm{DF}=6.109, \mathrm{CFI}=.869, \mathrm{RMSEA}=.139, \mathrm{SRMR}=.0771)$. There are positive associations between academic identity, athletic identity, and ethnic identity exploration and the latent variable, self-efficacy. Model 1 did not fit.

\section{Model 2 - Role Interference and Role Separation as Predictors of Self-Efficacy}

Model 2 depicts the observed variables of interference (RCInt) and separation (RCSep) as predictors of the latent variable self-efficacy (Figure 3). 


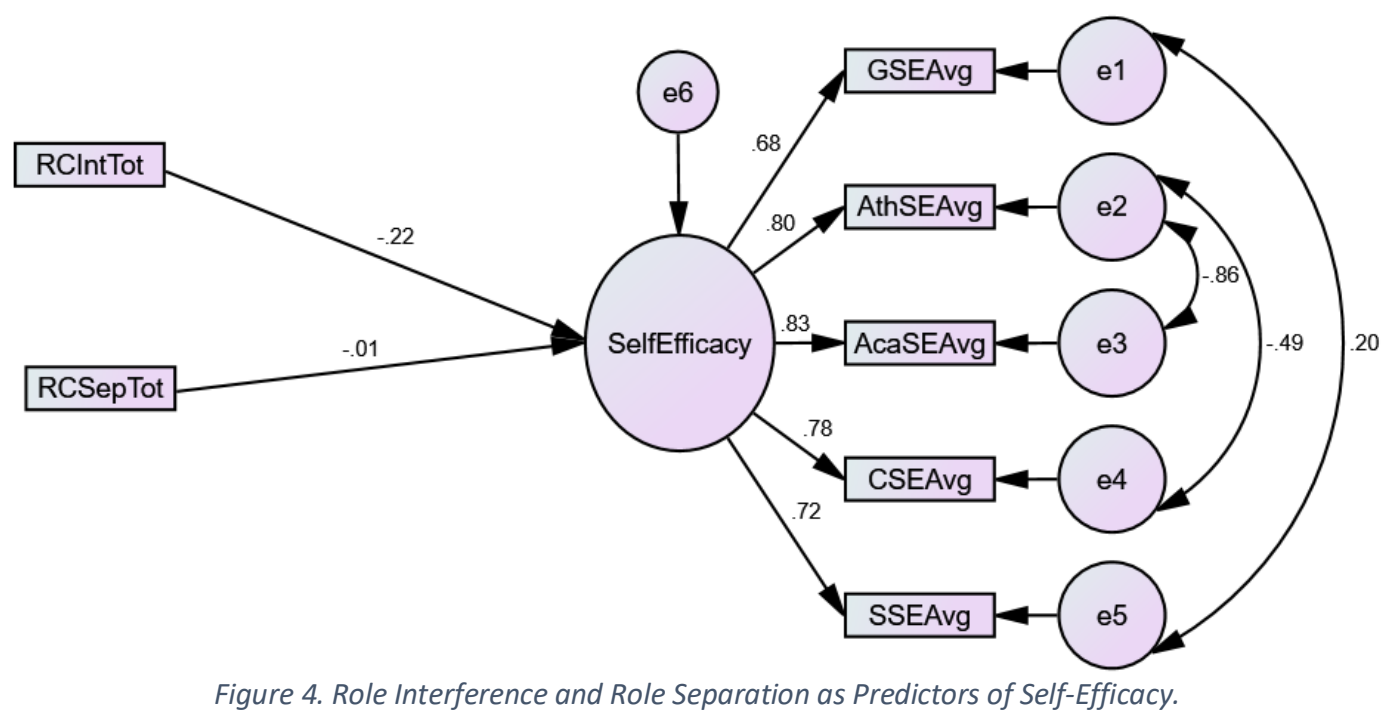

Model 2 did not have a good fit $(\mathrm{CMIN} / \mathrm{DF}=3.098, \mathrm{CFI}=.961, \mathrm{RMSEA}=.089, \mathrm{SRMR}=.0501)$. After examining the modification indices, it was determined that no appropriate covariances could be made between remaining error terms. There are negative associations between role conflict interference and the latent variable self-efficacy as well as role conflict separation and the latent variable self-efficacy. The negative association is stronger between interference and self-efficacy than separation and self-efficacy. Model 2 did not fit.

\section{Model 3 - Internal and External Locus of Control as Predictors of Self-Efficacy}

Model 3 depicts the observed variables of internal locus of control (LOCITot), powerful others locus of control (LOCPTot), and chance locus of control (LOCCTot) as predictors of the latent variable self-efficacy. However, due to the results of the measurement model, powerful others and chance locus of control were depicted as a latent variable for external locus of control (ExtLOC) (Figure 5). 


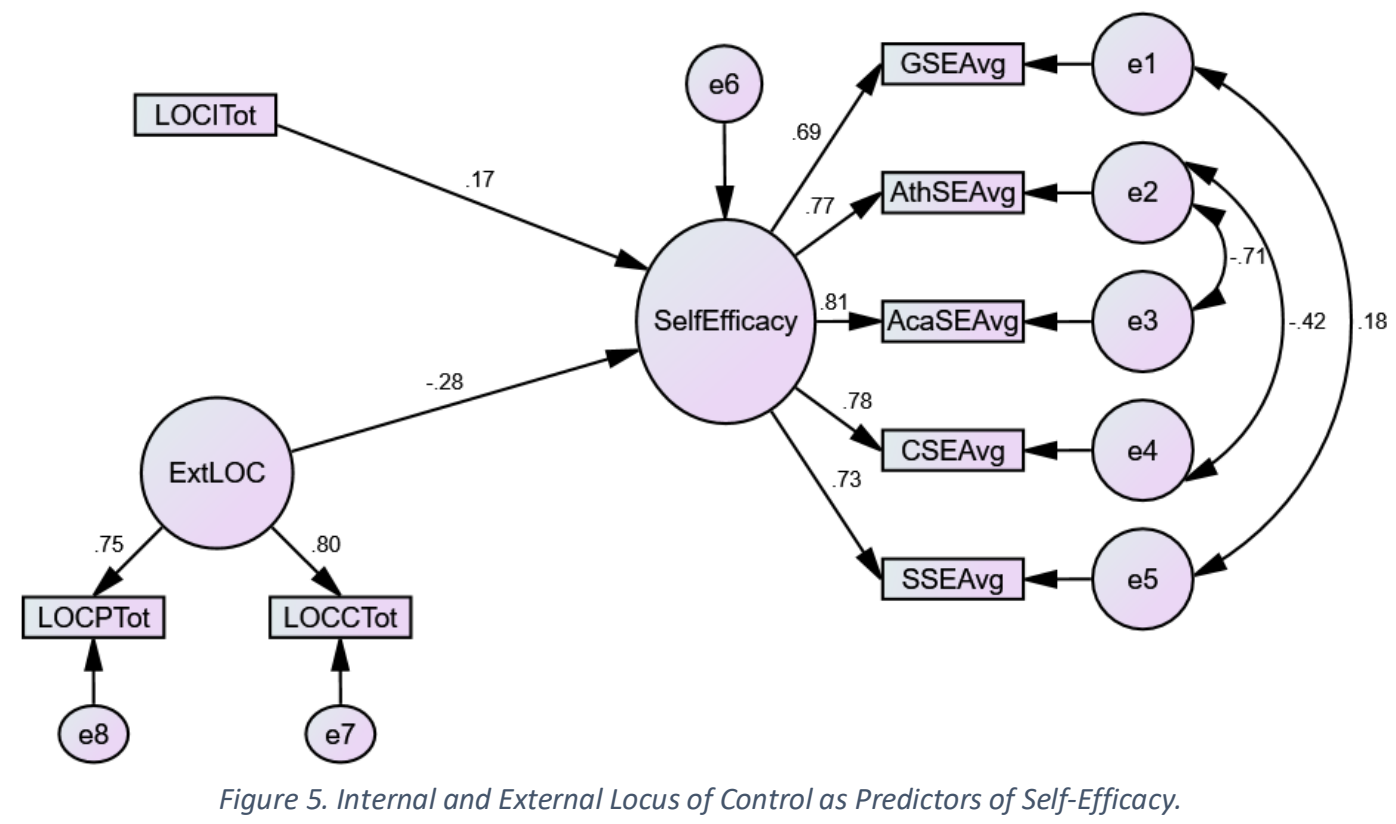

Model 3 did not have a good fit $(\mathrm{CMIN} / \mathrm{DF}=2.484, \mathrm{CFI}=.967, \mathrm{RMSEA}=.075, \mathrm{SRMR}=.0615)$. After examining the modification indices, it was determined that no appropriate covariances could be made between remaining error terms. There is a negative association between the latent variable external locus of control and the latent variable self-efficacy. Additionally, there is a positive association between the observed variable of internal locus of control and latent variable self-efficacy. Model 3 did fit.

\section{Model 4 - Role Conflict and Locus of Control as Predictors of Self-Efficacy}

Model 4 (Figure 6) depicts the observed variables of interference and separation of role conflict, internal locus of control, and the latent variable of external locus of control as predictors for the latent variable self-efficacy. Because Model 2 and Model 3 were near good-fitting, the researcher determined it necessary to test the fit of a model that incorporated the two independent variables from those models. 


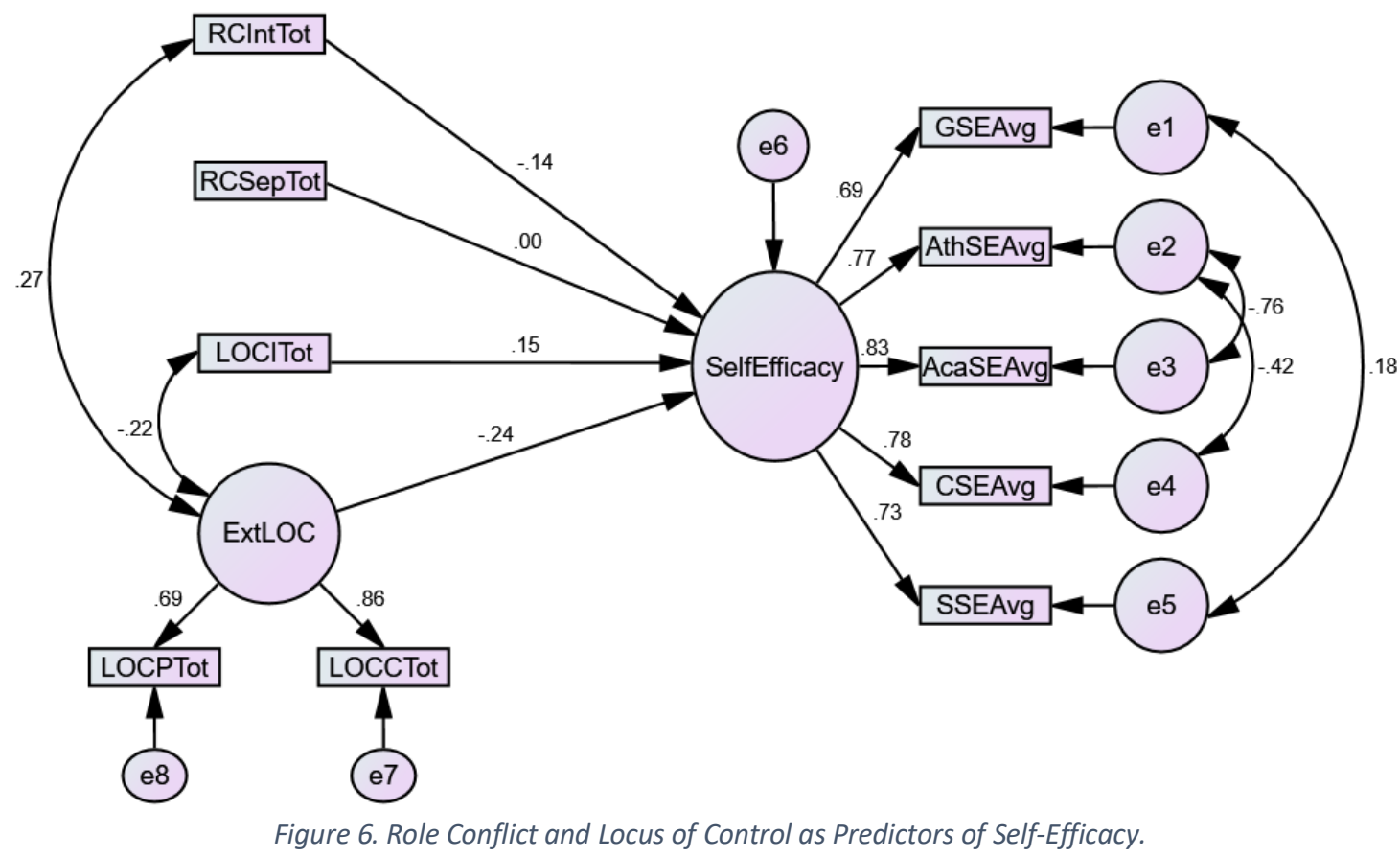

Model 4 did not have a good fit $(\mathrm{CMIN} / \mathrm{DF}=3.032, \mathrm{CFI}=.918, \mathrm{RMSEA}=.088, \mathrm{SRMR}=.0801)$. After examining the modification indices, it was determined that one covariance could be made between remaining variables, RCIntTot and ExtLOC. The modification resulted in a model with much better fit $(\mathrm{CMIN} / \mathrm{DF}=2.522, \mathrm{CFI}=.941, \mathrm{RMSEA}=.076, \mathrm{SRMR}=.0641)$, but still enough to be considered a good fit. The modification indices of the adjusted model indicated that an additional covariance between LOCITot and ExtLOC would improve the fit of the model. The resulting model (Figure 5) is one of $\operatorname{good}$ fit $(\mathrm{CMIN} / \mathrm{DF}=2.252, \mathrm{CFI}=.953, \mathrm{RMSEA}=.069$, $\mathrm{SRMR}=.0509)$

There is a positive association between the observed variable role conflict interference and latent variable external locus of control and observed variable internal locus of control and latent variable self-efficacy. The negative associations between the observed variable role conflict interference and latent variable self-efficacy and latent variable external locus of control and latent variable self-efficacy weakened in this model. Because Model 4 ultimately had a good 
fit, the researcher determined it necessary to incorporate the observed variables of identity into subsequent models to test for good fit. Model 4 did fit.

Model 5 - Academic Identity, Role Conflict and Locus of Control as Predictors of Self-

Efficacy

Model 5 depicts the observed variable of academic identity with role conflict and locus of control as an additional predictor of self-efficacy (Figure 7).

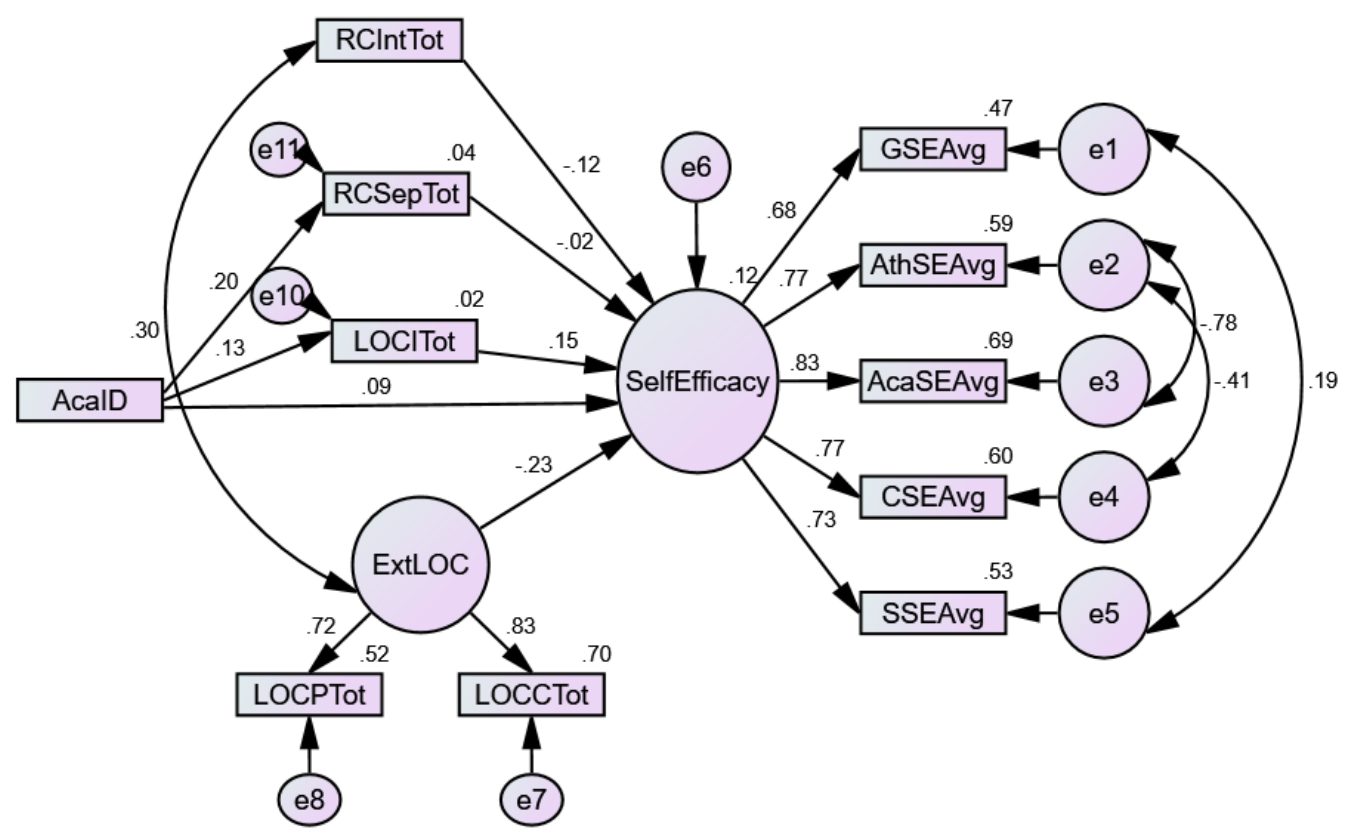

Figure 7. Academic Identity, Role Conflict, and Locus of Control as Predictors of Self-Efficacy.

Model 5 did not have a good fit $(\mathrm{CMIN} / \mathrm{DF}=2.932, \mathrm{CFI}=.912, \mathrm{RMSEA}=.086, \mathrm{SRMR}=.0717)$.

There are positive associations between academic identity and role conflict separation and academic identity and internal locus of control. Model 5 did not fit.

Model 6 - Athletic Identity, Role Conflict and Locus of Control as Predictors of SelfEfficacy

Model 6 depicts the observed variable of athletic identity with role conflict and locus of control as an additional predictor of self-efficacy (Figure 8). 


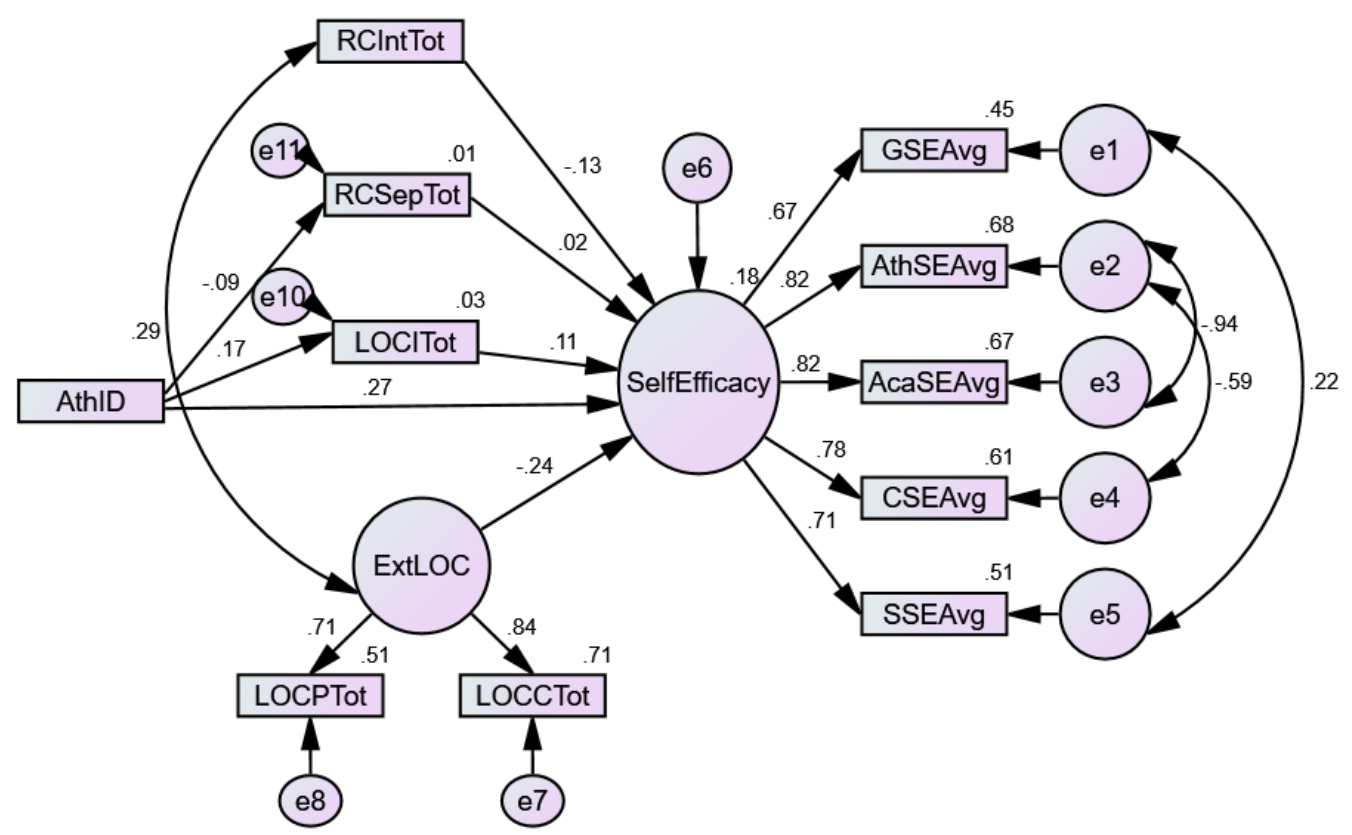

Figure 8. Athletic Identity, Role Conflict, and Locus of Control as Predictors of Self-Efficacy.

Model 6 did not have a good fit $(\mathrm{CMIN} / \mathrm{DF}=2.854, \mathrm{CFI}=.917, \mathrm{RMSEA}=.084, \mathrm{SRMR}=.0678)$. An examination of the modification indices revealed that no appropriate covariances could be made between remaining error terms. There is a negative association between athletic identity and role conflict separation. There is a positive association between athletic identity and internal locus of control. Model 6 did not fit.

\section{Model 7 - Ethnic Identity, Role Conflict and Locus of Control as Predictors of Self-Efficacy}

Model 7 depicts the observed variables of ethnic identity exploration and ethnic identity commitment with role conflict and locus of control as additional predictors of self-efficacy (Figure 9). 


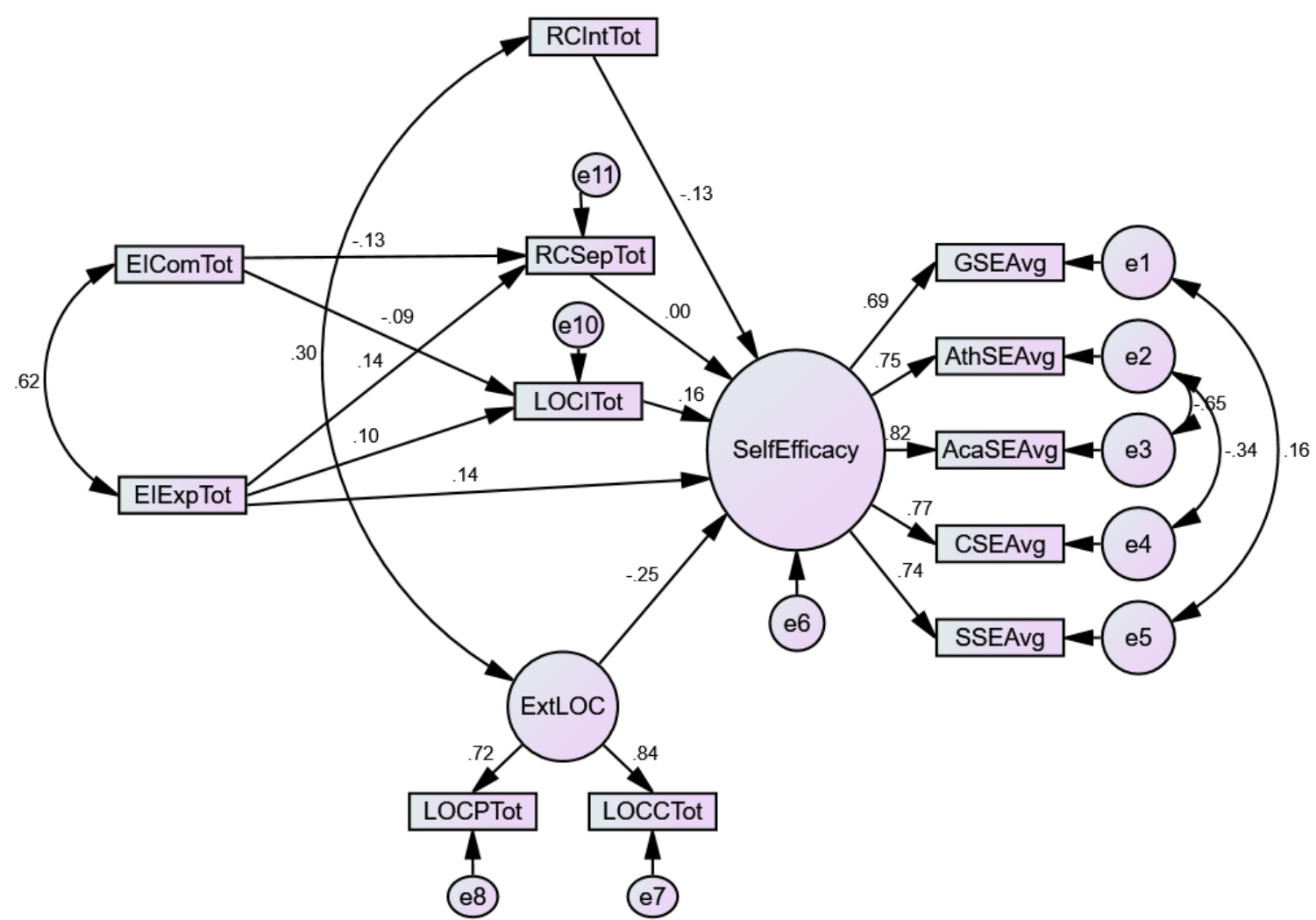

Figure 9. Ethnic Identity, Role Conflict, and Locus of Control as Predictors of Self-Efficacy.

Model 7 did not have a good fit $(\mathrm{CMIN} / \mathrm{DF}=2.574, \mathrm{CFI}=.921, \mathrm{RMSEA}=.077, \mathrm{SRMR}=.0718)$. An examination of the modification indices revealed that a covariance of RCIntTot and ExtLOC could improve the fit of the model. The covariance was made and resulted in a good fit $(\mathrm{CMIN} / \mathrm{DF}=2.224, \mathrm{CFI}=.940, \mathrm{RMSEA}=.068, \mathrm{SRMR}=.0594)$. There are positive associations between ethnic identity exploration and role conflict separation, internal locus of control and self-efficacy. Simultaneously, there are negative associations between ethnic identity commitment and each of the following variables: role conflict separation and internal locus of control. Model 7 did fit.

\section{Ad Hoc Analysis}

Ad hoc analysis for these models included mediation testing. Analyses were run to determine whether locus of control and role conflict mediate the relationship between identity and selfefficacy. Because the relationship between identity and self-efficacy had to be tested using three 
separate models (Models 5-7), the mediation tests were conducted on three separate models as well.

Table 3

Mediation Analyses

$\begin{array}{cccccc}\text { Model } & \text { Relationship } & \begin{array}{c}\text { Direct } \\ \text { with } \\ \text { Mediator }\end{array} & \begin{array}{c}\text { Direct } \\ \text { without } \\ \text { Mediators }\end{array} & \begin{array}{c}\text { Direct } \\ \text { with all } \\ \text { Mediators }\end{array} & \text { Indirect } \\ 5 & \text { AcaID } \rightarrow \text { RCSepTot } \rightarrow \text { SelfEfficacy } & .091(.132) & .091(.125) & .091(.136) & -.003(.607) \\ 5 & \text { AcaID } \rightarrow \text { LOCITot } \rightarrow \text { SelfEfficacy } & .091(.128) & .091(.125) & .091(.136) & .020(.003) \\ 6 & \text { AthID } \rightarrow \text { RCSepTot } \rightarrow \text { SelfEfficacy } & .268(\mathrm{NS}) & .268(\mathrm{NS}) & .267(\mathrm{NS}) & -.002(.633) \\ 6 & \text { AthID } \rightarrow \text { LOCITot } \rightarrow \text { SelfEfficacy } & .267(\mathrm{NS}) & .268(\mathrm{NS}) & .267(\mathrm{NS}) & .018(.023) \\ 7 & \text { EIExpTot } \rightarrow \text { RCSepTot } \rightarrow \text { SelfEfficacy } & .137(.023) & .137(.023) & .137(.023) & .000(.824) \\ 7 & \text { EIExpTot } \rightarrow \text { LOCITot } \rightarrow \text { SelfEfficacy } & .137(.069) & .137(.023) & .137(.023) & .016(.093)\end{array}$

Table 3 - Mediation Analyses

The mediation analyses revealed that there were four significant mediation relationships. First, internal locus of control mediated the relationship between academic identity and self-efficacy with significant indirect effects. Second, internal locus of control mediated the relationship between athletic identity and self-efficacy with significant indirect effects. Third, role conflict separation mediated the relationship between ethnic identity exploration and self-efficacy with significant direct effects. Finally, internal locus of control mediated the relationship between ethnic identity exploration and self-efficacy with significant direct and indirect effects.

\section{Results Summary}

A summary of the fit indices and overall model fit for each model is listed in the table below (Table 2). Models without overall good fit met three of the four standards for fit indices. 
Table 2

\begin{tabular}{|c|c|c|c|c|c|}
\hline \multicolumn{6}{|c|}{ Model Fit Summary } \\
\hline Model & $\begin{array}{c}\text { CMIN/DF } \\
(\leq 3)\end{array}$ & $\begin{array}{c}\text { CFI } \\
(\geq .95)\end{array}$ & $\begin{array}{c}\text { RMSEA } \\
(\leq .05, \leq .08)\end{array}$ & $\begin{array}{l}\text { SRMR } \\
(\leq .08)\end{array}$ & Fit \\
\hline 1 & 6.109 & .869 & .139 & .0771 & $\begin{array}{l}\text { Not } \\
\text { Good }\end{array}$ \\
\hline 2 & 3.098 & .961 & .089 & .0501 & $\begin{array}{l}\text { Not } \\
\text { Good }\end{array}$ \\
\hline 3 & 2.484 & .967 & .075 & .0615 & Good \\
\hline 4 & 2.252 & .953 & .069 & .0509 & Good \\
\hline 5 & 2.932 & .912 & .086 & .0717 & $\begin{array}{l}\text { Not } \\
\text { Good }\end{array}$ \\
\hline 6 & 2.854 & .917 & .084 & .0678 & $\begin{array}{l}\text { Not } \\
\text { Good }\end{array}$ \\
\hline 7 & 2.224 & .940 & .068 & .0594 & Good \\
\hline
\end{tabular}

Table 2 - Model Fit Summary

Due to the latent variable issues with the hypothesized structural model, some of the hypotheses were not able to be tested and therefore the null hypothesis must be accepted in those cases. For the first hypothesis, there is not a positive relationship between identity and self-efficacy as latent variables because identity was not measured as a latent variable. For the second hypothesis, there was a negative relationship between all three types of identity and role conflict interference. For the third hypothesis, the relationship between all three types of identity and external locus of control could not be tested, but there was a positive relationship between all three types of identity and internal locus of control. For the fourth hypothesis, there was a negative relationship between role conflict interference and self-efficacy, so the null hypothesis was rejected. For the fifth hypothesis, there was a positive relationship between internal locus of control and self-efficacy, so the null hypothesis was rejected. Finally, for the sixth hypothesis, internal locus of control was revealed to be a significant mediator between identity and selfefficacy, but role conflict was not. Therefore, the null hypothesis about role conflict and selfefficacy as mediators must be accepted. 


\section{Discussion}

The current study found partial support for the hypotheses that there is a positive relationship between student-athlete academic, athletic, and ethnic identity and self-efficacy and that the relationship between identity and self-efficacy is mediated by role conflict and locus of control. The current study does not support the hypothesis that identity, role conflict, locus of control, and self-efficacy could each be examined as latent variables in a good-fitting model in the way that they were measured. However, the good fit of models 3 and 4 illustrate the influence that locus of control and role conflict have on student-athlete self-efficacy in life skills. The good fit of model 7 illustrates the influence that ethnic identity exploration has on self-efficacy, even with the presence of locus of control and role conflict. Models 5 and 6 reveal associations among variables despite the absence of good fit. While the models did not meet the commonly accepted standards of good fit, the narrow margin by which they missed those standards may be a result of the sample size (Weston \& Gore, 2006). The associations among the variables in many of the models provides evidence of relationships among the variables worthy of further exploration.

There are positive associations between one's academic identity and self-efficacy, one's athletic identity and self-efficacy, and one's ethnic identity exploration and self-efficacy. There are negative associations between the degree to which one is committed to their ethnic identity and self-efficacy. The negative association between ethnic identity commitment and self-efficacy is supported in the literature that describes ethnic identity commitment as functioning similar to identity foreclosure (Phinney \& Ong, 2007). Additionally, there are negative associations in both the amount that one feels their roles as a student and an athlete conflict in their experiences. There is a stronger negative association with student-athletes who feel that the roles of student and athlete interfere with each other as compared to those who can effectively separate the two 
roles. Based on the items in the questionnaire, interference can come from the athletic demands interfering with academic work, perceptions from non-athlete peers, and social support in academic efforts as compared to athletic efforts (Settles et al., 2002). Separation of the two roles can come from seeing similarities between the roles of student and athlete, seeing the two roles distinctly when in an academic setting and an athletic setting, seeing oneself as more of a student than an athlete, and perceiving that they can successfully fulfill both roles.

Finally, there is a positive association between internal locus of control and self-efficacy and a negative association between external locus of control and self-efficacy. Because an internal locus of control is defined as one who believes that they have the power to influence events or outcomes in their lives, it makes sense that it would be positively associated with the amount of confidence one has in their abilities to perform a series of listed actions. A number of research studies have uncovered that those with an internal locus of control experience a range of positive outcomes such as certainty in tasks that they undertake (Battle \& Rotter, 1963).

Conversely, a belief that outside people or forces determine the events or outcomes in one's life would logically be negatively associated with one's confidence in performing that same series of listed actions.

When role conflict and locus of control are in the same model to predict self-efficacy, the strength of the associations weakens, but remains between the two variables and self-efficacy. Additionally, there is a positive association between role conflict interference and external locus of control. This finding supports previous literature that found a negative relationship between role conflict interference and well-being (Settles et al., 2002). Additionally, Watson (2016) found that student-athletes who reported having a more external locus of control perceived that they endured more stress in their lives. This perceived stress could connect to the student-athletes in 
this study that indicated their roles as student and athlete interfere. Therefore, one who has an external locus of control is also likely to feel that the roles of student and athlete interfere.

When different elements of identity are in the same model as role conflict and locus of control to predict self-efficacy, the strength of associations among the previous three variables remains the same. But, the elements of identity are associated differently with role conflict and locus of control. Academic identity is negatively associated with role conflict interference and external locus of control, while positively associated with role conflict separation and internal locus of control. The positive association between role conflict separation and academic identity supports the literature that describes student-athletes who are able to separate their roles as student and athlete as those who are possibly more likely to identify with the student role and more likely to better in both athletics and academics (Settles et al., 2002).

On the other hand, athletic identity is negatively associated with role conflict separation and positively associated with internal locus of control. This positive association makes sense given that a belief in one's ability to influence outcomes and events is paramount to achieve success in athletic competition. The negative association is represented in the literature that has uncovered time and time again how student-athletes are often isolated on campus in structures specifically modified for student-athletes such as separate dormitories, cafeterias, or academic support centers (Comeaux \& Harrison, 2011). Engaging in nearly every part of the college experience in a way that is modified due to one's status as a student-athlete likely contributes to difficulty in separating other roles from that of an athlete. Furthermore, there are negative associations among the error terms of average athletic self-efficacy and average academic and career self-efficacy. The negative associations point to the notion that average athletic self- 
efficacy in the sample may have been so high that the self-efficacy in other domains was influenced.

Ethnic identity provided the most interesting associations. There is a positive association between ethnic identity exploration and ethnic identity commitment. Although ethnic identity commitment on the scale functions as a form of identity foreclosure and thus occurring without exploration (Phinney \& Ong, 2007), one can reach a level of commitment after engaging in exploration. However, when connected as predictors of role conflict and locus of control, ethnic identity commitment was negatively associated with role conflict separation and internal locus of control. When ethnic identity exploration was connected as predictors of role conflict and locus of control, there were positive associations between role conflict separation and internal locus of control. Ethnic identity exploration has been found to positively contribute to a strong sense of self in a way that helps mediate threats to different aspects of identity, which could connect to role conflict separation and internal locus of control (Pizzolato et al., 2008). Furthermore, establishing an achieved ethnic identity has been found to help students make sense of themselves in multiple contexts based on their ethnicity (Pizzolato et al., 2008), which also supports the positive relationship with role conflict separation.

Overall, the associations between variables in the models tested support the literature on college student-athlete development that highlight the importance of identity development and exploration (Howard-Hamilton \& Sina, 2001). Identity development and exploration can impact the college experience as students are expected to move towards developing autonomy and a sense of interdependence (Chickering, 1969), but student-athletes who experience role conflict and do not develop an internal locus of control may also not develop the self-efficacy to carry 
out the life skills that help them successfully matriculate through and be prepared for life after college.

The results of this study can be of benefit to those who work in collegiate student-athlete development, whether specifically in the athletic department or in an advising or counseling capacity. The positive and negative associations between different variables provide insight in how the constructs interact simultaneously and can guide interventions designed to enhance student-athlete development across different domains. The associations among the variables in the models that include variables for identity, role conflict, locus of control, and self-efficacy have a number of implications for programming efforts from athletic departments or other student services departments that work with student-athletes.

\section{Implications}

The fact that the different domains of self-efficacy loaded strongly onto the latent variable of self-efficacy and that the error term of average athletic self-efficacy is negatively associated with academic and career self-efficacy is troubling. The negative association indicates that high athletic self-efficacy can put high self-efficacy in other domains at risk to be lower. The associations among role conflict, locus of control, and self-efficacy illustrate that life skill development across different domains is influenced beyond skill development and skill acquisition programming. There could be value in programming for student-athletes that helps them gain perspective on how to separate and distinguish their roles as student and athlete. The ability to identify as a college student and college athlete demonstrates the capacity to explore multiple identities and roles and lays a foundation for further identity exploration. Identity exploration beyond athletic identity (academic identity and ethnic identity) is positively associated with the ability to separate roles and the developing an internal locus of control. 
Additionally, there could be value in programming that helps student-athletes develop and reinforce an internal locus of control as they matriculate. Internal locus of control is positively associated with developing self-efficacy, which could improve performance, across a number of different domains including athletics. This could be done through a series of workshops or presentations but could also be infused existing programming structures such as freshman orientation or summer bridge programs for incoming student-athletes.

Special attention can be paid to understanding the ways that student-athletes perceive their identities as students and as athletes. Positive associations between academic identity and locus of control and role conflict separation indicate that programming efforts that reinforce the student element of identity could be effective for student-athletes. Many of the indicators of the academic identity subscale focus on grades and grade point average on academic work; however, the researcher suggests that programming focuses more on two items of the subscale: "being a capable student" and "being satisfied with my academic work." Programming that can address academic capability and satisfaction as a matter of how central to one's sense of who they really are could be very effective in developing academic identity beyond grade outcomes.

The structure of collegiate sport allows for constant reinforcement of the athletic identity for student-athletes. Feedback from coaches, fans, peers, and exclusivity from the general student population in living quarters, dining, and academic support all work towards reinforcing items on the athletic identity subscale such as being proud to be an athlete and being satisfied with athletic achievements as elements central to one's sense of who they really are during this time in their lives.

The associations among ethnic identity exploration and commitment and role conflict and locus of control as predictors of self-efficacy indicate that there is value in establishing/creating/ 
maintaining/increasing the number of student-athlete programs that focus on the exploration, development and maintenance of identities beyond that of student or athlete. Additionally, programs that allow for a space of ethnic identity exploration and commitment positively contribute to holistic identity development that is beneficial for student-athletes. This could be particularly challenging given the amount structure and lack of autonomy that exists for studentathletes (Kimball, 2007).

Many of the specific implications cut across the micro, meso, and macro levels of the sociological imagination of college athletics. The different level implications of the results of this study leave a charge for student-athletes, athletic administrators, academic departments, and conference level and national level college athletic administrators.

Student-athletes. Student-athletes can be intentional about the roles and identities that they explore during their time in college. College campuses often feature speakers, workshops, and other types of programming that allow for engagement outside of athletics. Despite the time constraints, a genuine effort to attend and engage in these opportunities can have lasting positive effects on life skill development.

Athletic administrators. Athletic administrators can collaborate with student affairs professionals across campus to facilitate programming for student-athletes that emphasizes ethnic identity development, academic identity, or any other role and identity beyond athletic identity. Many college campuses have student racial/ethnic affinity groups, but student-athletes are often unable to attend those meetings or events due to athletic obligations. A deliberate effort on the part of athletic administration to connect student-athletes to these organizations could facilitate the ethnic identity exploration process. Furthermore, in their daily interactions with 
student-athletes there should be attention paid to the verbal encouragement and reinforcement of student-athlete engagement with the college campus beyond athletics.

Athletic departments. Athletic departments can utilize the researcher constructed selfefficacy scale as a measure of assessment for student-athletes as they matriculate through college. Ideally, student-athlete self-efficacy across different domains will be at its highest as they graduate and leave the athletic department. Self-efficacy in the academic and career development domains can be particularly useful to analyze in conjunction with existing academic support and career development programing. Additionally, athletic departments can create academic courses specifically for student-athletes that can address the aspects of this study that have been found to positively contribute to self-efficacy in life skills across many domains: internal locus of control, role conflict separation, and ethnic identity exploration. Some athletic departments do this already for freshmen student-athletes transitioning into college. Another option is to utilize existing structures such as a summer bridge program for incoming studentathletes and similar spaces to assess for these constructs and address them accordingly.

Conference and national policy. Literature (Miller \& Kerr, 2003; Monda et al., 2015) emphasizes the importance of ensuring that collegiate student-athletes engage in role experimentation and exploration. The results of this study revealed that there is a positive relationship between ethnic identity exploration and role separation and self-efficacy across different domains. Administration at the conference and national level can work to increase the self-efficacy student-athletes develop by instituting programming that specifically addresses ethnic identity exploration and the separation of student and athlete roles. The NCAA Faculty Athletics Representative (FAR) position is an existing connection in athletic departments that could facilitate those connections between student-athletes and other parts of campus. 


\section{Limitations}

Although efforts were taken to ensure that the study was conducted in a comprehensive manner, this study was not without limitations. Perhaps the most notable limitation of the study is the size of the sample. While the sample size exceeded the commonly accepted threshold of 200 variables, the number of latent variables in the proposed model require that the sample far exceeds the minimum to truly determine model fit indices. Another limitation of this study related to the sample is the sample demographics. Despite the survey being made available to student-athletes across all sports at the institutions, the sample is not representative of the demographics of student-athletes across athletic departments at these institutions in categories such as race, gender, and type of sport. The study was designed to assess for differences in model fit for student-athletes of different races and ethnicities, different genders, and different types of sport, but the sample did not allow for that analysis. The demands placed on student-athletes that compete in revenue-generating sports are different than the demands placed on student-athletes that compete in non-revenue-generating sports (Paule \& Gilson, 2010). These demands such as the media attention, number of fans that consume their sport, and travel and practice schedule may serve to reinforce the existence of the variables of identity, role conflict, locus of control, and self-efficacy differently than student-athletes in non-revenue sports.

Additionally, the sample was limited to student-athletes from NCAA Division I member institutions, which has the smallest number of student-athletes of the three NCAA membership divisions. Furthermore, there are NCAA Division I member institutions that have unique histories and missions such as HBCUs where student-athletes may have different experiences with the constructs of identity, role conflict, locus of control, and self-efficacy. Although there was an attempt to collect data from student-athletes at HBCUs, there were not enough 
participants in this study to serve as a representative sample for student-athletes at these institutions. As a result, the results cannot be generalized to student-athletes across NCAA Division I member institutions or NCAA collegiate student-athletes across divisions.

\section{Future Directions}

A simultaneous limitation and future direction of this study is the method of analysis. The use of quantitative measures to analyze non-observable constructs and measures limits the depth of analysis and nuances of experiences that student-athletes have surrounding their identity, locus of control, role conflict, and self-efficacy. Reporting a high value on one of the survey items provides insight into the perceptions a student-athlete holds about his or her identity but does not provide information about how those perceptions affect day-to-day decision-making and engagement in different parts of their experience. A mixed-methods approach that added a qualitative component to the study could provide insight into the factors that contribute to the levels of different elements of identity, role conflict, locus of control, and self-efficacy.

Future directions of research should continue to examine constructs that are known to exist uniquely for student-athletes simultaneously. Examining how constructs such as motivation (Gaston-Gayles, 2004), locus of control (Watson, 2016), and role conflict (Adler \& Adler, 1987; Settles et al., 2002) that have been proven to exist uniquely for student-athletes will enhance student-athlete programming and support. Additionally, re-examining the direction of causal or predictive paths among these constructs can further illuminate the relationships among constructs in a meaningful way. For example, this study hypothesized that identity predicts role conflict, locus of control, and self-efficacy, but future research can examine whether role conflict, locus of control, or other non-cognitive variables predict different elements of identity. 
There is value in replicating and expanding this study design in many ways: gathering this data from other student-athlete populations beyond the NCAA Division I level to include student-athletes in organizing bodies such as the National Association of Intercollegiate Athletics (NAIA) or National Junior College Athletic Association (NJCAA), gathering this data from student-athlete populations in high school, adding a qualitative component to further examine components of the four measured latent variables, examining other non-cognitive psychological variables using a path analysis or model to understand how the relationships co-exist. Regardless of the population, the connection of sport to the education system exists because of the perceived value that it adds to life skill and personal development. It is important to know if participants perceive that there is an impact on their life skill and personal development across different levels of sport.

Additionally, future research could explore the ways that athletic departments and athletic administrators currently measure the growth and development of their student-athletes. Using constructs based in research such as identity, locus of control, role conflict, and self-efficacy allows for a connection to peer-reviewed literature that could help develop research-validated program evaluation methods for student-athlete programs. Results from research-validated program evaluation for student-athlete programs could then lead to a standardization of policy and programs that are revealed to be effective. Finally, the findings of this study reinforce the notion that identity is a dynamic, fluid construct that is consistently molded and reinforced by one's social settings. Thus, continuing to examine identity as an independent or exogenous variable can shift the paradigm of identity research in college athletics. 


\section{References}

Adler, P. \& Adler, P. A. (1985). From idealism to pragmatic detachment: The academic performance of college athletes. Sociology of Education, 58(4), 241-250.

Adler, P., \& Adler, P. A. (1987). Role conflict and identity salience: College athletics and the academic role. The Social Science Journal, 24(4), 443-455.

Ahlren-Bedics, R., \& Monda, S. (2009). Life skills for collegiate student-athletes: Defining the need and model practices. In E. Etzel (Editor), Counseling and psychological services for college student-athletes (pp. 113-142). Morgantown, WV: FiT Publishing Company.

Bandura, A. (1977). Self-efficacy: Toward a unifying theory of behavioral change. Psychological Review, 84, 191-215.

Bandura, A. (1986). Social foundations of thought and action. Englewood Cliffs, NJ: Prentice Hall.

Bandura, A. (1989). Human agency in social cognitive theory. American Psychologist, 44(9), $1175-1184$.

Bandura, A. (1997). Self-efficacy: The exercise of control. Stanford University: B. W. H. Freeman and Company New York.

Bandura, A. (2006). On integrating social cognitive and social diffusion theories. In A. Singhal \& J. Dearing (Eds.), Communication of innovations: A Journey with Ev Rogers (111135). Thousand Oaks, CA; Sage.

Battle, E. \& Rotter, J. B. (1963). Children's feelings of personal control as related to social class and ethnic group. Journal of Personality, 31, 482-490.

Beamon, K. (2008). “Used goods”: Former African American college student-athletes' 
perception of exploitation by division I universities. Journal of Negro Education, 77(4), 352364.

Bimper, A. Y., \& Harrison, L. (2011). Meet me at the crossroads: African American athletic and racial identity. Quest, 63(3), 275-288. doi:10.1080/00336297.2011.10483681

Bimper, A. Y. (2014). Game changers: The role athletic identity and racial identity play on academic performance. Journal of College Student Development, 55(8), 795-807.

Brewer, B. W., Van Raalte, J. L., \& Linder, D. E. (1993). Athletic identity: Hercules' muscles or Achilles heel? International Journal of Sport Psychology, 24, 237-254.

Brewer, B. W., \& Petitpas, A. J. (2017). Athletic identity foreclosure. Current Opinion in Psychology. 16, 118-122.

Brown, C., Glastetter-Fender, C., \& Shelton, M. (2000). Psychosocial identity and career control in college student-athletes. Journal of Vocational Behavior, 56, 53-62.

Byrne, B. M. (2001). Structural equation modeling with AMOS: Basic concepts, applications, and programming. Mahwah, NJ: Lawrence Erlbaum.

Chemers, M. M., Hu, L., \& Garcia, B. F. (2001). Academic self-efficacy and first-year college student performance and adjustment. Journal of Educational Psychology, 93, 55-64.

Chickering, A. W. (1969). Education and identity. San Francisco: Jossey-Bass

Cho, S. J., Hudley, C., Lee, S., Barry, L., \& Kelly, M. (2008). Roles of gender, race, and SES in the college choice process among first-generation and nonfirst-generation students. Journal of Diversity in Higher Education, 1(2), 95-107. http://dx.doi.org/10.1037/1938-8926.1.2.95

Chu, D. (1982). The American conception of higher education and the formal incorporation of intercollegiate sport. Quest, 34(1), 53-71. 
Comeaux, E. \& Harrison, C. K. (2011). A conceptual model of academic success for studentathletes. Educational Researcher, 40, 235-245.

Cornelius, A. (1995). The relationship between athletic identity, peer and faculty socialization, and college student development. Journal of College Student Development, 36(6), 560573.

Deaux, K., Reid, A., Mizrahi, K., \& Ethier, K. A. (1995). Parameters of social identity. Journal of Personality and Social Psychology, 68(2), 280-291. http://dx.doi.org/10.1037/0022-

\section{$\underline{3514.68 .2 .280}$}

Dillman, D. (2000). Constructing the questionnaire. Mail and internet surveys. New York: John Wiley \& Sons.

Edwards, H. (1985). Educating Black athletes. In D. Chu, J. O. Segrave, \& B. J. Becker (Eds.), Sport and higher education (pp. 373-384). Champaign, IL: Human Kinetics Publishers, Inc.

Erikson, E. H. (1959). Identity and the life cycle: Selected papers. Psychological Issues, 1, 1-71.

Fanning, E. (2005). Formatting a paper-based survey questionnaire: Best practices. Practical Assessment, Research \& Evaluation, 10(12), 1-14.

Ferrera, A. J., Watson II, J. C., \& Zizzi, S. (2017). Division I college student-athlete attitudes toward career counseling. Journal for the Study of Sports and Athletes in Education, 11(3), 175-192. https://doi.org/10.1080/19357397.2017.1346740

Gaston-Gayles, J. L. (2004). Examining academic and athletic motivation among student athletes at a Division I university. Journal of College Student Development, 45(1), 75-83. doi:10.1353/csd.2004.0005

Harrison, C. K., Stone, J., Shapiro, J., Yee, S., Boyd, J., \& Rultan, V. (2009). The role of gender 
identities and stereotype salience with the academic performance of male and female college athletes. Journal of Sport and Social Issues, 78-96.

Harrison, C. K., Martin, B. E., \& Fuller, R. (2015). “Eagles don't fly with sparrows”: Selfdetermination theory, African American male scholar-athletes, and peer group influences on motivation. The Journal of Negro Education, 84(1), 80-93.

Howard-Hamilton, M. F., \& Sina, J. A. (2001). How college affects student athletes. New Directions for Student Services, 93, 35-45. doi:10.1002/ss.3

Jackson, L. A., Sullivan, L. A., Harnish, R., \& Hodge, C. N. (1996). Achieving positive social identity: Social mobility, social creativity, and permeability of group boundaries. Journal of Personality and Social Psychology, 70(2), 241-254.

Kimball, A. C. (2007). "You signed the line": Collegiate student-athletes' perceptions of autonomy. Psychology of Sport and Exercise, 8, 818-835.

doi:10.1016/j.psychsport.2007.03.005.

Lally, P. S., \& Kerr, G. A. (2005). The career planning, athletic identity, and student role identity of intercollegiate student athletes. Research Quarterly for Exercise and Sport, 76(3), $275-285$.

LaMorte, W. W. (2016). The Social Cognitive Theory. Boston University School of Public Health. Retrieved from http://sphweb.bumc.bu.edu/otlt/MPHModules/SB/BehavioralChangeTheories/BehavioralChangeTheories5.html

Leonard, W. M. (1986). Exploitation in collegiate sport: The views of basketball players in NCAA divisions I, II, and III. Journal of Sport Behavior, 9(1), 11

Levenson, H. (1981). Differentiating among internality, powerful others, and chance. In H.M. Lefcourt (Ed.) Research with the locus of control construct (Vol. 1, pp. 15-63). New York: Academic Press. 
Logan, A. D., Harrison, L., \& Logan, A. (2015). 4 years a football player: The social reproduction of restricted agency. Race, Gender, \& Class, 22(1/2), 36-53.

Lyons, L. K., Dorsch, T. E., Bell, L. F., \& Mason, L. G. (2018). Renegotiating identity: A phenomenological investigation of the college transition of former high school athletes no longer engaged in varsity competition. Identity: An International Journal of Theory and Research, 18(1), 18-33. doi:10.1080/15283488.2017.1410156

MacNab, B. A. (2015). Student-athlete academic and athletic identity and self-efficacy (Master's thesis, LSU). Retrieved from http://digitalcommons.1su.edu/gradschool theses/3476

Marcia, J. E. (1966). Development and validation of ego-identity status. Journal of Personality and Social Psychology, 3, 551-558.

Marcia, J. E. (1976). Studies in ego identity. Burnaby, British Columbia: Simon Fraser University.

Marcia, J. E. (2002). Identity and psychosocial development in adulthood. Identity: An International Journal of Theory and Research, 2(1), 7-28.

Marcia, J. E., Waterman, A., Matteson, D., Archer, S., \& Orlofsky, J. (1993). Ego identity: A handbook for psychosocial research. Springer-Verlag.

Medalie, J. (1981). The college years as a mini-life cycle: Developmental tasks and adaptive options. Journal of American College Health Association, 30, 75-79.

Melendez, M. (2010). Psychosocial influence on college adjustment in division 1 studentathletes: The role of athletic identity. Journal of College Student Retention, 11(3), 345361.

Miller, P. S., \& Kerr, G. A. (2003). The role experimentation of intercollegiate student athletes. The Sport Psychologist, 17, 196-219. 
Monda, S. J., Etzel, E. F., Shannon, V. R., \& Wooding, C. B. (2015). Understanding the academic experiences of freshman football athletes: Insight for sport psychology professionals. Athletic Insight, 7(2), 115-128.

Murphy, G. M., Petitpas, A. J., \& Brewer, B. W. (1996). Identity foreclose, athletic identity, and career maturity in intercollegiate athletics. The Sport Psychologist, 10, 239-246.

National Collegiate Athletic Association. (2013). Do NCAA student-athletes view themselves as students or athletes? NCAA. Retrieved from http://www.ncaa.org/sites/default/files/Identity.pdf

National Collegiate Athletic Association. (2016). Results from the 2015 GOALS study of the student-athlete experience. $N C A A$. Retrieved from http://www.ncaa.org/sites/default/files/GOALS_convention_slidebank_jan2016_public.p $\underline{\mathrm{df}}$

National Collegiate Athletic Association. (2018a). Student-athletes. NCAA. Retrieved from http://www.ncaa.org/student-athletes

National Collegiate Athletic Association . (2018b). Health and safety. NCAA. Retrieved from http://www.ncaa.org/health-and-safety

National Collegiate Athletic Association. (2018c). Life skills. NCAA. Retrieved from http://www.ncaa.org/about/resources/leadership-development/life-skills

National Collegiate Athletic Association. (2018d). SCORE study. NCAA. Retrieved from http://www.ncaa.org/about/resources/research/score-study

NCAA Research [NCAAResearch]. (2017, December 30). Nearly a half million student-athletes played NCAA sports last year. 190,901 student-athletes competed in \#whyD3, making it 
the largest NCAA division. http://on.ncaa.com/2CqS03O [Tweet]. Retrieved from https://twitter.com/NCAAResearch/status/947153073088159745

NCAA Research [NCAA Reserch]. (2018, January 1). 1 in 4 NCAA football players is a firstgeneration college student. [Tweet]. Retrieved from https://witter.com/NCAAResearch/status/948004180593139712

Nyquist, E. (1979). Wine, women, and money: College athletics today and tomorrow. Education Review, 60, 376-393.

Pascarella, E. T., Bohr, L., Nora, A., \& Terenzini, P. T. (1995). Intercollegiate athletic participation and freshman-year cognitive outcomes. The Journal of Higher Education, $66(4), 369-387$.

Petitpas, A. J., \& Champagne, D. E. (1988). Developmental programming for intercollegiate athletes. Journal of College Student Development, 22, 454-460.

Petrie, T. A., \& Russell, R. K. (1995). Academic and psychosocial antecedents of academic performance for minority and nonminority college football players. Journal of Counseling \& Development, 73, 615-620.

Phinney, J. S., \& Ong, A. D. (2007). Conceptualization and measurement of ethnic identity: Current status and future directions. Journal of Counseling Psychology, 54(3), 271-281. doi: 10.1037/0022-0167.54.3.271.

Pizzolato, J. E., Chaudhari, P., Murrell, E. D., Podobnik, S., \& Schaeffer, Z. (2008). Ethnic identity, epistemological development, and academic achievement in underrepresented students. Journal of College Student Development, 49, 301-318.

Purdy, D., Eitzen, S., \& Hufnagel, R. (1982). Are athletes also students? The educational attainment of college athletes. Social Problems, 29(4), 439-448. 
Rotter, J. B. (1966). Generalized expectancies for internal versus external control of reinforcement. Psychological Monographs, 80, 1-28. doi: 10.1037/h0092976.

Sailes, G. A. (1986). Guest editorial: The exploitation of the Black athlete: Some alternative solutions. The Journal of Negro Education, 55(4), 439-442.

Scott, B. M., Paskus, T. S., Miranda, M., Petr, T. A., \& McArdle, J. J. (2008). In-season vs. outof-season academic performance of college student-athletes. Journal of Intercollegiate Sports, 1, 202-228.

Settles, I. H., Sellers, R. M., \& Damas, Jr., A. (2002). One role or two? The function of psychological separation in role conflict. Journal of Applied Psychology, 87(3), 574-582.

Simons, H. D., Van Rheenen, D., \& Covington, M. V. (1999). Academic motivation and the student athlete. Journal of College Student Development, 40(2), 151-161.

Singer, J. (2008). Benefits and detriments of African American male athletes' participation in a big-time college football program. International Review for the Sociology of Sport, 43, 399-408. doi: 10.1080/13613320500323963

Tajfel, H., \& Turner, J. C. (1979). An integrative theory of intergroup conflict. In W. G. Austin \& S. Worchel (Eds.), The social psychology of intergroup relations (pp. 33-47). Monterey, CA: Brooks/Cole.

Torres, V., Jones, S. R., \& Renn, K. A. (2009). Identity development theories in student affairs: Origins, current status, and new approaches. Journal of College Student Development, 50, $577-596$.

Torres, V. (2011). Perspectives on Identity Development. In J. H. Schuh, S. R. Jones and S. R. Harper (Eds.), Student Services: A Handbook for the Profession, (5th Ed., pp. 187-206). San Francisco: Jossey Bass. 
Wallston, K. A., Wallston, B. S., \& DeVellis, R. (1978). Development of the multidimensional health locus of control (MHLC) scales. Health Education Monographs, 6, 160-170.

Watson, J. C. (2016). The effect of athletic identity and locus of control on the stress perceptions of community college student-athletes. Community College Journal of Research and Practice, 40(9), 729-738. http://dx.doi.org/10.1080/10668926.2015.1072595

Weston, R., \& Gore Jr., P. A. (2006). A brief guide to structural equation modeling. The Counseling Psychologist, 34(5), 719-751. http://dx.doi.org/10.1177/0011000006286345

Woodruff, A. L., \& Schallert, D. L. (2008). Studying to play, playing to study: Nine college student-athletes' motivational sense of self. Contemporary Educational Psychology, 33(1), 34-57. doi:10.1016/j.cedpsych.2007.04.001

Wylleman, P., \& Lavalle, D. (2004). A developmental perspective on transitions faced by athletes. In M. Weiss (Ed.), Developmental sport and exercise psychology: A lifespan perspective (pp. 503-524). Morgantown, WV: Fitness Information Technology.

Yopyk, D. J. A., \& Prentice, D. A. (2005). Am I an athlete or a student? Identity salience and stereotype threat in student-athletes. Basic and Applied Social Psychology, 27(4), 329336.

Yukhymenko-Lescroart, M. A. (2014). Students and athletes? Development of the academic and athletic identity scale (AAIS). Sport, Exercise, and Performance Psychology, 3(2), 89101. 


\section{Appendix A - Extended Literature Review}

\section{Introduction}

In this extended literature review associated with this study, the researcher outlined the theoretical framework for this study. The theoretical framework includes seminal college student development theories, social cognitive theory, and social identity theory. The theoretical framework for this study is at the intersection of these four theories. Additionally, the extended literature review includes notable peer-reviewed literature about the population for this study, college student-athletes, and the constructs that are tested in the model for this study: identity, role conflict, locus of control, and self-efficacy.

Theoretical framework. College student development theories focus on the broader context surrounding collegiate student-athletes. Collegiate student-athletes can be classified in the general college student population although their experiences are heavily influenced by their varsity sport participation. The experiences of collegiate student-athletes can be influenced by the type of institution they attend. Research has revealed that student-athletes that compete at Historically Black Colleges and Universities (HBCUs) have experiences related to their holistic identity development that are different from student-athletes at other types of universities as they engage in intercollegiate athletics (Hawkins, Cooper, Carter-Francique, \& Cavil, 2015). Because this study includes responses from student-athletes that compete at HBCUs, there is a portion of the literature review dedicated to the experiences of this population.

Social identity theory explains that people identify themselves between "in-groups" and “out-groups," (Tajfel \& Turner, 1979) and then modify their behavior such that it is favorable or desirable for their conceptions of how those in the "in-group" would act. Collegiate studentathletes hold many social identities, primarily college student or athlete. Other social identities include race, gender and socioeconomic status. Perceptions of which identity places them in the 
"in group" and therefore how they will behave can have implications for their engagement with their academic and athletic obligations.

Social cognitive theory (SCT) explains that people learn how to engage with their roles and responsibilities based on the combination of personal factors, environmental factors, and behavior in a setting. SCT states that personal factors, environmental factors, and behavior are all related and influence each other simultaneously. SCT is applicable to understanding human learning across the lifespan, but the unique nature of the social structures of college and intercollegiate athletics makes this theory particularly of interest for this study.

College student development. The college years are a crucial time in young adult development. Developmental theorists consider this period of young adulthood a time to develop autonomy, seek to form romantic partnerships, and struggle between forming intimacy or facing isolation (Erikson, 1959). College student development theories detail how young adults have their development affected by the college structure.

For example, Chickering (1969) created seven vectors of development to describe the developmental tasks that students encounter and overcome as they matriculate through college. The seven vectors are developing competence, managing emotions, moving through autonomy through interdependence, developing mature interpersonal relationships, establishing identity, developing purpose, and developing integrity (Chickering, 1969). Medalie (1981) broke the four years of the college student experience into a series of developmental tasks and challenges that generally occur in a temporal sequence. Medalie (1981) referred to the significance of the years between 17 and 22 as a time that is widely regarded in Western culture as a time of transition and development, particularly in leaving childhood behind and creating a new life transitioning into adulthood. Freshman year is defined by the tasks of divesting from childhood ties and investing 
in college life (Medalie, 1981). Sophomore year is defined by the tasks of increasing mastery in work and consolidating interests in order to form future goals and making a decision about next steps towards a meaningful future (Medalie, 1981). Medalie (1981) refers to experiences such as choosing an academic major and presumable has a connection to life and work after college, and challenges in completing these tasks may lead to what is commonly known as a sophomore slump. Junior year is defined by the tasks of mastering the study skills, background, and experiences that are required for one to perform to the best of their abilities and commit to moving forward into life beyond college (Medalie, 1981). Senior year is defined by anticipating life after college, which may lead to concern about developmental tasks and experiences that may not have been achieved prior to this point or concern about the ability to function well within the college structure but anxiety about functioning outside of the structure (Medalie, 1981).

Identity foreclosure. Brewer and Petitpas (2017) describe how one of the primary tasks of late adolescence is to develop a sense of identity, which optimally occurs when one has the opportunity to explore a variety of activities. The exploration process is crucial for helping make informed decisions and developing effective coping strategies (Brewer \& Petitpas, 2017). However, those who do not have the opportunity to engage in this exploratory process are said to be in a state of identity foreclosure (Petitpas \& Champagne, 1988; Marcia, 1966), a term first used by Erikson (1959) in his stages of human development. Marcia (1966) later re-introduced the term in his ego-identity development process of adolescents and described it as the dynamic that occurs when individuals prematurely commit to an occupation, ideology, or roles associated with those in order to avoid a crisis in their identity. Despite the fact that a commitment to an identity provides a sense of psychological safety and security, identity foreclosure sacrifices 
personal freedoms and opportunities for further psychosocial growth (Brewer \& Petitpas, 2017). Marcia's (1966) research determined that it is critical for individuals to engage in identity exploratory behavior before expressing commitment to an identity, or they will experience identity foreclosure marked by elevated levels of authoritarian thinking, lower autonomy and self-directedness, and an external locus of control (Marcia et al., 1993).

Although the degree of identity foreclosure that one experiences can be mitigated by psychological and situational factors, foreclosure occurs when one commits to a career or option due to its approval from parents and/or society to avoid a crisis at a later time. In sport participation, athletic identity foreclosure can happen for athletes at any age when they get enmeshed in the sport system and spend the extended amount of time required to be successful and begin to experience some of the benefits of sport participation such as approval from peers, intrinsic and extrinsic rewards that come from competition (Brewer \& Petitpas, 2017). Athletic identity has often been measured using the AIMS, but there has been no way to measure identity foreclosure. Instead, research has been marked by inferences about scores on the AIMS. Previous research has indicated that athletic identity and identity foreclosure did not differ in college athletes in their first two years as compared to their last two years (Brewer \& Petitpas, 2017). There have been mixed results about the correlations between athletic and academic identity and academic performance in collegiate student-athletes (Yukhymenko-Lescroart, 2014; Harrison et al., 2009). Brewer and Petitpas (2017) suggest that future research further examine how to measure commitment and exploratory components of identity foreclosure in sport participants. Petitpas and France (2012) juxtapose the ego identity phase of exploration with foreclosure. Exploratory behavior in identity development is important because it helps people solidify their values, interests, and skills while enabling them to develop coping strategies and 
confidence in their abilities through different experiences and acquiring information (Petitpas \& France, 2012). Individuals who are in a state of identity foreclosure have been found to have high levels of stereotyped and authoritarian thinking as well as an external locus of control and lower levels of moral development (Petitpas \& France, 2012). Prolonged intense involvement in sport can lead to not only the development of an athletic identity, but the foreclosure to exploration of other identities. Research about this dynamic in intercollegiate student-athletes has revealed a range of results including lower levels of career maturity, career decision-making self-efficacy and career planning in male student-athletes of revenue generating sports despite these same results not existing across student-athletes in other sports and student-athletes at the community college level (Petitpas \& France, 2012). Petitpas and France (2012) concluded many reasons that the results of the link between intercollegiate athletic participation and identity foreclosure have been inconsistent, but one that is of particular interest for this study is the dynamic of role conflict in this population. Role conflict literature has revealed that college student-athletes tend to overidentify with the athlete role during their first years in college but shift to place more emphasis and attention on academic and career concerns as they reach the end of their eligibility (Miller \& Kerr, 2003).

Kroger, Martinussen, and Marcia (2010) conducted a comprehensive meta-analysis on studies focused on developmental patterns and identity status change during adolescence and young adulthood. Kroger et al. (2010) concluded that identity foreclosure and identity diffusion statuses declined throughout high school and fluctuated throughout late adolescence and young adulthood. These findings reinforce the notion that identity is still in a fluid place when studentathletes enter college and can be firmly achieved by the time they leave college. This makes understanding identity development and negotiation during college even more important. 
Lyons et al. (2018) explored the concepts of identity salience, role transition, and identity renegotiation in varsity high school athletes who entered college and did not play a varsity sport. Lyons et al. (2018) framework utilized existing research about collegiate student-athlete role transition (Taylor \& Ogilvie, 2001; Wylleman \& Lavallee, 2004) and examined how the process occurs for student-athletes at an earlier point in their college matriculation via semi-structured interviews with incoming college freshmen at three different time points. Of the themes identified in the study, identity renegotiation, a reengagement in sport or physical activity by use of the student recreation center for informal exercise or intramural and club sport participation, is the most applicable to the experiences of collegiate student-athletes. These spaces were avenues to form new social networks to replace the ones they left behind at This new identity included some athletic components but was an identity that was more than an identity as an 'athlete' and helped them positively adjust to college life.

Collegiate student-athletes don't always get the opportunity to see themselves as disengaged athletes, which will likely complicate their ability to see themselves holding multiple identities, particularly one as a student as well as an athlete. Therefore, it is important to explore and understand how much different athletes see themselves as students, and the factors that positively contribute to appropriate salience of both of those identities. Participants reported that a dual identity was beneficial and allowed them to buffer the loss of their athletic identity despite the fact that they missed the structure in their lives that came from sport participation, particularly how that structure helped with their time management (Lyons et al., 2018). Participants also shared that parents and coaches were those who structured their time, and without those figures, it was harder to be as productive as their obligations required (Lyons et al., 2018). It is important to understand what the lack of parents, coaches, and other authority figures 
from high school means for student-athlete acquisition of time management and other skills and the belief in their abilities to utilize these skills independently once they leave college.

Lyons et al. (2018) acknowledge that future research should purposefully examine the processes of identity renegotiation and role transition occur in diverse groups of college students, particularly in factors such as culture, race, and socioeconomic status. It is important to note the findings of this study may have implications for collegiate student-athletes who discontinue their varsity sport experience during their college matriculation.

College student-athletes. The theoretical framework that underpins much of the research on college student-athletes emphasizes academic experiences and outcomes. Purdy et al. (1982) examined data from student-athletes across sports over a ten-year time period and compared data such as the standardized test scores, high school GPA, college GPA, and graduation rates to data from the general student population. The results revealed that athletes on average were less prepared for college and achieved lower scores academically in college than the general student population, which led to the assertion that college athletic participation may hinder the educational growth and development of college students (Purdy et al., 1982). Particularly of note, scholarship student-athletes, student-athletes in revenue-generating sport, and black student-athletes had the poorest precollege academic preparation and college academic performance.

The structure of college athletics contributes to a loss of self-awareness which leads to student-athletes being subjected to socialization towards athletics instead of academics (Adler \& Adler, 1985). This socialization reduces individual differences between student-athletes, which leads to a collective detachment from the academic experience (Adler \& Adler, 1985). The socialization process is marked by a struggle to balance academic and athletic obligations and the 
encouragement and validation for athletic accomplishments without that same feedback for academic achievement; for example, student-athlete loss of autonomy over course and major selections, purchasing books, and contacting professors (Adler \& Adler, 1987). This not only reinforced the role of an athlete, but also took away from student-athletes developing the skills and abilities to manage for themselves. Student-athletes were then left with a false sense of security that someone was always taking care of them academically and could give them additional chances whenever they felt it was deserved. This dynamic led to a separation of the concepts of not performing academically and paying consequences. This process led to an increase in the degree to which these student-athletes identified as an athlete and detached from their identity as a college student (Adler \& Adler, 1985). When student-athletes experienced academic failures, they externalized the blame for the failure, which research posited served as a buffer to accepting the frequent failure without threatening their sense of self (Adler \& Adler, 1985). Even participants' social experiences were marked by isolation from non-athlete peers leading to the formation of strong bonds solely between other collegiate student-athletes (Adler \& Adler, 1985).

There are often underlying messages and structures that validate the athlete role more than the student role such as spaces exclusively designed for student-athlete academic support that isolate student-athletes from the general student population (Comeaux, 2007). Comeaux (2007) argues that this disengages student-athletes from their college experience, leaving behind ownership and agency in their learning process that has been relinquished to coaches and academic advisors. A result of these dynamics can be that there is a lack of understanding of the ways that student-athletes self-identify aspects of their lives, whether student-athletes accurately appraise themselves and their skills and abilities in other domains, and the ways that student- 
athletes create and engage in opportunities for personal and academic development (Comeaux, 2007).

Ultimately, research findings revealed that role conflict was exacerbated for studentathletes by the professionalization of their athletic experience and the realization that their athletic obligations prohibited them from having certain academic experiences such as taking courses they wanted or needed for their academic majors and regularly missing lectures, classes, or review sessions.

Role conflict. Role conflict can be best understood as the process that occurs when individuals experience difficulty as they attempt to meet the expectations and demands that come with having multiple roles in their lives (i.e. mother, wife, professor). Sometimes the roles are compatible with each other, but many times they are not. In the case of collegiate studentathletes, Adler and Adler (1987) explained how student-athletes resolved their role conflict. Instead of devoting attention to both roles, the researchers found that student-athletes distanced themselves from their academic role and embraced the way that the athletic role engulfed their experience. The embrace of the athletic role led to significant changes in their academic and social experiences, resulting in changing their academic major without concern for professional goals and life after college and a pressing feeling of 'representing the program' first and foremost. This led to them being viewed as athletes in all parts of campus, in and out of uniform, and a loss of privacy and freedom. As the common response to the athletic role engulfment was to drop the academic role completely, the results of this study beg the question of whether it is of most value to make sure academic goals do not drop, teach coping skills to help them better function in the environment, or to modify the environment itself. 
Outside of the student-athlete context, research has focused on some of the consequences of role conflict via the potential incongruence between work and family roles (Settles et. al, 2002). The way that individuals compartmentalize the self and those who define themselves in terms of a larger number of independent self-schemas were less variable in their day-to-day affect and that high self-complexity could serve as a buffer for negative feelings (Showers, 1992; Linville, 1985). This means that those who identify themselves in many different domains or ways are possibly less affected by negative events happening in a specific domain or less likely to have negative affect about events in a specific domain bleeding into others. Settles et al. (2002) explained this dynamic using an example of a student-athlete with compartmentalized roles: "For instance, a student athlete who is struggling on the athletic field may be buffered by receiving good grades in the classroom if he or she sees the athletic and student roles as distinct (p. 575)." Generally, individuals at some point experience some difficulty in performing one or more of their roles as a result of the responsibilities of another role (Van Sell et al., 1981) and may be closer to role overload - the dynamic of having multiple roles but lacking the resources to appropriately fulfill them (Barnett \& Baruch, 1985; Cooke \& Rosseau, 1984; Duxbury, Higgins, \& Lee, 1994; Creary \& Gordon, 2016) than role conflict, but both are marked by the individual feeling that the responsibilities in their roles interfere with each other.

College student-athlete membership in social groups beyond 'student' and 'athlete' may also contribute to role conflict (Lance, 2004) that influences psychological outcomes. Settles et. al. (2002) studied the influence that student-athletes' college student and college athlete roles had on their personality, wellbeing, and identity. Results indicated that women had higher GPA and higher levels of stress and depressive symptoms; upper classmen had higher GPA and more scholarship but also scored higher on self-esteem scale and less stress and depression. Student- 
athletes of higher SES were more likely to view their academic and athletic roles separate. Receiving more athletic financial aid was related to identifying stronger with being an athlete, placing less importance on doing well in school, experiencing more role interference, and reporting more depressive symptoms (Settles et al., 2002). Lance (2004) investigated gender differences in the degree of role conflict experienced by collegiate student-athletes across eight different sports and ultimately found that female student-athletes experienced more conflict that male student-athletes, but that male student-athletes in commercialized sport (basketball) experienced higher levels of role conflict than all other student-athletes.

\section{College student-athlete academic and personal development experiences. The} academic experience of student-athletes has been limited to measures of outcomes of graduation rates and grade point average. However, researchers (Monda, Etzel, Shannon, \& Wooding, 2015) have suggested that noncognitive variables such as positive self-concept and social support (Sedlacek \& Adams-Gaston, 1992; LeCrom, Warren, Clark, Marolla, Gerber, 2009), motivation (Gaston-Gayles, 2004) and life stress (Petrie \& Russell, 1995) may be more important for analysis to better understand academic performance of student-athletes.

It is important to note, Sedlacek and Adams-Gaston (1992) found that noncognitive variables of self-concept, self-appraisal, support systems, and community service were better predictors of academic performance in first year student-athletes than SAT scores. Petrie and Russell (1995) sought to deepen the understanding between academic and nonacademic variables that influence student-athletes' academic performances and the researchers found that academic variables such as ACT score predicted semester GPA while life stress and trait anxiety did not for minority student-athletes. Gaston-Gayles (2004) examined the influence that academic motivation has on academic performance and found that academic motivation was significant in 
a regression model that also included variables such as ACT score and ethnicity. Woodruff and Schallert (2008) outlined the importance of the contextual factors for these students as they negotiated their experiences as student-athletes. The results from this study revealed a model that depicts self and motivational processes as a student and an athlete as inseparable. Woodruff and Schallert (2008) use this notion to contribute the importance of the construct of a 'sense of self' and the impact that motivation has on this construct. All of this evidence points to the growing importance of analyzing noncognitive factors and traditional precollege characteristics to predict and understand academic performance for college students and student-athletes.

The focus on academic performance solely measured by grades and graduation rates is absent of a critical awareness that accounts for differences in student-athlete experiences based on sport (revenue-generating) and student-athlete cultural background (Comeaux, 2007). Comeaux (2007) criticized the way that NCAA has addressed the student-athlete academic experience, has focused on progress towards degree, graduation rates, and the proportion that institutions support student-athletes as they matriculate. Comeaux (2007) concluded his criticism of the NCAA and student-athlete experience by challenging colleges and universities to employ a critical lens and look beyond what cosmetically passes the test of effectiveness for assessing programs and student-athlete experience. Athletic departments have consistently failed to address the student role for student-athletes in a manner similar to the way that they address the athlete role (Comeaux, 2007). Despite the existence of programs designed to support studentathletes as they matriculate, little is known about the degree to which student-athletes are motivated to engage with these programs or their perceived effectiveness.

Ganim (2015) articulated how there appears to be conflicting messages between statements and messages on the NCAA website and their stance in wake of the recent academic 
scandal at the University of North Carolina at Chapel Hill (UNC-CH). Ganim (2015) stated: “On its website, the NCAA prominently states, 'It's our commitment — and our responsibility — to give young people opportunities to learn, play and succeed...in the collegiate model of sports, the young men and women competing on the field or court are students first, athletes second."' However, when asked to comment on the lawsuits filed by former UNC-CH student-athletes alleging that they did not get receive and education because of the ongoing academic fraud, the NCAA stated that it has no legal responsibility to ensure the academic integrity of the courses offered to student-athletes at its member institutions (Ganim, 2015). The president of the Drake Group stated that the NCAA clearly contradicts itself in these two messages (Ganim, 2015).

Osborne (2014) drew attention to recent issues in college athletics ranging from arguments about academic exploitation in educational quality and graduation rates to the compensation of student-athletes are abnormal experiences for student-athletes. Ultimately, Osborne (2014) argued that the burden of ensuring that the educational experience is of quality falls upon the student-athlete. Osborne (2014) presumed that student-athletes engage in entitled behavior that leads to some of the academic challenges that they face, citing that the value of a college degree has never been higher in society, and athletes must ensure that they focus on that instead of their athletic identity and opportunities to compete professionally. Special admissions for student-athletes is also not a valid argument for academic issues as Osborne (2014) argued that a large percentage of the students at any institution are admitted with below average academic credentials.

Comeaux (2007) and Osborne's (2014) viewpoints intersect when analyzing the experiences of student-athletes of a variety of racial and ethnic backgrounds. Cooper and Dougherty (2015) cited research that points to PWI failing to develop and cultivate campus 
environments conducive to positive educational experiences and personal growth for black student-athletes and the resulting poor educational outcomes for Black student-athletes.

However, research conducted about the experiences of Black student-athletes at HBCUs revealed that these institutions were effective at cultivating higher levels of academic achievement, institutional commitment, and a sense of belonging among black student-athletes (Cooper \& Dougherty, 2015). Cooper and Dougherty (2015) used the aforementioned information to call for the need of additional exploratory research about the experiences of black student-athletes across institution types to better understand how race may influence academic and other personal outcomes.

\section{Athletic and Racial/Ethnic Identity}

Athletic identity. Singularly, an assessment of one's athletic identity provides very little insight into the issues that that one may face by holding that social identity. However, its creators posit that it has practical and research implications as it can be examined in conjunction with emotional disturbances and across sport situations such as over adherence to sport ethic and exercise addiction (Brewer et al.,1993). Athletic identity is defined as, "the degree to which an individual identifies with the athlete role," (Brewer et al., 1993) which can have implications for the way that they view and present themselves (Steinfeldt \& Steinfeldt, 2010, 2012), interact with others socially (Benson, Evans, Surya, Martin, \& Eys, 2015), and understand themselves as they face critical decisions such as career development outside of athletics (Cabrita, Rosado, Leite, Serpa, \& Sousa, 2014; Houle \& Kluck, 2015; Murphy et al., 1996) or retirement from athletics (Grove, Lavallee, \& Gordon, 1997). Athletic identity has been studied in sport participants of many ages and levels ranging from youth recreational sport participants to collegiate student-athletes and even physical educators (Tunçkol, 2015). 
Since its creation as a concept, athletic identity has been researched extensively in sport science literature. Brewer et al. (1993) developed the Athletic Identity Measurement Scale (AIMS) with the college student-athlete in mind, but research has taken it across ages, sport level, and cultures. The AIMS has continued to develop as researchers seek to explore how those who participate and excel in athletics at a high level navigate the process of participation and involvement in athletics as it plays out in their academic experience and as it compares to other areas of their lives. In a meta-analysis done by Ronkainen, Kavoura, and Ryba (2016), athletic identity has been researched qualitatively in conjunction with career development and transition for athletes (Cosh, Crabb, \& Tully, 2015; Stambulova, Engström, Franck, Linnér, \& Lindahl, 2014; Cosh, LeCouteur, Crabb, Kettler, 2013; Park, Tod, \& Lavallee, 2012), other aspects of identity development and formation (Kavoura, Ryba, \& Chroni, 2015; Crawford, Gayman, \& Tracey, 2014; Carless \& Douglas, 2013; \& Lavallee \& Robinson, 2007), transition out of and retirement from sport (Stoltenurg, Kamphoff, \& Bremer, 2011; Lotysz \& Short, 2004), and burnout (Gustafsson, Hassmén, Kenttä, \& Johansson, 2008; Gustaffson, Kenttä, Hassmen, Lundqvist, \& Durand-Bush, 2007).

Yopyk and Prentice (2005) sought to examine the relationship between identity salience and task performance. The researchers hypothesized that task performance is a consequence and a cause of identity salience (Yopyk \& Prentice, 2005). The findings of their research indicated that self-definition is very fluid and can change based on how one's identity is primed. Salience of certain identities can change at a moment's notice, and individuals who can adapt and connect to positive thoughts, feelings, and memories of these different identities may be better able to complete tasks. However, Yopyk and Prentice (2005) still noted that even one who can adapt to different identities effectively could still be subjected to stereotype threat, meaning that the 
ability to adapt is still too weak to override stereotypes. Yopyk and Prentice (2005) emphasized that minority status is all too common for collegiate student-athletes in a way that is often linked to negative stereotypes, but it is also important to understand that student-athletes may occupy multiple minority statuses. There is value in exploration and commitment to minority identities beyond that of an athlete for student-athletes such as racial and/or ethnic identity.

Ethnic/racial identity. The meaning of racial identity is not always clear (Torres, 2011). A commonality among the different racial identity development theories was they each involved a change from low race salience to an increase in salience and recognition that race influence their life experience (Torres, 2011). The recognition of the influence of race can come from a positive or negative experience, however, the power of the recognition is that one is able to create a personal meaning of the significance of race in their lives. As a result, one can develop a more integrated sense of self and a sense of self that promotes positive views of their race and other racial groups (Torres, 2011). Torres (2011) acknowledged the challenges in working with white students through these different developmental processes but stated that there is value in restructuring commonly taken approaches in focusing on other races so that they focus on understanding the influence of their own culture. The importance of recognizing the influence of race on one's life experience is especially visible when examining the processes that multiracial students engage in to understand their own racial identity.

Torres (2011) argued that social identity theory focuses on the positive sense of belonging to a specific group, but an exploration of which ethnic groups hold power and express oppression can lead to the production of negative images of particular ethnic groups that may influence those in ethnic groups to seek being part of the majority. An example of this dynamic is illustrated by a research study done to examine how Asian Americans develop their racial 
identity (Torres, 2011; Chen, 2005). Chen (2005) found that Asian Americans viewed social identities such as race, ethnicity, gender, and socioeconomic status as assigned by society instead of assigned by self. Torres (2011) concurred with the findings of Chen's study reinforce that race is socially constructed and that the context in which one explores their racial identity is important, specifically in the college student environment. Torres (2011) also concluded that Latino college students use four conditions to make sense of their ethnic identity, including their self-perceptions of status in society and the college environment. This finding is significant because Torres (2011) took the position that the more dissonance there is between the environment in which Latinos grew up and their college environment, the more salient and pressing cultural conflicts will be in their self-identification process. Not surprisingly, this dynamic also occurs with American Indians, who face several pressures and influences to acculturate to the majority White culture. Therefore, when examining racial and ethnic identity development, it is important to note that Western cultural values may conflict with an individual who may be balancing other cultural values (Torres, 2011).

One of the most impactful components of identity theories and identity development in the college setting is that they help explain the experiences of those in many of the subcultures that often coexist on college campuses (Torres, 2011). Torres (2011) wrote, “Assisting individual members to develop stronger internal definitions of self will help a group to be more responsible and to consider multiple perspectives (p. 203)."

The intersection of athletic and racial identity. Although evidence suggests that education is the most viable form of social and economic mobility for African Americans, sometimes African American males subscribe to the notion that sport, not education, is the better path to attain success (Harrison, Sailes, Rotich, \& Bimper, 2011). The overrepresentation of 
African Americans in revenue-producing collegiate and professional sports contributes to this dynamic (Harrison et al., 2011). Subscription to this notion can be problematic because when in a setting where sports and education are paired, one could adopt a stronger, more salient athletic identity, which has been shown to negative impact academic ambition and performance (Harrison et al., 2011). Harrison et al. (2011) suggested that examining race as a social construct instead of a biological factor provides a better understanding of its impact on the socio-political history of the United States. Using the lens of race as a social construct illuminates the nuances that exist in race such as individuals who are of mixed race heritage with part of the mixture being African being categorized as Black or African-American.

Examining race as a social construct provides insight into how athletic identity may exist differently for Black student-athletes than student-athletes of other races or ethnicities. Harrison et al. (2011) compared the scores of Black and White collegiate football players on the Athletic Identity Measurement Scale (AIMS) using analysis of variance (ANOVA) (race by AIMS score). Their (Harrison et al., 2011) results revealed that Black participants had higher scores than white players and significant differences existed for specific AIMS items such as \#5-"I spend more time thinking about sport than anything else (p. 95)," \#7-“Other people see me mainly as an athlete (p. 95)," and \#9-“Sport is the only important thing in my life (p. 95)." Scores from two more items were very close to significance_- \#3-“Most of my friends are athletes (p. 96)," and \#6-“I need to participate in sport to feel good about myself (p. 96)." Harrison et al. (2011) frame their results as being important because it reveals the significance of race and its relationship to athletic identity as individuals who played for the same team, same coach, and similar influences have significant differences in their degrees of athletic identity. Also, the significant differences in item \#7-“Other people see me mainly as an athlete (p. 95)," may speak to the existence of 
stereotype threat for black student-athletes. Harrison et al. (2011) posit that implications from this study can enhance the work with college educators and athletic academic advisors. Those who work with black student-athletes on the daily basis must work to ensure that student-athletes do not foreclose other aspects of their identity due to their athletic participation as well as facilitate exploration and development of other identities outside of athletics.

Bimper and Harrison's (2011) discussion focused on how the social environment of sport is a prime environment to study how people make sense of themselves, but also outlined how little we know about how black athletes understand themselves and their racial/ethnic identity in conjunction with their athletic identity. Identities create value, and the value of an identity increases how salient it becomes for an individual and how strongly an individual may commit to a group where others share that identity (Stryker \& Burke, 2000). Previous research (Steinfeldt, Reed, \& Steinfeldt, 2010) has documented that both of these identities can be salient in black athletes, which is significant because both groups can be subject to negative stereotypes. Of more importance, Singer (2008) conducted a qualitative study with African American student-athletes and one of the major themes was that the title athlete-student was a more fitting title than student-athlete. Singer (2008) concluded that the participants' repeated mentioning of this dynamic is attributed to the environment of college athletic stakeholders such as coaches, administrators, academic counselors, and others encouraging Black student-athletes to identify primarily with the athlete role. This can be problematic because of the way that sport has been viewed as an accessible vehicle for upward social mobility in the African American community (Edwards, 2000) despite the fact that the chances of earning a sustainable living are miniscule. Identifying primarily as an athlete and believing that athletics is the most viable form of social mobility for black athletes limits the degree to which they are engaged in exploring other 
identities. Additionally, this overidentification subjects them to some of the detrimental risks that come with having an overly strong sense of athletic identity such as a lack of academic achievement, poor behavior choices, and issues successfully transitioning out of sport (Beamon \& Bell, 2006; Harrison, Harrison, \& Moore, 2002; Webb, Nasco, Riley, \& Headrick, 1998).

Previous research has also concluded that African American racial centrality was masked by more central beliefs of athletic identity compared to white collegiate student-athletes (Brown et al., 2003). Additionally, African American student athletes with high athletic identity perceived less racial discrimination than those with more moderate levels of athletic identity. Bimper and Harrison (2011) reflects that athletic identity may actually mask the development and persistence of a racial or ethnic identity, particularly reinforced by tropes in sport such as coming together as a team regardless of color or other cultural identifiers not being of importance in the midst of competition.

Bimper, Harrison, and Clark (2013) worked to counter the narrative of the academically ailing black student-athlete by examining the experiences of black student-athletes who have maintained above a 3.0 GPA. Comeaux (2007) posited that an effective way to learn how to make improvements in student-athlete development is to investigate the experiences of those who have experienced success as student-athletes. Bimper et al. (2013) also discussed how existing research details the struggles that black student-athletes have and barriers they face to have successful academic outcomes. While existing research has detailed that these issues exist, it has not taken inventory of their beliefs in their abilities in the midst of their development as student-athletes. The results indicated that successful Black male student-athletes benefit from seeing themselves beyond the scope of an athlete, despite the fact that they were able to acknowledge that their role as an athlete was a hugely significant part of their lives. Furthermore, 
the identity that consistently came up in interviews with the researcher was that of their racial identity. One participant went as far as noting that his racial identity is more 'real' than his athletic identity, and that some black student-athletes don't realize that until it is 'too late.' The results also indicate that academically successful Black student-athletes had a more central sense of racial identity and sense of self beyond the athletic role. The athletic and racial identities coexist and are both salient in their successful experiences.

\section{Locus of Control}

Levenson's locus of control. Levenson (1981) believed the previously existing framework to internal-external control was too simplistic as she noted an observation by Hersch and Scheibe (1967) that noted those who scored low (internals) on Rotter's I-E scale were more homogenous in their test performances than those who scored high (externals) on Rotter's I-E scale. This led to a question about the diversity of experiences of those with external loci of control. Lindbloom and Faw (1982) had 175 undergraduate students complete the Rotter, Adult Nowicki-Strickland, and Levenson IPC scale. The results revealed that the three scales were significantly correlated in their measurement of external control, which provided evidence to the fact that locus of control is multidimensional, beyond internal and external. Blau (1984) analyzed the factor stability and reliability of the Rotter and Levenson locus of control scales and found that the Levenson measure was more factorially stable and not very different from Rotter in terms of reliability.

Levenson (1981) made an important distinction to Rotter's internal-external locus of control scale. Levenson's distinction made the construct multidimensional by putting forth the notion that there are two different types of external locus of control—-belief in random chance and belief in being under the control of powerful others. This distinction is significant because 
they have two different implications for the way that one believes events occur in their life. One who believes that their life is in control by powerful others may believe that their behavior can be subject to reinforcement through intentional actions which would actually mirror aspects of an internal locus of control. One who believes that their life is subject to fate or the random events of chance simply believes that they do not have control over things that happen. Levenson (1981) created a locus of control measure with three subscales - internal (I), powerful others (P), and chance $(\mathrm{C})$.

Levenson's IPC scale differs from Rotter's scale in five ways, but three are the most significant. First, each item is presented as a Likert-type scale instead of a forced-choice scale. Second, each item is phrased from the I perspective instead of in a manner where one makes a choice based on their perceptions of what generally happens to people. Third, special attention was paid to each item to ensure that the wording does not imply that any presented issues could be modified. This third modification was made because it was found that personal versus ideological control and the fact that statements could be modified were found to be contaminating factors in Rotter's I-E scale (Gurin, Gurin, Lao, \& Beattie, 1969).

Reliability and validity scores for the IPC scale as compared to the Rotter IE scale are satisfactory. Kuder-Richardson reliabilities in a 152-undergraduate student sample were .64 for the I scale, .77 for the $\mathrm{P}$ scale, and .78 for the $\mathrm{C}$ scale. Test-retest reliability scores for a 1-week range were between .60 and .79 . Research also found that the $\mathrm{P}$ and $\mathrm{C}$ scales are unrelated to the I scale (-.25 to .19) and P and C scales were found to correlate with each other (.41-.54). Rotter's scale has also been found to correlate positively with the $\mathrm{P}$ and $\mathrm{C}$ scales (.25 and .56) and negatively with the I scale (-.41). Furthermore, the IPC scales had very small correlations with the Marlowe-Crowne Social Desirability Scale (.09, .04, and -.10) and broke into seven factors 
that accounted for $52 \%$ of the variance in a principle component factor analysis using Kaiser's Varimax method (Levenson, 1981).

Levenson (1981) concluded that there are differences on locus of control scales based on demographics such as sex, race, and gender, but these differences are not found consistently. Also, the IPC scale was tested across cultures in separate studies for Portuguese, Japanese, and German samples. Generally, the findings indicated that American values influence the scores to be higher on the I subscale than in other populations, demonstrating the impact of cross-cultural effects (Levenson, 1981).

Levenson (1981) tested the hypothesis that expectations of control by powerful others is positively related to the length of time one is in prison and the punishment enacted upon those who violated rules in the prison by administering the IPC scales to 200 inmates at a large state prison. Inmates who had been imprisoned for five years or more were significantly more likely to believe that they were controlled by powerful others than those who had been imprisoned within the last six months, but there were no significant differences between their internal or chance orientations. This may be of value when looking at the amount of time an athlete has participated in their varsity sport and their academic year in school.

Levenson's IPC scales connect to self-efficacy in two distinct ways. Research has been conducted that examined the role of self-efficacy in understanding evaluative perception as well as academic experiences such as study habits, attitudes, and performance as measured by grade point average. Evaluative perception research revealed that irrationality was found to consistently relate to higher scores on the P subscale while belief in happiness through passivity was most highly correlated with scores on the C subscale (Levenson, 1981). Academic experiences were found to show that study habits and academic performance were positively 
related to high scores on the I scale and negatively related to high scores on the $\mathrm{C}$ subscale. There is also the notion of defensive externality, which posits that individuals adopt an external control as a way of avoiding responsibility for something where they expect a negative outcome (Levenson, 1981). Research examining the academic performance and locus of control of collegiate student-athletes could reveal findings that perhaps add to existing research about academic detachment from student-athletes under certain conditions.

Ultimately, Levenson (1981) believed that external locus of control does not guarantee negative outcomes despite how it is sometimes interpreted and perceived by results in research. Levenson (1981) stated that the Protestant work ethic and American value system influenced the existence of this perception, and that it is important to understand that there may be certain subgroups that have perceptions of control by powerful others because of their cultural experiences such as blacks or women. For these groups, perceptions of internal control and personal responsibility for outcomes may ultimately be dysfunctional. Levenson (1981) also argues that there may be positive aspects of "externality" (higher scores on the P or C subscales) and that research could benefit from focusing on those positive aspects, such as awareness of a system influencing outcomes and being motivated to change that system into one that does allow for more internal, individual control. This notion situates itself well with critical race theory, which also acknowledges that the individual experience is dictated by social structures and forces that contribute to subjugation and oppression of minority groups (Levenson, 1981).

Locus of control and other variables. Carter, Mollen, and Smith (2014) used the framework of minority stress theory to explain that lesbian, gay, and bisexual (LGB) individuals are conceptualized as members of a minority group defined by sexual orientation. Carter et al. (2014) hypothesized that locus of control could moderate the relationship between internal 
heterosexism and overall psychological distress in this population and between the experience of workplace-based prejudice events and overall psychological distress of LGB individuals. The results revealed that locus of control was a moderator in the relationship between workplacebased prejudice events and psychological distress although there was not a significant relationship between one's experience with prejudice events and psychological distress. However, if participants had more external locus of control, there was a significant relationship between the prejudice events and psychological distress. Finally, Carter et al. (2014) found that locus of control did not serve as a moderator between internalized heterosexism and psychological distress. This finding is significant because it shows that simply adjusting the locus of control for members of oppressed populations does not significantly impact internalized oppression and psychological distress. This also gives further support for theoretical orientations and frameworks such as critical race theory that emphasize the importance of recognizing and dismantling oppressive structures in addition to validating the human experience of every individual. Carter et al. (2014) concluded that internal locus of control may be an important factor in terms of resilience for LGB individuals and likely the general population as well. However, a limitation of the study is that there was little racial and ethnic diversity in the sample. The construct of core self-evaluations (CSE) was created to better understand dispositional sources of job satisfaction (Johnson, Rosen, Chang, \& Lin, 2015). In this theory, it was proposed that the appraisals those hold of themselves and their abilities combine to establish a baseline appraisal that then influences how they view their environment and experiences (Johnson et al., 2015). The appraisals included in the construct are self-esteem, general selfefficacy, emotional stability, and internal locus of control. Research has indicated that CSE has not only been useful to predict job satisfaction, but other work-related behaviors and attitudes 
(Johnson et al., 2015). However, this study sought to examine whether locus of control is more closely related to an assessment of the environment than an assessment of self.

The researchers posited that the requirements for an appraisal to be considered under the umbrella of CSE do not quite fit as well for locus of control as they do for other appraisals. Johnson et al. (2015) found that their results across the four samples used in analysis consistently showed that the fit of the CSE construct was better when locus of control was excluded. This finding implies that there is value in assessing for self-efficacy and locus of control and that locus of control may be more of an indicator of the environment than a personal trait than previously thought by research (Johnson et al., 2015).

\section{Self-Efficacy}

Bandura (1977) began his seminal article with the notion that successful performance of tasks was becoming more important than symbolic experiences regarding human behavior change. Bandura (1977) hypothesized that initiating behavior, the amount of effort in persisting in that behavior, and the degree to which the behavior will be sustained in the face of adversity are all determined by one's expectations of personal efficacy.

Self-efficacy vs. locus of control. Bandura (1977) differentiates self-efficacy from locus of control by explaining that locus of control is more concerned with causal beliefs about actionoutcome contingencies than personal efficacy. For example, one who believes that their actions can have a significant impact on the outcome of an event can still have low efficacy about their ability to perform the actions necessary to be successful. However, Bandura (1977) noted that one's locus of control (internal or external) can mediate the effects of the impact of successful mastery experiences as it contributes to their self-efficacy. 
Bandura (1977) concluded that people's behavior towards a task is dictated by the way the amount they believe in their capabilities, but that belief is influenced by the information that they receive from their environment. The most poignant point raised in the conclusion of this article is that people can develop different efficacy expectations from similar environments and experiences. Bandura (1977) stated, "Because people have met with different types and amounts of efficacy-altering experiences, providing one new source of efficacy information would not be expected to affect everyone uniformly (p. 212)" "Thus, for example, extinguishing arousal to threats will enhance self-efficacy, but more so in individuals whose past coping attempts have occasionally succeeded than in those who have consistently failed (Bandura, 1977, p.212)" This is important to consider in why measuring self-efficacy and assessing for differences across groups is significant.

Bandura (2012) argued against research that aimed to prove that perceived self-efficacy has debilitating or null effects on their capacity and ability to complete a given task. Self-efficacy is rooted in social cognitive theory, which allows for room for error in self-efficacy. Social cognitive theory is founded with agency in mind, meaning that one can exert intentional influence over their functioning and the course of events by taking action. Social cognitive theory's structure is triadic, depicting that human function or behavior is a product of the interactions and interplay of personal factors and environmental factors (Bandura, 2012). Bandura (2012) also described the aforementioned environment as something that is not stagnant or monolithic. Instead, Bandura (2012) posited that there are three different types of environments, each of which affect the individual and their interactions differently-imposed, selected, and constructed. Additionally, Bandura (2012) posited that the environment is not limited to physical influences and settings and extends to the symbolic environment which 
includes a broader social network of forces based on the social network theory (Bandura, 2006).

Social cognitive theory is multifaceted and does not only provide knowledge for predicting behavior but provides a theory for better understanding learning and change (Bandura, 2012).

Academic self-efficacy. Academic self-concept and academic self-efficacy are similar constructs but have key differences. Key differences as they relate to this study are as follows: integration vs. separation of cognition and affect, heavily normative vs. goal-referenced evaluation of competence, aggregated vs. context-specific judgment, past vs. future orientation, and relative temporal stability vs. malleability (Bong \& Skaalvik, 2003). Instead of looking at academic self-concept, this study is seeking to use the construct academic identity, which has its roots in academic self-concept literature.

Chemers et al. (2001) conducted a longitudinal study of the adjustment of first year college students and examined how academic self-efficacy and optimism affected students' academic performance, stress, health, and commitment to remain in school. Chemers et al. (2001) found that academic self-efficacy and optimism were strongly related to performance and adjustment through a direct connection to academic performance and an indirect connection to perceptions of coping skills (challenge-threat evaluations) (Chemers et al., 2001).

A significant implication from this study is that the psychological orientations that students have as they transition into college are critical to their adjustment and success in the college setting. This implication is significant because that logic can be applied to studentathletes leaving college and heading into 'the real world.' It is valuable to understand psychological variables such as self-efficacy for student-athletes as they matriculate through and transition out of college. Other psychological variables that are valuable to this study such as 
challenge-threat assessment, confidence, and optimism are significantly positively correlated with self-efficacy.

Majer (2009) conducted a longitudinal analysis of self-efficacy and sociodemographic characteristics such as age, race, employment status, and other household income of firstgeneration college students at an urban community college $(n=96)$. First-generation college students were defined as students whose parents did not attend college or university (HahsVaughn, 2004; Inman \& Mayes, 1999; Shields, 2002). Majer collected data about self-efficacy using The Beliefs in Educational Success Test (BEST), a researcher-created instrument that was based upon the research of Chemers et al. (2001) that assessed a participant's efficacy to complete tasks that do not focus on one academic area and instead reflect a range of tasks associated with pursuing a degree in higher education. The data were collected at baseline and at a 4-month assessment interval. Majer (2009) found that there was a significant positive relationship between levels of self-efficacy for education and cumulative GPA, which suggests that self-efficacy for education can be instrumental in promoting educational improvement in first generation college students of a diverse population. Self-efficacy has already been found to predict increased academic performance in predominantly European American students (Chemers et al., 2001). There is significant value in extending these findings to a racially and ethnically diverse group of college students beyond a four-year college setting.

Honicke and Broadbent (2016) conducted a systematic review of research that examines the relationship between academic self-efficacy and academic performance in college students. Academic self-efficacy has consistently been shown to positively correlate with academic performance in different meta-analytic studies (Honicke \& Broadbent, 2016). However, much of this research has not included the moderating and mediating variables that influence the 
relationship between academic self-efficacy and academic performance or grade point average. It is important to note that Honicke and Broadbent (2016) found that variables such as effort regulation, academic procrastination, deep processing strategies, parental involvement and goal orientations mediated the relationship between academic self-efficacy and academic performance.

Athletic self-efficacy. Shelangoski, Hambrick, Gross, and Weber (2014) used selfefficacy (1977) and sport confidence (1986) to explore differences in athletic self-efficacy based on gender, playing experience, and academic class status. Shelangoski et al. (2014) utilized the fact that research has been conducted on self-efficacy in individual sport domains, but no published research had examined self-efficacy across a number of sports and at the collegiate level. Self-efficacy could exist differently for participants in individual sports as compared to those in team sports. Furthermore, this study aimed to add to existing self-efficacy and sport confidence literature by not only exploring differences based on gender, but also playing experience and academic class status (Shelangoski et al., 2014).

There were no statistically significant relationships between male and female studentathlete self-efficacy based on playing experience, but males had higher levels of self-efficacy across all four types of self-efficacy (Shelangoski et al., 2014). Results also indicated that selfefficacy changed from year to year, but overall showed the following trends: first year studentathletes were comparatively low, sophomore student-athletes appeared to experience something that mirrored a "sophomore slump," and self-efficacy tended to increase as student-athletes were juniors and seniors in college (Shelangoski et al., 2014).

Career self-efficacy. Lent, Brown, and Larkin (1986) used hierarchical regression analyses to examine the relationship between self-efficacy beliefs and educational/vocational 
choice and performance in 105 undergraduate students who participated in a career planning course on science and engineering fields. Lent et al. (1986) used the Self-Efficacy for Technical/Scientific Fields measure that was designed based on procedures followed by Betz and Hackett (1981). The scale allowed for the researchers to determine the level of self-efficacy and the strength of the self-efficacy that each participant held towards each task. The findings of the study extended previous research that showed how self-efficacy expectations are related to academic performance, vocational interests, and career options. Lent et al. (1986) suggested that self-efficacy would be good to explore along with other attributes that are commonly assessed in clients that come in for counseling; but, they could not back their suggestions with findings from conducted research and further suggest that research be done to examine a causal relationship between self-efficacy and career-related behaviors.

Gainor and Lent (1998) examined the relationships among racial identity attitudes and self-efficacy and other academic indices in 164 Black first year undergraduate students. Gainor and Lent (1998) cited Helms's (1990) and Cross's (1991) racial identity theories as well, stating that racial identity theory is understood to be important and relevant to Black students' career development. However, their research extended racial identity work by examining whether certain racial identity attitudes are related to math self-efficacy, outcome expectations, etc., and whether certain racial identity attitudes moderate the relations of math self-efficacy and math intentions and outcome expectations or choice intentions. Racial identity attitudes did not did not reveal significant relationships on Black students' math enrollment intentions, but the results of the study supported a relationship between social cognitive theory and the career-related choice behavior of Black college students (Lent, Brown, \& Hackett, 1994). 
Smith and Betz (2000) explained how self-efficacy can have a tremendous influence on the way that career development professionals understand individuals' career decisions and performance as well as help form effective interventions. Smith and Betz (2000) concluded that social self-efficacy is strongly related to shyness, which has been found to hinder career development in young adults. Social behaviors such as the ability to maintain group relationships with peers, the capacity to experience intimate relationships have been found to be positively related to academic performance in first year college students and found to indicate greater levels of environmental exploration and greater progress in committing to career choices (Smith \& Betz, 2000).

Brown, Glastetter-Fender, and Shelton (2000) cited research within their study that stated that the experience of collegiate student-athletes is generally more demanding than that of nonathlete college students. Although there are documented positive benefits to sport participation in different levels and intensities throughout the lifespan, one of the risks is developing an athletic identity that functions as a way to foreclose the exploration and commitment to other identities (Brown et al., 2000). This dynamic has been explored in collegiate student-athletes, but identity foreclosure in this population can be problematic because of the understood growth and development that is to occur for college students. Brown et al. (2000) and other researchers have found that student-athletes who have a foreclosed athletic identity may be less engaged academically and ultimately struggle with athletic career transitions and/or termination at the end of their college sport participation.

Brown et al. (2000) used social learning theory as the theoretical framework for their study. Social learning theory encompasses two concepts that have been found to influence college students' career attitudes and behaviors-locus of control (Rotter, 1966) and self- 
efficacy (Bandura, 1977). Brown et al. (2000) believed that those who have internal locus of control and appropriate levels of self-efficacy will be more likely to make better career decisions for themselves. Brown et al. (2000) hypothesized that those who spend more hours in sport will exhibit lower career decision-making self-efficacy, those who have a high athletic identity and foreclosed identities will demonstrate low self-efficacy for career decision-making tasks, and those who have an internal locus of control will exhibit higher levels of career decision-making self-efficacy. Each of the hypotheses was supported through the study and has implications for understanding the experiences that student-athletes while balancing their academic and athletic obligations as it relates to their career development. However, there was not a significant relationship found between athletic identity and identity foreclosure. This finding suggests that one can hold a strong athletic identity and not necessarily foreclose other identities. It challenges the narrative that high athletic identity certainly means that other identities will be foreclosed and can be used to influence programming and policy for holistic identity development of college student-athletes. Brown et al. (2000) suggested that administrators, educators, and counseling professionals must provide opportunities for student-athletes to balance those two roles as well as explore other aspects of their identity during this crucial point in their growth and development. Nauta, Kahn, Angell, and Cantarelli (2002) assessed college students' career interests and self-efficacy across three different time points to determine whether there was a temporal relationship between the two constructs. Nauta et al. (2002) used structural equation modeling to reveal that there was a reciprocal relationship between the two variables but the results for a temporal relationship were inconsistent. 


\section{Summary}

The previous review of literature explained how college student-athlete development is influenced by a number of non-cognitive factors, personality, and environment. College student development theories (Chickering, 1969; Medalie, 1981) have been found to be applicable to the experience of the general college student population and emphasize the importance of completing processes such as developing a sense of autonomy and interdependence, developing competence across different domains, and establishing identity in a temporal sequence. It has not yet been determined whether existing theories fit differently for college student-athletes when including the structure of college sports. The NCAA's (2018e) promise to work towards helping student-athletes have a fulfilling college experience, providing a safe and inclusive environment, and encourage student-athletes to learn and grow in all aspects can be further examined by analyzing how these established college student development theories align with the experiences of student-athletes.

Collegiate student-athletes have their college matriculation experience impacted by the existence and reinforcement of athletic identity, encouragement of academic identity, and role conflict (Adler \& Adler, 1985, 1987; Brown et al., 2000; Settles et al., 2002; Woodruff \& Schallert, 2008). Additionally, black student-athletes (Harrison et al., 2011; Beamon, 2008; Bimper \& Harrison, 2011) and student-athletes at HBCUs have been found to have different experiences than student-athletes at PWIs (Steinfeldt et al., 2010; Miller, David, \& Steinfeldt, 2015), but the differences in growth and development have not been studied. The differences in college student-athlete experience have led to outcomes such as struggles to transition into a life that does not include athletics (Brewer \& Petitpas, 2017; Brown et al., 2000; Wylleman \& 
Lavalle, 2004) and lower career decision making self-efficacy (Brown et al., 2000; Nauta et al., 2002).

Self-efficacy has been outlined as an individual's belief in their capacity to execute a task in a certain domain (Bandura, 1977, 1986, 1997), and is particularly relevant to this literature review's discussion of student-athlete growth and development. Self-efficacy has been studied across a number of domains that are part of the student-athlete experience-academic (Bong \& Skaalvik, 2003; Chemers et al., 2001; Honicke \& Broadbent, 2016), athletic (Shelangoski et al., 2014), social (Smith \& Betz, 2000), and career development (Brown et al, 2000). Each of those studies indicated that higher levels of self-efficacy in their respective domain are highly correlated to higher attainment and achievement in those domains. In addition to self-efficacy, locus of control (Rotter, 1966; Levenson, 1981) has been found to contribute to positive outcomes in different domains such as self-esteem (Anderson, 1998) and life satisfaction (Isikoff, 1983). Locus of control has also been found to contribute to negative outcomes in different domains such as depression (Presson \& Benassi, 1996), anxiety (Molinari \& Khanna, 1981), and overall psychological adjustment (Rotter, 1966). However, literature about locus of control and self-efficacy have not yet been explored in collegiate student-athletes and can contribute to our understanding of the college student-athlete development experience.

\section{Conclusion}

The constructs of identity, role conflict, locus of control, and self-efficacy are ones that exist and interact for college students and can uniquely interact for college student-athletes. The relationships that exist among these constructs have been outlined in this literature review. Identity has been revealed to be a consistently changing construct based on perceptions (Torres, 2011; Harrison et al., 2011; Bimper et al., 2013), roles (Adler \& Adler, 1985; Settles et al., 
2002), responsibilities in those roles, and reinforcement (Adler \& Adler, 1987; Comeaux, 2007)

of behaviors in different contexts (Singer, 2008; Bimper \& Harrison, 2011) and environments (Cooper \& Dougherty, 2015) throughout the college experience. Role conflict and locus of control can negatively influence holistic growth and development across life skills in many domains for student-athletes, resulting in differing levels of self-efficacy and perceptions to execute tasks essential to being successful during and after college. If the study reveals that these constructs do uniquely interact, using existing college student development theories, social identity theory, and social cognitive theory are appropriate frameworks to further interpret the significance of the interaction. 


\section{References}

Adler, P. \& Adler, P. A. (1985). From idealism to pragmatic detachment: The academic performance of college athletes. Sociology of Education, 58(4), 241-250.

Adler, P., \& Adler, P. A. (1987). Role conflict and identity salience: College athletics and the academic role. The Social Science Journal, 24(4), 443-455.

Ahlren-Bedics, R., \& Monda, S. (2009). Life skills for collegiate student-athletes: Defining the need and model practices. In E. Etzel (Editor), Counseling and psychological services for college student-athletes (pp. 113-142). Morgantown, WV: FiT Publishing Company.

Anderson, A. L. (1998). Strengths of gay male youth: An untold story. Child and Adolescent Social Work Journal, 15, 55-71. doi:10.1023/A:1022245504871

Bandura, A. (1977). Self-efficacy: Toward a unifying theory of behavioral change. Psychological Review, 84, 191-215.

Bandura, A. (1986). Social foundations of thought and action. Englewood Cliffs, NJ: Prentice Hall.

Bandura, A. (1989). Human agency in social cognitive theory. American Psychologist, 44(9), $1175-1184$.

Bandura, A. (1997). Self-efficacy: The exercise of control. Stanford University: B. W. H. Freeman and Company New York.

Bandura, A. (2006). On integrating social cognitive and social diffusion theories. In A. Singhal \& J. Dearing (Eds.), Communication of innovations: A Journey with Ev Rogers (111135). Thousand Oaks, CA; Sage.

Bandura, A. (2012). On the functional properties of perceived self-efficacy revisited. Journal of Management, 38(1), 9-44. doi:10.1177/0149206311410606 
Battle, E. \& Rotter, J. B. (1963). Children's feelings of personal control as related to social class and ethnic group. Journal of Personality, 31, 482-490.

Beamon, K., \& Bell, P. A. (2006). Academics versus athletics: An examination of the effects of background and socialization on African American male student athletes. The Social Science Journal, 43(3), 393-403. doi:10.1016/j.soscij.2006.04.009

Beamon, K. (2000). Constructing academic inadequacy: African American athletes' stories of schooling. The Journal of Higher Education, 71, 223-246. doi:10.2307/2649249

Beamon, K. (2008). 'Used goods”: Former African American college student-athletes' perception of exploitation by division I universities. Journal of Negro Education, 77(4), 352364.

Benson, A. J., Evans, M. B., Surya, M., Martin, L. J., \& Eys, M. A. (2015). Embracing athletic identity in the face of threat. Sport, Exercise, and Performance Psychology, 4(4), 303315.

Betz, N. E., \& Hackett, G. (1981). The relationship of career-related self-efficacy expectations to perceived career options in college women and men. Journal of Counseling Psychology, 28, 399-410.

Bimper, A. Y., \& Harrison, L. (2011). Meet me at the crossroads: African American athletic and racial identity. Quest, 63(3), 275-288. doi:10.1080/00336297.2011.10483681

Bimper, A Y, Harrison, L., \& Clark, L. (2013). Diamonds in the Rough: Examining a Case of Successful Black Male Student Athletes in College Sport. Journal of Black Psychology, 39(2), 107-130. doi:10.1177/0095798412454676

Bimper, A. Y. (2014). Game changers: The role athletic identity and racial identity play on academic performance. Journal of College Student Development, 55(8), 795-807. 
Bimper, A. Y. Jr. (2015). Lifting the veil: Exploring colorblind racism in Black student athlete experiences. Journal of Sport and Social Issues, 39(3), 225-243.

Blau, G. J. (1984). Brief note comparing the Rotter and Levenson measures of locus of control. Perceptual and Motor Skills, 58, 173-174.

Bong, M., \& Skaalvik, E. M. (2003). Academic self-concept and self-efficacy: How different are they really? Educational Psychology Review, 15(1), 1-39.

Brewer, B. W., Van Raalte, J. L., \& Linder, D. E. (1993). Athletic identity: Hercules' muscles or Achilles heel? International Journal of Sport Psychology, 24, 237-254.

Brewer, B. W., \& Petitpas, A. J. (2017). Athletic identity foreclosure. Current Opinion in Psychology. 16, 118-122.

Brown, C., Glastetter-Fender, C., \& Shelton, M. (2000). Psychosocial identity and career control in college student-athletes. Journal of Vocational Behavior, 56, 53-62.

Brown, T. N., Jackson, J. S., Brown, K. T., Sellers, R. M., Keiper, S., \& Manuel, W. J. (2003). There's no race on the playing field: Perceptions of racial discrimination among white and black athletes. Journal of Sport and Social Issues, 27, 162-183.

Byrne, B. M. (2001). Structural equation modeling with AMOS: Basic concepts, applications, and programming. Mahwah, NJ: Lawrence Erlbaum.

Cabrita, T. M., Rosado, A. B., Leite, T. O., Serpa, S.O., \& Sousa, P. M. (2014). The relationship between athletic identity and career decisions in athletes. Journal of Applied Sport Psychology, 26, 471-481.

Carter, L. W., Mollen, D., \& Smith, N. G. (2014). Locus of control, minority stress, and psychological distress among lesbian, gay, and bisexual individuals. Journal of Counseling Psychology, 61(1), 169-175. doi:10.1037/a0034593 
Chemers, M. M., Hu, L., \& Garcia, B. F. (2001). Academic self-efficacy and first-year college student performance and adjustment. Journal of Educational Psychology, 93, 55-64.

Chen, G. A. (2005). The complexity of "Asian American identity”: The intersection of multiple social identities. Unpublished doctoral dissertation, University of Texas, Austin.

Chickering, A. W. (1969). Education and identity. San Francisco: Jossey-Bass

Chickering, A. W., \& Reisser, L. (1993). Education and identity (2 ${ }^{\text {nd }}$ edition). San Franscisco: Jossey-Bass

Cho, S. J., Hudley, C., Lee, S., Barry, L., \& Kelly, M. (2008). Roles of gender, race, and SES in the college choice process among first-generation and nonfirst-generation students. Journal of Diversity in Higher Education, 1(2), 95-107.

\section{http://dx.doi.org/10.1037/1938-8926.1.2.95}

Chu, D. (1982). The American conception of higher education and the formal incorporation of intercollegiate sport. Quest, 34(1), 53-71.

Cooper, J. N., \& Dougherty, S. (2015). Does race still matter?: A post Bowl Championship Series (BCS) era examination of student athletes' experiences at a division 1 historically Black college/university (HBCU) and predominantly White institution (PWI). Journal of Issues in Intercollegiate Athletics, 8, 74-101.

Comeaux, E. (2007). The student(less) athlete: Identifying the unidentified college student athlete. Journal for the Study of Sports and Athletes in Education, 1, 37-44.

Comeaux, E., \& Harrison, C. K. (2007). Faculty and male student-athletes: Racial differences in the environmental predictors of academic achievement. Race, Ethnicity, and Education, 10, 199-214. doi:10.1080/13613320701330726 
Comeaux, E. \& Harrison, C. K. (2011). A conceptual model of academic success for studentathletes. Educational Researcher, 40, 235-245.

Cornelius, A. (1995). The relationship between athletic identity, peer and faculty socialization, and college student development. Journal of College Student Development, 36(6), 560573.

Cross, W. E., Jr. (1991). Shades of Black: Diversity in African-American identity. Philadelphia: Temple University Press.

Creary, S. J., \& Gordon, J. R. (2016). Role conflict, role overload, and role strain. Encyclopedia of Family Studies. http://dx.doi.org/10.1002/9781119085621.wbefs012

Deaux, K., Reid, A., Mizrahi, K., \& Ethier, K. A. (1995). Parameters of social identity. Journal of Personality and Social Psychology, 68(2), 280-291. http://dx.doi.org/10.1037/0022$\underline{3514.68 .2 .280}$

Dillman, D. (2000). Constructing the questionnaire. Mail and internet surveys. New York: John Wiley \& Sons.

Edwards, H. (1985). Educating Black athletes. In D. Chu, J. O. Segrave, \& B. J. Becker (Eds.), Sport and higher education (pp. 373-384). Champaign, IL: Human Kinetics Publishers, Inc.

Edwards, H. (2000). Crisis of Blck athletes on the eve of the $21^{\text {st }}$ century. Society, 37, 9-13.

Erikson, E. H. (1959). Identity and the life cycle: Selected papers. Psychological Issues, 1, 1-71.

Fanning, E. (2005). Formatting a paper-based survey questionnaire: Best practices. Practical Assessment, Research \& Evaluation, 10(12), 1-14.

Ferrera, A. J., Watson II, J. C., \& Zizzi, S. (2017). Division I college student-athlete attitudes 
toward career counseling. Journal for the Study of Sports and Athletes in Education, 11(3), 175-192. https://doi.org/10.1080/19357397.2017.1346740

Gainor, K. A., \& Lent, R. W. (1998). Social cognitive expectations and racial identity attitudes in predicting the math choice intentions of Black college students. Journal of Counseling Psychology, 45(4), 403-413.

Ganim, S. (2015). NCAA: It's not our job to ensure educational quality. CNN. Retrieved from http://www.cnn.com/2015/04/01/sport/ncaa-response-to-lawsuit/

Gaston-Gayles, J. L. (2004). Examining academic and athletic motivation among student athletes at a Division I university. Journal of College Student Development, 45(1), 75-83. doi:10.1353/csd.2004.0005

Gist, M. E., \& Mitchell, T. R. (1992). Self-efficacy: A theoretical analysis of its determinants and malleability. Academy of Management Review, 17(2), 183-211.

Gurin, P., Gurin, G., Lao, R. C., \& Beattie, M. (1969). Internal-external control in the motivational dynamics of Negro youth. Journal of Social Issues, 25, 29-53.

Hahs-Vaughn, D. (2004). The impact of parents' educational level on college students: An analysis using the beginning post-secondary students longitudinal study, 1990-92/94. Journal of College Student Development, 45, 483-498.

Harrison, C. K., Stone, J., Shapiro, J., Yee, S., Boyd, J., \& Rultan, V. (2009). The role of gender identities and stereotype salience with the academic performance of male and female college athletes. Journal of Sport and Social Issues, 78-96.

Harrison, C. K., Martin, B. E., \& Fuller, R. (2015). "Eagles don’t fly with sparrows”: Selfdetermination theory, African American male scholar-athletes, and peer group influences on motivation. The Journal of Negro Education, 84(1), 80-93. 
Harrison, L., Jr., Harrison, K., \& Moore, L. N. (2002). African American racial identity and sport. Sport Education and Society, 7, 121-133.

Harrison, Jr., L., Sailes, G., Rotich, W. K., \& Bimper, Jr., A. Y. (2011). Living the dream or awakening from the nightmare: Race and athletic identity. Race Ethnicity and Education, 14(1), 91-103.

Hawkins, B., Cooper, J., Carter-Francique, A., \& Cavil, J. K. (2015). The athletic experience at historically black colleges and universities: Past, present, and persistence. Lanham, MD: Rowman \& Littlefield.

Helms, J. E. (Ed.). (1990). Black and White racial identity. New York: Greenwood.

Hersch, P. D., \& Scheibe, K. E. (1967). Reliability and validity of internal-external control as personality dimensions. Journal of Consulting Psychology, 31, 609-613.

Honicke, T., \& Broadbent, J. (2016). The relation of academic self-efficacy to university student academic performance: A systematic review. Educational Research Review, 17, 63-84. http://dx.doi.org/10.1016/j.edurev.2015.11.002

Houle, J. L. W., \& Kluck, A. S. (2015). An examination of the relationship between athletic identity and career maturity in student-athletes. Journal of Clinical Sport Psychology, 9, 24-40.

Howard-Hamilton, M. F., \& Sina, J. A. (2001). How college affects student athletes. New Directions for Student Services, 93, 35-45. doi:10.1002/ss.3

Inman, W. E., \& Mayes, L. (1999). The importance of being first: Unique characteristics of first generation community college students. Community College Review, 26, 3-17.

Isikoff, J. G. (1983). Locus of control and life satisfaction in aged homosexual men (Doctoral 
dissertation). Retrieved from Dissertation Abstracts Online and ProQuest Digital Dissertations. (1983-74308-001)

Jackson, L. A., Sullivan, L. A., Harnish, R., \& Hodge, C. N. (1996). Achieving positive social identity: Social mobility, social creativity, and permeability of group boundaries. Journal of Personality and Social Psychology, 70(2), 241-254.

Johnson, R. E., Rosen, C. C., Chang, C. H. D., \& Lin, S. H. J. (2015). Getting to the core of locus of control: Is it an evaluation of the self or the environment? The Journal of Applied Psychology, 100(5), 1568-1578. doi:10.1037/ap10000011

Johnson, W., Crowley, C., \& Carter-Francique, A. R. (2015). Black college athletes: The sporting life at historically black colleges and universities: Essential factors for restoring academic and athletic excellence at HBCUs. In B. Hawkins, J. Cooper, A. CarterFrancique, \& J. K. Cavil (Eds.), The athletic experience at historically black colleges and universities: Past, present, and persistence (229-244). Lanham, MD: Rowman \& Littlefield.

Kimball, A. C. (2007). "You singed the line": Collegiate student-athletes' perceptions of autonomy. Psychology of Sport and Exercise, 8, 818-835. doi:10.1016/j.psychsport.2007.03.005.

Kroger, J., Martinussen, M., \& Marcia, J. E. (2010). Identity status change during adolescence and young adulthood: A meta-analysis. Journal of Adolescence, 33, 683-698.

Lally, P. S., \& Kerr, G. A. (2005). The career planning, athletic identity, and student role identity of intercollegiate student athletes. Research Quarterly for Exercise and Sport, 76(3), $275-285$. 
LaMorte, W. W. (2016). The Social Cognitive Theory. Boston University School of Public Health. Retrieved from http://sphweb.bumc.bu.edu/otlt/MPHModules/SB/BehavioralChangeTheories/BehavioralChangeTheories5.html

Lance, L. (2004). Gender differences in perceived role conflict among university studentathletes. College Student Journal, 38(2), 179-185.

LeCrom, C. L., Warren, B. J., Clark, H. T., Marolla, J., \& Gerber, P. (2009). Factors contributing to student-athlete retention. Journal of Issues in Intercollegiate Athletics, 1, 14-24.

Lent, R. W., Brown, S. D., \& Larkin, K. C. (1986). Self-efficacy in the prediction of academic performance and perceived career options. Journal of Counseling Psychology, 33(3), $265-269$.

Lent, R. W., Brown, S. D., \& Hackett, G. (1994). Toward a unified social cognitive theory of career/academic interest, choice, and performance [Monograph]. Journal of Vocational Behavior, 45, 79-122.

Leonard, W. M. (1986). Exploitation in collegiate sport: The views of basketball players in NCAA divisions I, II, and III. Journal of Sport Behavior, 9(1), 11

Levenson, H. (1981). Differentiating among internality, powerful others, and chance. In H.M. Lefcourt (Ed.) Research with the locus of control construct (Vol. 1, pp. 15-63). New York: Academic Press.

Lindbloom, G., \& Faw, T. T. (1982). Three measures of locus of control: What do they measure? Journal of Personality Assessment, 46(1), 70-71.

Logan, A. D., Harrison, L., \& Logan, A. (2015). 4 years a football player: The social reproduction of restricted agency. Race, Gender, \& Class, 22(1/2), 36-53.

Lyons, L. K., Dorsch, T. E., Bell, L. F., \& Mason, L. G. (2018). Renegotiating identity: A 
phenomenological investigation of the college transition of former high school athletes no longer engaged in varsity competition. Identity: An International Journal of Theory and Research, 18(1), 18-33. doi:10.1080/15283488.2017.1410156

MacNab, B. A. (2015). Student-athlete academic and athletic identity and self-efficacy (Master's thesis, LSU). Retrieved from http://digitalcommons.1su.edu/gradschool theses/3476

Majer, J. M. (2009). Self-efficacy and academic success among ethnically diverse firstgeneration community college students. Journal of Diversity in Higher Education, 2(4), 243-250. doi:10.1037/a0017852

Marcia, J. E. (1966). Development and validation of ego-identity status. Journal of Personality and Social Psychology, 3, 551-558.

Marcia, J. E. (1976). Studies in ego identity. Burnaby, British Columbia: Simon Fraser University.

Marcia, J. E. (2002). Identity and psychosocial development in adulthood. Identity: An International Journal of Theory and Research, 2(1), 7-28.

Marcia, J. E., Waterman, A., Matteson, D., Archer, S., \& Orlofsky, J. (1993). Ego identity: A handbook for psychosocial research. Springer-Verlag.

Medalie, J. (1981). The college years as a mini-life cycle: Developmental tasks and adaptive options. Journal of American College Health Association, 30, 75-79.

Melendez, M. (2010). Psychosocial influence on college adjustment in division 1 studentathletes: The role of athletic identity. Journal of College Student Retention, 11(3), 345361.

Miller, I. S. K., David, J. L., \& Steinfeldt, J. A. (2015). The culture of revenue-producing sports 
at hbcus: The experiences of black male student-athletes. In B. Hawkins, J. Cooper, A. Carter-Francique, \& J. K. Cavil (Eds.), The athletic experience at historically black colleges and universities: Past, present, and persistence (pp. 85-106). Lanham, MD: Rowman \& Littlefield.

Miller, P. S., \& Kerr, G. A. (2003). The role experimentation of intercollegiate student athletes. The Sport Psychologist, 17, 196-219.

Mills, C. W. (1959). The sociological imagination. New York, NY: Oxford University Press.

Molinari, V., \& Khanna, P. (1981). Locus of control and its relationship to anxiety and depression. Journal of Personality Assessment, 45, 314-319. doi:10.1207/s15327752jpa4503_14

Monda, S. J., Etzel, E. F., Shannon, V. R., \& Wooding, C. B. (2015). Understanding the academic experiences of freshman football athletes: Insight for sport psychology professionals. Athletic Insight, 7(2), 115-128.

Murphy, G. M., Petitpas, A. J., \& Brewer, B. W. (1996). Identity foreclose, athletic identity, and career maturity in intercollegiate athletics. The Sport Psychologist, 10, 239-246.

National Collegiate Athletic Association. (2013). Do NCAA student-athletes view themselves as students or athletes? NCAA. Retrieved from http://www.ncaa.org/sites/default/files/Identity.pdf

National Collegiate Athletic Association. (2016). Results from the 2015 GOALS study of the student-athlete experience. $N C A A$. Retrieved from http://www.ncaa.org/sites/default/files/GOALS_convention_slidebank_jan2016_public.p $\underline{\mathrm{df}}$ 
National Collegiate Athletic Association. (2018a). Student-athletes. NCAA. Retrieved from http://www.ncaa.org/student-athletes

National Collegiate Athletic Association . (2018b). Health and safety. NCAA. Retrieved from http://www.ncaa.org/health-and-safety

National Collegiate Athletic Association. (2018c). Life skills. NCAA. Retrieved from http://www.ncaa.org/about/resources/leadership-development/life-skills

National Collegiate Athletic Association. (2018d). SCORE study. NCAA. Retrieved from http://www.ncaa.org/about/resources/research/score-study

Nauta, M. M., Kahn, J. H., Angell, J. W., \& Cantarelli, E. A. (2002). Identifying the antecedent in the relation between career interests and self-efficacy: Is it one, the other, or both? Journal of Counseling Psychology, 49(3), 290-301. doi: 10.1037//0022-0167.49.3.290.

NCAA Research [NCAAResearch]. (2017, December 30). Nearly a half million student-athletes played NCAA sports last year. 190,901 student-athletes competed in \#whyD3, making it the largest NCAA division. http://on.ncaa.com/2CqS03O [Tweet]. Retrieved from https://twitter.com/NCAAResearch/status/947153073088159745

NCAA Research [NCAA Reserch]. (2018, January 1). 1 in 4 NCAA football players is a firstgeneration college student. [Tweet]. Retrieved from https://witter.com/NCAAResearch/status/948004180593139712

Nyquist, E. (1979). Wine, women, and money: College athletics today and tomorrow. Education Review, 60, 376-393.

Osborne, B. (2014). The Myth of the Exploited Student-Athlete. Journal of Intercollegiate Sport, 7(2), 143-152. doi:10.1123/jis.2014-0136

Pascarella, E. T., Bohr, L., Nora, A., \& Terenzini, P. T. (1995). Intercollegiate athletic 
participation and freshman-year cognitive outcomes. The Journal of Higher Education, $66(4), 369-387$.

Petitpas, A. J., \& Champagne, D. E. (1988). Developmental programming for intercollegiate athletes. Journal of College Student Development, 22, 454-460.

Petitpas, A. J., \& France, T. (2012). Identity foreclosure in sport. In S.J. Hanrahan \& M. B. Andersen (Eds.), Routledge handbook of applied sport psychology: A comprehensive guide for students and practitioners (pp. 282-291). New York, NY: Routledge.

Petrie, T. A., \& Russell, R. K. (1995). Academic and psychosocial antecedents of academic performance for minority and nonminority college football players. Journal of Counseling \& Development, 73, 615-620.

Phinney, J. S., \& Ong, A. D. (2007). Conceptualization and measurement of ethnic identity: Current status and future directions. Journal of Counseling Psychology, 54(3), 271-281. doi: 10.1037/0022-0167.54.3.271.

Pizzolato, J. E., Chaudhari, P., Murrell, E. D., Podobnik, S., \& Schaeffer, Z. (2008). Ethnic identity, epistemological development, and academic achievement in underrepresented students. Journal of College Student Development, 49, 301-318.

Presson, P. K., \& Benassi, V. A. (1996). Locus of control orientation and depressive symptomatology: A meta-analysis. Journal of Social Behavior and Personality, 11, 201212.

Purdy, D., Eitzen, S., \& Hufnagel, R. (1982). Are athletes also students? The educational attainment of college athletes. Social Problems, 29(4), 439-448.

Ronkainen, N. J., Kavoura, A., \& Ryba, T. V. (2016). A meta-study of athletic identity research 
in sport psychology: Current status and future directions. International Review of Sport and Exercise Psychology, 9(1), 45-64.

\section{http://dx.doi.org/10.1080/1750984X.2015.1096414}

Rotter, J. B. (1966). Generalized expectancies for internal versus external control of reinforcement. Psychological Monographs, 80, 1-28. doi: 10.1037/h0092976.

Sailes, G. A. (1986). Guest editorial: The exploitation of the Black athlete: Some alternative solutions. The Journal of Negro Education, 55(4), 439-442.

Scott, B. M., Paskus, T. S., Miranda, M., Petr, T. A., \& McArdle, J. J. (2008). In-season vs. outof-season academic performance of college student-athletes. Journal of Intercollegiate Sports, 1, 202-228.

Sedlacek, W. E., \& Adams-Gaston, J. (1992). Predicting the academic success of student-athletes using SAT and noncognitive variables. Journal of Counseling \& Development, 70, 724 727.

Settles, I. H., Sellers, R. M., \& Damas, Jr., A. (2002). One role or two? The function of psychological separation in role conflict. Journal of Applied Psychology, 87(3), 574-582.

Shelangoski, B. L., Hambrick, M. E., Gross, J. P., \& Weber, J. D. (2014). Self-efficacy in intercollegiate athletes. Journal of Issues in Intercollegiate Athletics, 7, 17-42.

Shields, N. (2002). Anticipatory socialization, adjustment to university life, and perceived stress: Generational and sibling effects. Social Psychology and Education, 5, 365-392.

Simons, H. D., Van Rheenen, D., \& Covington, M. V. (1999). Academic motivation and the student athlete. Journal of College Student Development, 40(2), 151-161.

Singer, J. (2008). Benefits and detriments of African American male athletes' participation in a 
big-time college football program. International Review for the Sociology of Sport, 43, 399-408. doi: 10.1080/13613320500323963

Smith, H. M., \& Betz, N. E. (2000). Development and validation of a scale of perceived social self-efficacy. Journal of Career Assessment, 8(3), 283-301.

Steinfeldt, J. A., Reed, C., \& Steinfeldt, M.C. (2010). Racial and athletic identity of African American football players at historically Black colleges and universities and predominantly White institutions. The Journal of Black Psychology, 36, 3-24.

Steinfeldt, J. A., \& Steinfeldt, M. C. (2010). Gender role conflict, athletic identity, and helpseeking among high school football players. Journal of Applied Sport Psychology, 22, $262-273$.

Steinfeldt, M., \& Steinfeldt, J. A. (2012). Athletic identity and conformity to masculine norms among college football players. Journal of Applied Sport Psychology, 24, 115-128.

Stryker, S., \& Burke, P. (2000). The past, present, and future of an identity theory. Social Psychology Quarterly, 63, 284-297.

Tajfel, H., \& Turner, J. C. (1979). An integrative theory of intergroup conflict. In W. G. Austin \& S. Worchel (Eds.), The social psychology of intergroup relations (pp. 33-47). Monterey, CA: Brooks/Cole.

Taylor, J., \& Ogilvie, B. (2001). Career termination among athletes. In R. Singer, H. Hausenblaus, \& C. Janelle (Eds.), Handbook of sport psychology. New York, NY: John Wiley \& Sons, Inc.

Torres, V., Jones, S. R., \& Renn, K. A. (2009). Identity development theories in student affairs: Origins, current status, and new approaches. Journal of College Student Development, 50, $577-596$. 
Torres, V. (2011). Perspectives on Identity Development. In J. H. Schuh, S. R. Jones and S. R. Harper (Eds.), Student Services: A Handbook for the Profession, (5th Ed., pp. 187-206). San Francisco: Jossey Bass.

Tunçkol, H. M. (2015). Applying athletic identity measurement scale on physical educators: Turkish version of AIMS. Educational Research and Reviews, 10(2), 177-183. doi: http://dx.doi.org/10.5987/ERR2014.1863

Van Sell, M., Brief, A. P., \& Schuler, R. S. (1981). Role conflict and role ambiguity: Integration of the literature and directions for future research. Human Relations, 34, 43-71.

iWallston, K. A., Wallston, B. S., \& DeVellis, R. (1978). Development of the multidimensional health locus of control (MHLC) scales. Health Education Monographs, 6, 160-170.

Watson, J. C. (2016). The effect of athletic identity and locus of control on the stress perceptions of community college student-athletes. Community College Journal of Research and Practice, 40(9), 729-738. http://dx.doi.org/10.1080/10668926.2015.1072595

Webb, W. M., Nasco, S. A., Riley, S., \& Headrick, B. (1998). Athlete identity and reactions to retirement from sports. Journal of Sport Behavior, 21, 338-362.

Weston, R., \& Gore Jr., P. A. (2006). A brief guide to structural equation modeling. The Counseling Psychologist, 34(5), 719-751. http://dx.doi.org/10.1177/0011000006286345

Woodruff, A. L., \& Schallert, D. L. (2008). Studying to play, playing to study: Nine college student-athletes' motivational sense of self. Contemporary Educational Psychology, 33(1), 34-57. doi:10.1016/j.cedpsych.2007.04.001

Wylleman, P., \& Lavalle, D. (2004). A developmental perspective on transitions faced by athletes. In M. Weiss (Ed.), Developmental sport and exercise psychology: A lifespan perspective (pp. 503-524). Morgantown, WV: Fitness Information Technology. 
Yopyk, D. J. A., \& Prentice, D. A. (2005). Am I an athlete or a student? Identity salience and stereotype threat in student-athletes. Basic and Applied Social Psychology, 27(4), 329336.

Yukhymenko-Lescroart, M. A. (2014). Students and athletes? Development of the academic and athletic identity scale (AAIS). Sport, Exercise, and Performance Psychology, 3(2), 89101. 


\section{Appendix B - Hypothesized Structural Model}

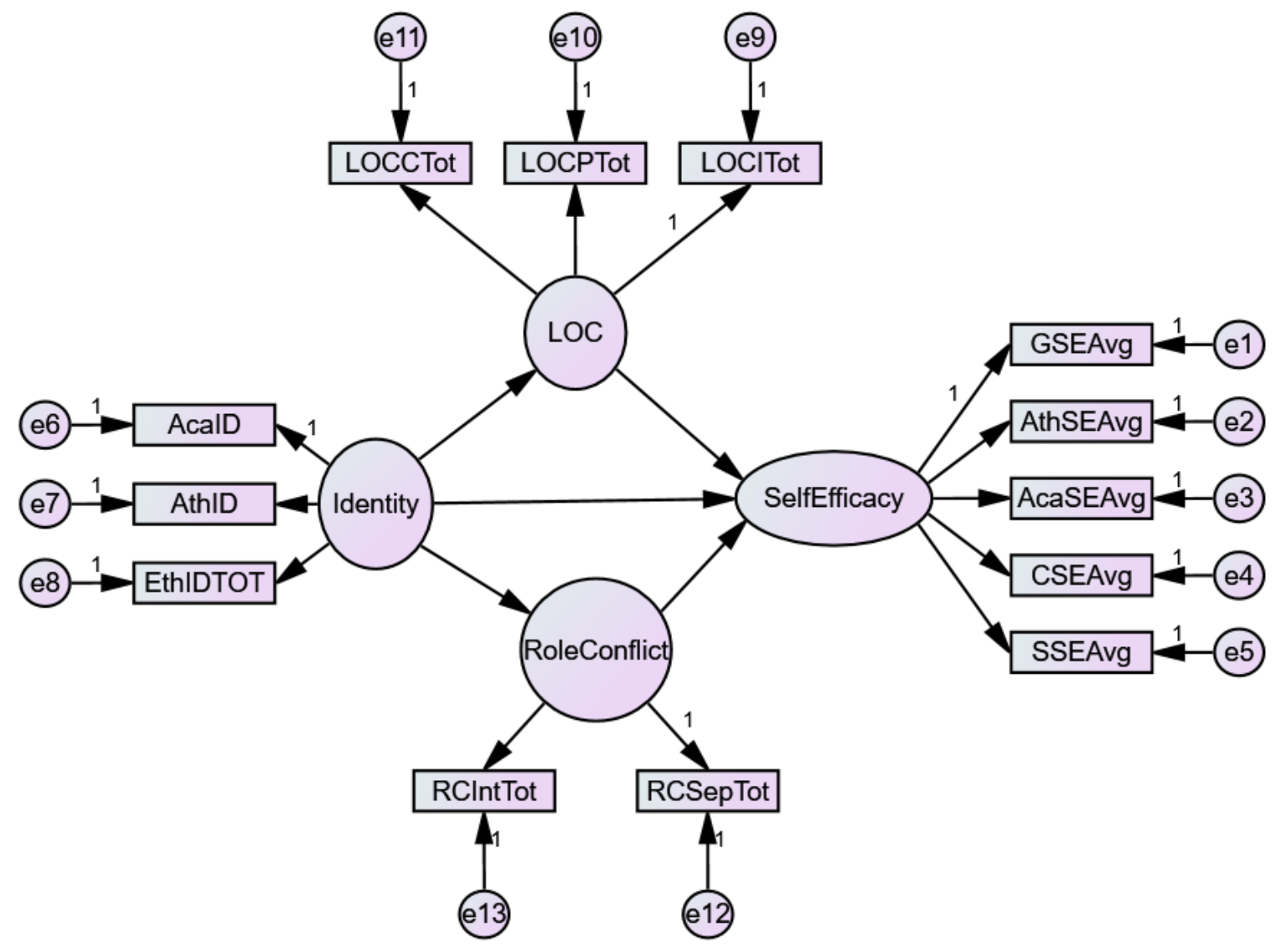




\section{Appendix C - Survey Instrument}

This survey was designed to study the growth and development of varsity collegiate studentathletes during their college years. There are three criteria for participating in this study:

1. You must be 18 years of age or older.

2. You must be a [Institution/Conference Name] undergraduate or graduate student.

3. You must be actively participating in a [Institution/Conference Name] Varsity Sport.

If you meet these criteria and want to complete the survey, please click yes. The information in this survey is kept anonymous and completion of the survey is voluntary. If you click no, you will be automatically taken to the end of the survey and cannot change your answer to complete the survey at a later time.

Your actual performance in this study and refusal to participate or withdrawal from this study will in no way affect your class standing, grades, or status in any athletic or other activity associated with [Institution Name] and the [Institution Name] Athletic Department.

Thank you very much for your time. If you have any questions about the research project, please feel free to contact Aaron Goodson at 910-308-4614 or ATGoodson@mix.wvu.edu 
Academic and Athletic Identity (11 questions)

(Yukhymenko-Lescroart, 2014)

How central to your sense of who you really are is each of these characteristics? (Not at all central (1) to Extremely central core (7))

\begin{tabular}{|c|c|c|c|c|c|c|}
\hline 1 & 2 & 3 & 4 & 5 & 6 & 7 \\
\hline $\begin{array}{c}\text { Not at all } \\
\text { central }\end{array}$ & \multicolumn{5}{|c|}{} & $\begin{array}{c}\text { Extremely } \\
\text { central core }\end{array}$ \\
\hline
\end{tabular}

1. Being a capable student.

2. Being satisfied with my academic work.

3. Doing well in school.

4. Getting good grades.

5. Having a high GPA.

6. Being a capable athlete.

7. Being a good athlete.

8. Being athletic.

9. Being proud to be an athlete.

10. Being satisfied with my athletic achievements.

11. Doing well during sport competitions.

\section{Ethnic Identity (6 questions)}

(Phinney \& Ong, 2007)

The following questions ask you questions about your Ethnic Identity. Remember there are no right or wrong answers, just answer as accurately as possible. Use the scale below to answer the questions. If you strongly disagree with the statement, select 1 ; if you strongly agree select 5 . If the statement is more or less true of you, find the number between 1 and 5 that best describes you.

\begin{tabular}{|c|c|c|c|c|}
\hline 1 & 2 & 3 & 4 & 5 \\
\hline Strongly Disagree & \multicolumn{3}{|c|}{} & \\
\hline
\end{tabular}

1. I have spent time trying to find out more about my ethnic group, such as its history, traditions, and customs.

2. I have a strong sense of belonging to my own ethnic group.

3. I understand pretty well what my ethnic group membership means to me.

4. I have often done things that will help me understand my ethnic background better.

5. I have often talked to other people in order to learn more about my ethnic group.

6. I feel a strong attachment towards my own ethnic group. 


\section{Role Conflict Measures (16 questions)}

(Settles, Sellers, \& Damas, Jr., 2002)

Below are a list of statements student-athletes have used to describe themselves and other student-athletes. Please read each statement and rate how true each sentence is for you from 'not really true of me' (1) to 'really true of me' (7).

\begin{tabular}{|c|c|c|c|c|c|c|}
\hline 1 & 2 & 3 & 4 & 5 & 6 & 7 \\
\hline $\begin{array}{c}\text { Not really true } \\
\text { of me }\end{array}$ & \multicolumn{5}{|c|}{$\begin{array}{c}\text { Really true of } \\
\text { me }\end{array}$} \\
\hline
\end{tabular}

1. I feel that if it were not for demands associated with being an athlete, courses that were once difficult would be easier.

2. I feel that the responsibilities related to my sport have forced them to drop a course at one time or another that I wanted or needed.

3. I worry that my non-athlete peers do not take me seriously as a student.

4. I am concerned that I would have chosen a different major if I was not an athlete.

5. I feel that their instructors discriminate against me because I am an athlete.

6. I feel that my family is more supportive of my athletic efforts than my academic performance.

7. I feel that the responsibilities associated with my sport make it difficult to keep up with my coursework.

8. I feel that my coaches are not supportive of my efforts to perform well academically.

9. I feel that sports limit my academic performance.

10. I worry that their non-athlete peers may feel that I was admitted into the university only because I am an athlete.

11. I feel pressured to place emphasis on their sport at the expense of my academics.

12. I feel that I would perform better academically if I was not an athlete.

13. I feel that the roles of a student and the roles of an athlete are similar and compatible.

14. I see myself as a student when in a classroom setting and see themselves as an athlete during competition.

15. I view myself more as a student than an athlete.

16. I feel that I can be both a student and an athlete at the same time. 


\section{Locus of Control (24 questions)}

(Levenson, 1981)

Read each statement carefully. Then indicate the extent to which you agree or disagree by circling the number following each statement. The numbers and their meanings are indicated at the top of the survey. $(-3=$ Strongly Disagree, $+3=$ Strongly Agree $)$

\begin{tabular}{|c|c|c|c|c|c|}
\hline-3 & -2 & -1 & +1 & +2 & +3 \\
\hline $\begin{array}{l}\text { Strongly } \\
\text { Disagree }\end{array}$ & & & & & Strongly Agree \\
\hline
\end{tabular}

1. Whether or not I get to be a leader depends mostly on my ability.

2. To a great extent my life is controlled by accidental happenings.

3. I feel like what happens in my life is mostly determined by powerful people.

4. Whether or not I get into a car accident depends mostly on how good of a driver I am.

5. When I make plans, I am almost certain to make them work.

6. Often there is no chance of protecting my personal interests from bad luck happenings.

7. When I get what I want, it's usually because I'm lucky.

8. Although I have good ability, I will not be given leadership responsibility without appealing to those in positions of power.

9. How many friends I have depends on how nice a person I am.

10. I have often found that what is going to happen will happen.

11. My life is chiefly controlled by powerful others.

12. Whether or not I get into a car accident is mostly a matter of luck.

13. People like myself have very little chance of protecting our personal interests when they conflict with those of strong pressure groups.

14. It's not always wise for me to plan too far ahead because many things turn out to be a matter of good or bad fortune.

15. Getting what I want requires pleasing those people above me.

16. Whether or not I get to be a leader depends on whether I'm lucky enough to be in the right place at the right time.

17. If important people were to decide they didn't like me, I probably wouldn't make many friends.

18. I can pretty much determine what will happen in my life.

19. I am usually able to protect my personal interests.

20. Whether or not I get into a car accident depends mostly on the other driver.

21. When I get what I want, it's usually because I worked hard for it.

22. In order to have my plans work, I make sure that they fit in with the desires of people who have power over me.

23. My life is determined by my own actions.

24. It's chiefly a matter of fate whether or not I have a few friends or many friends. 


\section{Appraisal Inventory (24 questions)}

(Bandura, 2006)

Please indicate on the scale 0-100 (5-point intervals) how much confidence you have in yourself to perform the actions in the given prompts.

1. I am confident that I could deal with unexpected events.

2. I can solve most problems if I invest the necessary effort.

3. My coping abilities allow me to remain calm when faced with a difficult situation.

4. I can execute the skills necessary to be successful at my sport.

5. I can be an integral part of my team in winning any given game/match.

6. I can think successfully during competition.

7. I can make critical decisions during competition.

8. I can take well-organized notes during a lecture.

9. I can develop the confidence to participate in a class discussion around course content.

10. I can explain a difficult concept from the course content to another student.

11. I can develop the courage to ask a professor in class to review a concept I don't understand.

12. I can study enough to understand content thoroughly.

13. I can schedule my time daily to fulfill my academic responsibilities.

14. I can accurately assess my preparation for life after college.

15. I can figure out what I am and am not ready to sacrifice to achieve my career goals.

16. I can talk with a person already employed in the field I am interested in.

17. I can choose an academic major or career that will fit my interests.

18. I can identify employers relevant to my career possibilities.

19. I can identify some reasonable academic major or career alternatives if I am unable to get my first choice.

20. I can develop positive relationships with my professors.

21. I speak up when I see things around me that aren't right.

22. I can form positive relationships with other students.

23. I can form positive relationships with student athletes who are not my teammates.

24. I can form positive relationships with members of the community near my school (e.g. non-students who live near the school). 


\section{Demographic Survey (15 questions)}

1. Which of the following best describes your gender?

- Female

- Male

- Other

2. Input your age (in years):

3. Which of the following best describes your racial identity?

- American Indian/Alaskan Native

- Asian

- Black, Non-Hispanic

- Hispanic/Latino

- White, Non-Hispanic

- Native Hawaiian/Other Pacific Islander

- Two or More Races

- International Student: (Type in home country)

4. Which of the following ranges describes the annual income of your family?

- $\$ 9,999$ or below

- $\$ 10,000$ - $\$ 29,999$

- $\$ 30,000-\$ 49,999$

- $\$ 50,000$ - $\$ 69,999$

- $\$ 70,000$ or above

5. Which varsity sport(s) do you compete in at your university?

- Baseball

- Basketball

- Bowling

- Crew/Rowing

- Cross Country

- Fencing

- Field Hockey

- Football

- Golf

- Gymnastics

- Ice Hockey

- Lacrosse
- Rifle

- Skiing

- Soccer

- Softball

- Swimming/Diving

- Tennis

- Track (Indoor or Outdoor)

- Volleyball

- Water Polo

- Wrestling

- Other (Input Sport): 
6. Based on your roster spot or frequency of competition, how would you classify your current status in your main sport?

- First team (for example, you start in a team sport or compete in your preferred events in individual sports)

- Second team (e.g., regular substitute in a team sport, often compete in some event in individual sports)

- Third team (e.g., participate in practice but compete infrequently)

- Practicing or training but not competing

7. This year, did you receive an athletics scholarship of any kind in your sport?

- No

- Yes, partial athletics scholarship

- Yes, full athletics scholarship

8. Are you currently in-season or out of season for your sport?

- In-season

- Out of season

9. What is your academic major? (Fill in text box)

10. Which of the following best describes your overall grade point average (GPA)?

- Less than 2.0

- $2.0-2.49$

- $2.5-2.99$

- $3.0-3.49$

- $3.5-4.0$ 
11. Which term best describes your most recent previous academic institution?

- High School

- Two Year Institution

- Four Year Institution

12. What is your current academic year or classification in college?

- Freshman

- Sophomore

- Junior

- Senior

- Graduate Student

13. Are you a first-generation college student (the first in your immediate family or your guardians to attend and complete college)?

- Yes

- No

14. How many years have you competed as a varsity student-athlete?

- I'm in my first year of participation

- 1

- 2

- 3

- $4+$

15. Which [Conference Name] institution do you attend? (Select from drop-down list) 


\section{Appendix D - Transcript of YouTube Recruitment Video}

\section{Transcript}

An Exploration of Collegiate Student-Athlete Development Through Identity and Self-Efficacy

ACC/MEAC Student-Athletes,

Thank you for clicking on this link to learn more about and possibly participate in my study. My name is Aaron Goodson and I am a $5^{\text {th }}$ year Sport Psychology Doctoral Student at West Virginia University.

I'm conducting a research study to examine how student-athletes identities as college students and athletes impact their growth and development as they go through college. Does the amount that one feels like a student or an athlete influence how they develop skills to complete college and function in the world after school? The findings from my study can help athletic administration at your school, the conference level, and even those in the NCAA National Office learn more about how to best support college student-athletes during this critical time in their lives. All participation is completely voluntary and confidential and will not be tied to your team or your school.

Click on the link below, complete my study, and let's see what we find out. If it helps, you can enter your name into a raffle for an opportunity to win one of ten $\$ 10$ Amazon.com gift cards. What comes out will certainly add to the important conversation of how student-athletes are supported during their time in college and may ultimately become helpful for you at your institution and those who come after you. Thank you. 


\section{Description Box}

Click on this link:

\section{ATG Dissertation - ACC Student-Athlete Development Survey}

ACC Student-Athlete,

Your response to my survey contributes to my dissertation designed to understand how studentathletes identify themselves as college students, athletes, and people outside of those contexts and the ways that influences the skills that they develop to prepare them for life after college. Collegiate athletic departments across the country work to provide effective programming for student-athletes like yourself in hopes of ensuring that you grow and develop as a person before you leave your institution. However, at this point in time, there is no data-based way to evaluate how much student-athletes grow and change during their time in college or the effectiveness of programming designed to support them. The results of this study will begin to contribute to those conversations at your institution, in your conference, and across the country.

Your participation is completely voluntary, and all data will be kept confidential. Thank you for your consideration and your time to complete my survey!

If you would like to know more about the results after the conclusion of the study, please don't hesitate to contact me at ATGoodson@mix.wvu.edu

Click on this link: 


\section{Appendix E - Recruitment Message to Athletic Administration}

Dr./Mr./Mrs.

I hope that this message finds you well. My name is Aaron Goodson, and I am a 5th year doctoral student studying Sport and Exercise Psychology at West Virginia University.

I am at the end of my studies and working to complete my dissertation this semester. My research interests lie in collegiate student-athlete psychosocial development, and I am seeking to gather data from student-athletes across a number of institutions, including ACC/MEAC member institutions.

I am reaching out to you for support in collecting data from student-athletes at your institution. I conducted pilot research with student-athletes here at WVU, so I have a draft of accepted versions of an IRB letter, recruitment email, and the study survey. I have attached each of these to this message.

I would love the opportunity to talk with you on the phone for 5-10 minutes to tell you more about the study, address any questions, comments, or concerns that you have about it, and how I envision your support. My schedule is flexible this semester, so any time that works for you to talk on the phone will likely work for me.

Thank you for taking the time to read my message. I look forward to your response.

Sincerely, Aaron Goodson 


\section{Appendix F - Demographics of Sample}

Table 1

Gender Demographics

Gender

Male

Female

Total
Number

69

196

265
Percentage of Sample

26.0

74.0

100.0

Table 1 - Gender Demographics

Table 2

Age Demographics

$\begin{array}{ccc}\text { Age } & \text { Frequency } & \text { Percent } \\ 18 & 29 & 10.9 \\ 19 & 75 & 28.3 \\ 20 & 65 & 24.5 \\ 21 & 51 & 19.2 \\ 22 & 36 & 13.6 \\ 23 & 9 & 3.4 \\ \text { Total } & 265 & 100.0\end{array}$

Table 2 - Age Demographics

Table 3

Race and Ethnicity Demographics

Race/Ethnicity

Asian

Black, Non-Hispanic

Hispanic/Latino

White, Non-Hispanic

Two or More Races

Other

International Student (Input Home Country)

Total

$\begin{array}{cc}\text { Frequency } & \text { Percent } \\ 2 & .8 \\ 41 & 15.5 \\ 13 & 4.9 \\ 167 & 63.0 \\ 20 & 7.5 \\ 2 & .8 \\ 20 & 7.5 \\ 265 & 100.0\end{array}$

Table 3 - Race and Ethnicity Demographics 
Table 4

Socioeconomic Status Demographics

$\begin{array}{ccc}\text { Socioeconomic Status } & \text { Frequency } & \text { Percent } \\ \$ 9,999 \text { or below } & 12 & 4.5 \\ \$ 10,000-\$ 29,999 & 20 & 7.5 \\ \$ 30,000-\$ 49,999 & 29 & 10.9 \\ \$ 50,000-\$ 69,999 & 41 & 15.5 \\ \$ 70,000 \text { or above } & 163 & 61.5 \\ \text { Total } & 265 & 100.0\end{array}$

Table 4 - Socioeconomic Status Demographics

Table 5

Academic Classification

$\begin{array}{crr}\text { Academic Year } & \text { Frequency } & \text { Percent } \\ \text { Freshman } & 57 & 21.5 \\ \text { Sophomore } & 55 & 20.8 \\ \text { Junior } & 72 & 27.2 \\ \text { Senior } & 68 & 25.7 \\ \text { Graduate Student } & 13 & 4.9 \\ \text { Total } & 265 & 100.0\end{array}$

Table 5 - Academic Classification 
Table 6

Sport Participation Breakdown

\begin{tabular}{|c|c|c|}
\hline Sport & Frequency & Percent \\
\hline Baseball & 4 & 1.5 \\
\hline Basketball & 7 & 2.6 \\
\hline Bowling & 3 & 1.1 \\
\hline Crew & 34 & 12.8 \\
\hline Cross Country & 9 & 3.4 \\
\hline Fencing & 1 & .4 \\
\hline Field Hockey & 8 & 3.0 \\
\hline Football & 23 & 8.7 \\
\hline Golf & 10 & 3.8 \\
\hline Gymnastics & 14 & 5.3 \\
\hline Ice Hockey & 4 & 1.5 \\
\hline Lacrosse & 7 & 2.6 \\
\hline Rifle & 1 & .4 \\
\hline Skiing & 1 & .4 \\
\hline Soccer & 20 & 7.5 \\
\hline Softball & 16 & 6.0 \\
\hline Swimming/Diving & 28 & 10.6 \\
\hline Tennis & 9 & 3.4 \\
\hline Track (Indoor or Outdoor) & 16 & 6.0 \\
\hline Volleyball & 29 & 10.9 \\
\hline Wrestling & 3 & 1.1 \\
\hline Other (Input Sport) & 7 & 2.6 \\
\hline $\begin{array}{l}\text { I compete in more than one sport at } \\
\text { my institution. }\end{array}$ & 11 & 4.2 \\
\hline Total & 265 & 100.0 \\
\hline
\end{tabular}

Table 6 - Sport Participation Breakdown 